\author{
UNIVERSIDADE DE SÃO PAULO \\ ESCOLA DE ENGENHARIA DE SÃO CARLOS
}

GUILHERME AUGUSTO LOPES DA SILVA

APLICAÇÃO DE PADRÕES DE BOSSAS POR FORMAS MODAIS NA OTIMIZAÇÃO DE FREQUÊNCIAS NATURAIS DE CHAPAS METÁLICAS

São Carlos 



\section{APLICAÇÃO DE PADRÕES DE BOSSAS POR FORMAS MODAIS NA OTIMIZAÇÃO DE FREQUÊNCIAS NATURAIS DE CHAPAS METÁLICAS}

Dissertação apresentada ao Programa de Pósgraduação em Engenharia Mecânica da Escola de Engenharia de São Carlos da Universidade de São Paulo como requisito para obtenção do título de Mestre em Ciências em Engenharia Mecânica e área de concentração Dinâmica de Máquinas Vibrações e Acústica

Orientador: Prof. Dr. Rodrigo Nicoletti

São Carlos 
AUTORIZO A REPRODUÇÃO TOTAL OU PARCIAL DESTE TRABALHO, POR QUALQUER MEIO CONVENCIONAL OU ELETRÔNICO, PARA FINS DE ESTUDO E PESQUISA, DESDE QUE CITADA A FONTE.

Ficha catalográfica preparada pelo Serviço de Tratamento da Informação do Serviço de Biblioteca - EESC/USP

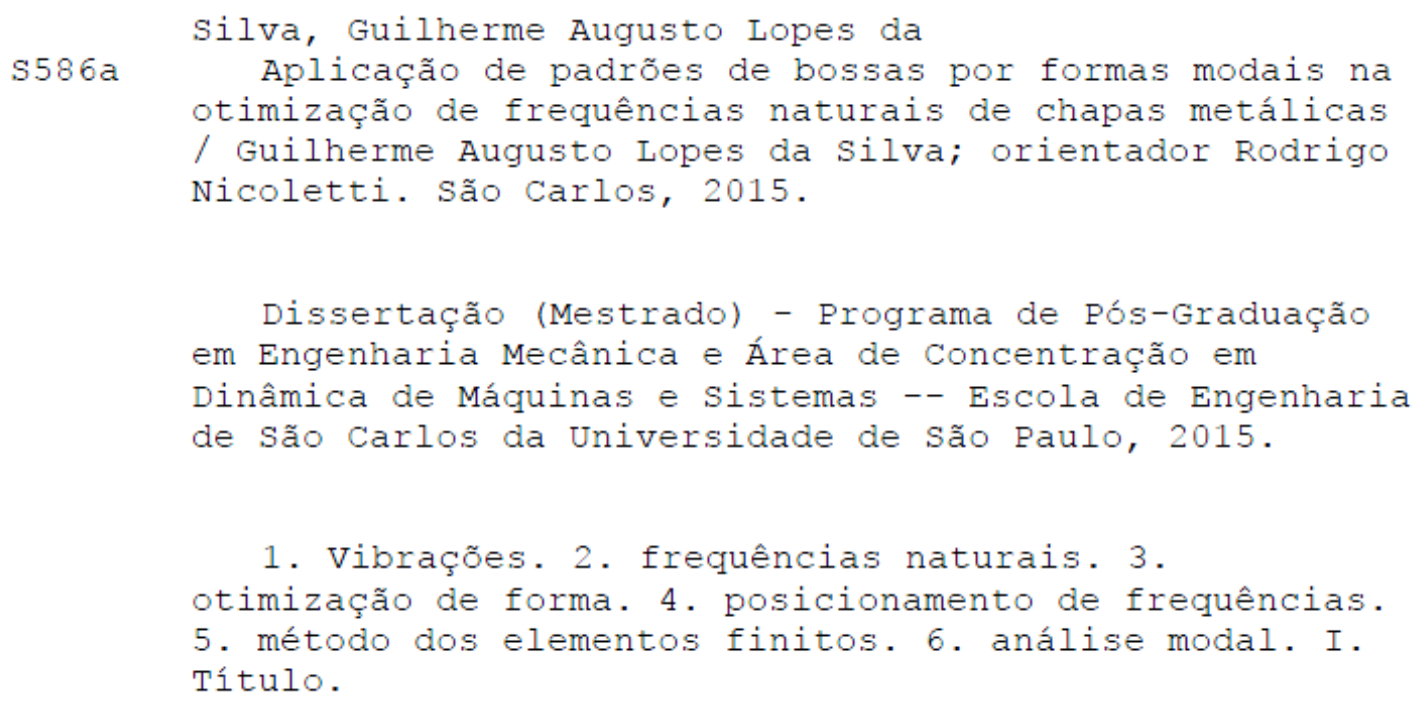


FOLHA DE JULGAMENTO

Candidato: Engenheiro GUILHERME AUGUSTO LOPES DA SILVA.

Título da dissertaçāo: "Aplicaçāo de padrões de bossas por formas modais na otimizaçāo de frequências naturais de chapas metálicas".

Data da defesa: 02/10/2015

\section{Comissāo Julgadora:}

Prof. Associado Rodrigo Nicoletti

(Orientador)

(Escola de Engenharia de São Carlos/EESC)

Prof. Dr. Helio Fiori de Castro

(Universidade Estadual de Campinas/UNICAMP)

Prof. Dr. Vitor Ramos Franco

(Universidade Federal de São Carlos/UFSCar)
Resultado:
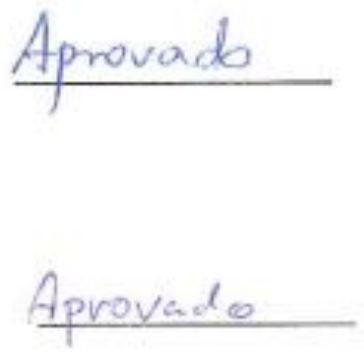

Aprovado

Coordenador do Programa de Pós-Graduaçāo em Engenheira Mecânica: Prof. Associado Gherhardt Ribatski

Presidente da Comissão de Pós-Graduaçã̃o:

Prof. Associado Paulo César Lima Segantine 
À minha família, por todo amor, carinho e suporte sem os quais este trabalho não teria sido concluído 


\section{Agradecimentos}

Ao meu orientador Prof. Dr. Rodrigo Nicoletti pelo suporte, paciência e orientação neste período de amadurecimento pessoal e acadêmico, sem os quais não seria possível a conclusão deste trabalho.

Aos professores da Escola de Engenharia de São Carlos, pelo suporte, ensinamento e orientação durante a vida acadêmica, cujo base permitiu que esta pesquisa pudesse ser almejada.

Aos meus pais, pelo incentivo e apoio que foram o alicerce para minha formação pessoal e profissional, sem as quais não seria possível alcançar esta etapa.

À minha esposa, pelo companheirismo, compreensão e paciência nesses anos, estando ao meu lado durante a jornada para alcançar este desafio.

Ao Sr. Luiz Lunkes, pela motivação e orientação que foram essenciais para que este trabalho tivesse início.

Ao Sr. Júlio Saez, pelo suporte e apoio nas fases inicias do projeto, sem o qual este não existiria.

Aos meus companheiros de trabalho e colegas de jornada durante o período de desenvolvimento do trabalho, cujo suporte contribui para que este trabalho existisse.

A todos os que, de alguma maneira, contribuíram para a concretização deste trabalho. 


\section{Resumo}

SILVA, G. A. L. Aplicação de padrões de bossas por formas modais na otimização de frequências naturais de chapas metálicas. Mestrado - Escola de Engenharia de São Carlos, Universidade de São Paulo, 2015, 114p.

Visando atender requisitos cada vez mais rigorosos de projeto e exigência dos consumidores, é necessário extrair o máximo desempenho de uma dada estrutura de produto, buscando sempre propriedades superiores as atuais. Para obter-se tais propriedades dinâmicas superiores (resistência, rigidez, peso) existem vários métodos de otimização estrutural, entre os quais a otimização de parâmetros, utilizada em ajustes finos de projeto; a otimização topológica, mais complexa e condicionada pelos processos de fabricação disponíveis e a otimização de forma utilizada em chapas estruturais. Dentre os métodos recentes de otimização de forma merece destaque o método de Padrões de Bossas por Formas Modais desenvolvido por Fredö e Hedlung (2004), que permite grandes ganhos de rigidez estrutural com pequenas deformações no formato das chapas. Entretanto, tal método tem sua aplicabilidade restrita, pois depende de fatores de ponderação cujo critério de escolha não foi explorado pelos autores. O presente trabalho analisa teoricamente o método desenvolvido por Fredö e Hedlung (2004), utilizando para tal uma chapa metálica em condições controladas para determinar um critério coerente de definição dos parâmetros de ponderação do método via otimização computacional suportado por uma análise modal via método dos elementos finitos. Com os resultados dessa análise pode-se criar um programa para implementação do método de Padrões de Bossas por Formas Modais em aplicações industriais, com ganhos significativos nas características estruturais de produtos sem impactos no custo final.

Palavras-chave: Vibrações, frequências naturais, otimização de forma, posicionamento de frequências, método dos elementos finitos, análise modal 


\begin{abstract}
SILVA, G. A. L. Sheet metal bending pattern optimization for desired natural frequencies. Master's Degree - Escola de Engenharia de São Carlos, Universidade de São Paulo, 2015, 114p.
\end{abstract}

To meet increasingly higher design requirements and consumer demands for design, it is necessary to extract the maximum performance of a given product structure, always seeking superior properties versus current design. To obtain such superior dynamic properties (strength, stiffness, weight) there are several methods of structural optimization, including the parameters optimization used to fine-tune design; the topology optimization, more complex and conditioned by manufacturing processes and the shape optimization as used in structural plates. Among the newer methods for shape optimization, it is worth mentioning the Panel embossing pattern optimization method developed by Frëdo and Hedlung (2004), which allows large structural rigidity gains with small deformations in the plate shape. However, this method has a limited applicability because it depends on weighting factors whose selection criterion was unexplored by the authors. This work theoretically analyzes the method developed by Frëdo and Hedlung (2004), using for such a metal sheet under controlled conditions to determine a coherent criterion for the weighting parameters definition process using computational optimization supported by a modal analysis via finite element method. With the results of this analysis, it was possible to create a program to implement the method embossing pattern optimization method in industrial applications, with significant gains in structural characteristics of products without affecting the final cost. .

Keywords: Structural vibrations, natural frequencies, shape optimization, Eigen frequencies placement, finite element method, modal analysis 


\section{Sumário}

1 INTRODUÇÃO 1

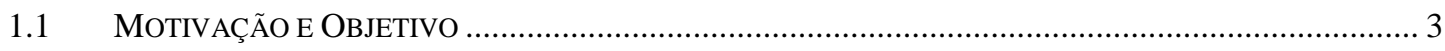

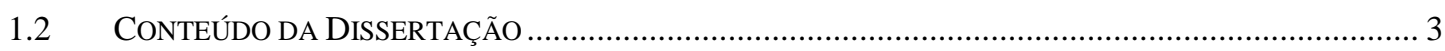

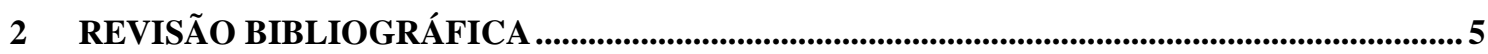

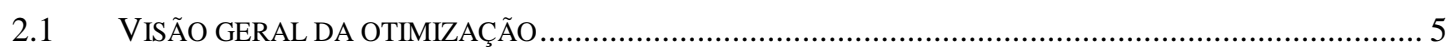

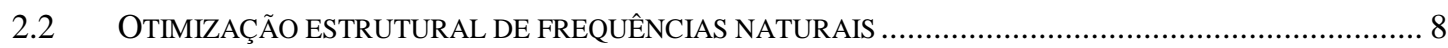

2.3 TRABalhos ReCENTES DE OtimizaÇão DE FORMa PaRA POSICIONAMENTO DE

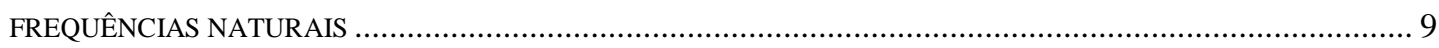

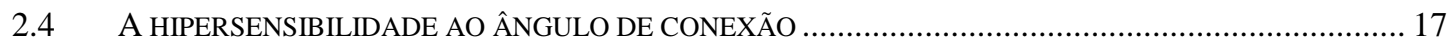

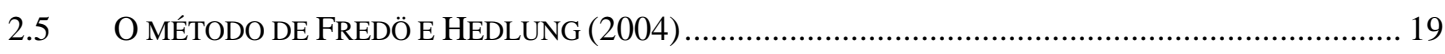

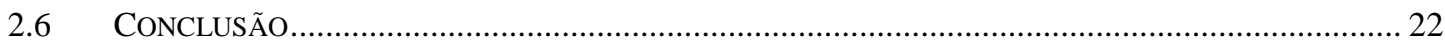

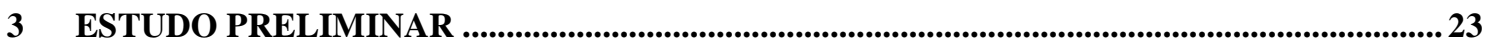

3.1 EFEITO DA DEFORMAÇÃO EM FORMA MODAL NA FREQUÊNCIA NATURAL …………………….... 24

3.1.1 Impacto do primeiro formato modal de flexão na frequência natural ..................................... 24

3.1.2 Impacto do primeiro formato modal de torção na frequência natural ................................... 26

3.1.3 Impacto do segundo formato modal de flexão na frequência natural..................................... 28

3.1.4 Impacto do módulo do segundo formato modal de flexão na frequência natural................... 31

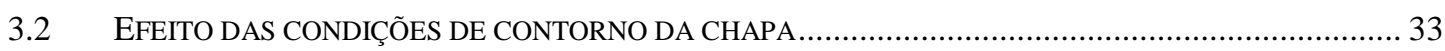

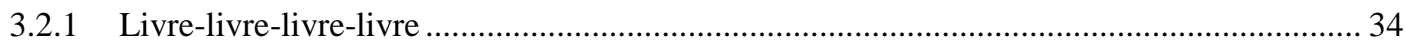

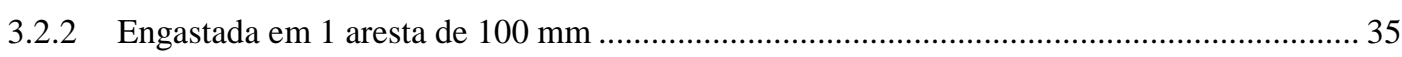

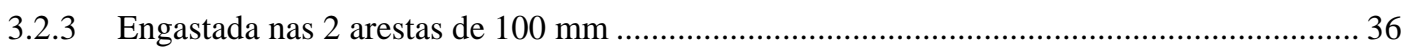

3.2.4 Engastada nas 4 arestas ......................................................................................... 37

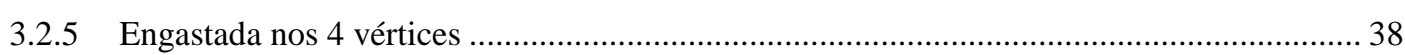

3.2.6 Engastada em 3 pontos, com plano de simetria............................................................. 39

3.2.7 Engastada em 3 pontos, sem plano de simetria .................................................................... 41

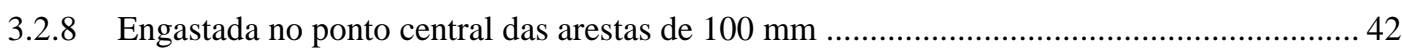

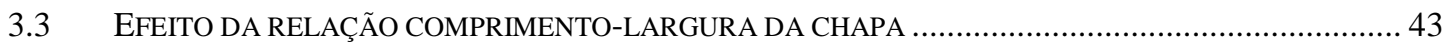

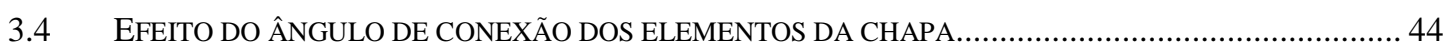

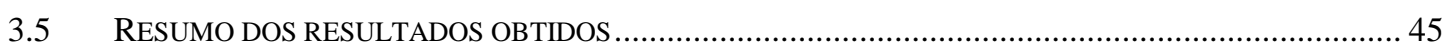

4 ESTRUTURA DO PROGRAMA DE OTIMIZAÇÃ̃ ............................................................. 48

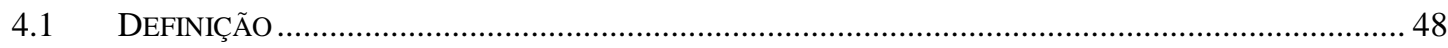

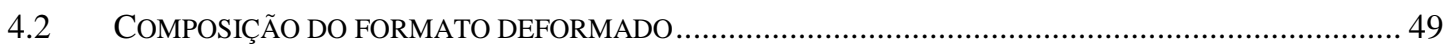

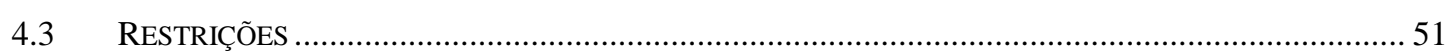

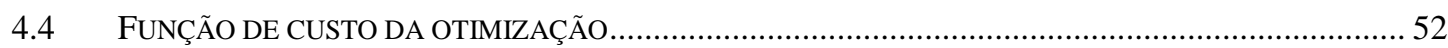




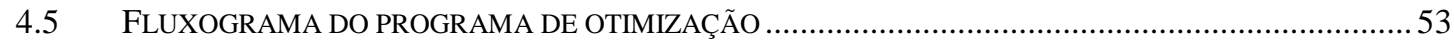

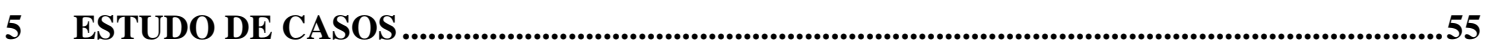

5.1 EFEITO DA UTILIZAÇÃO DOS MODOS DE TORÇÃO NA OTIMIZAÇÃO...............................................56

5.2 EFEITO DOS COEFICIENTES DE PONDERAÇ̃̃O INICIAIS NO RESULTADO DA OTIMIZAÇÃO ...............59

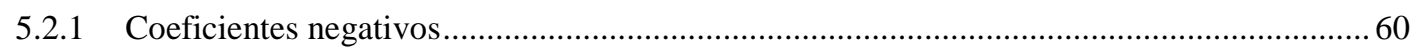

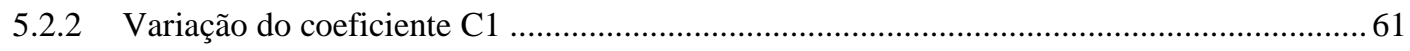

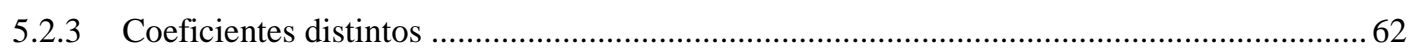

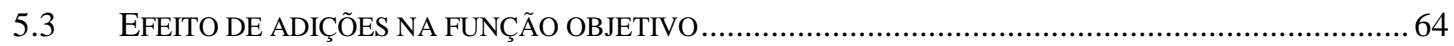

5.3.1 Maximização da primeira frequência natural e restrição da terceira ...................................... 64

5.3.2 Maximização da quinta frequência natural e posicionamento da terceira ............................... 65

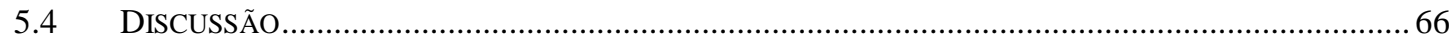

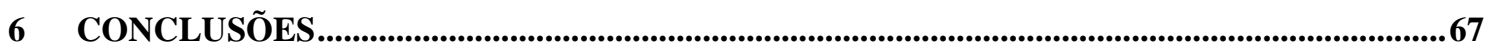

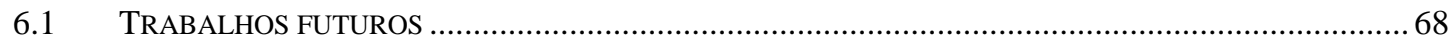

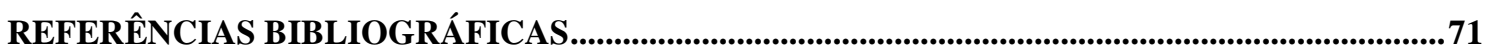

APÊNDICE A - PROGRAMA MATLAB® 


\section{Índice de figuras}

Figura 1 - Processo de otimização proposto por Liu e Shimoda (2013). a) chapa original. b) chapa otimizada para frequências naturais. c) chapa final otimizada para mínimo volume. Adaptado de Liu e Shimoda (2013). 10

Figura 2 - Ganho de rigidez (laranja) pelo aumento da primeira frequência com a manutenção do volume (azul) da chapa (a) e a posterior minimização do volume com a manutenção da primeira frequência natural (b). Adaptado de Liu e Shimoda (2013).

Figura 3 - Modelo de estudo (a) e região permissível para colocação dos reforços (b). Adaptado de Lee, Kim e Park (2005).

Figura 4 - Resultados de posição do reforço (a) e aumento da frequência com as gerações da otimização (b). Adaptado de Lee, Kim e Park (2005)

Figura 5 - Resultados da otimização para diversos fatores de peso entre a primeira frequência $\left(a_{1}\right)$ e a segunda frequência $\left(a_{2}\right)$ de uma viga apoiada nas extremidades. Adaptado de Meske, Lauber e Schnack (2005).

Figura 6 - Aumento da primeira e da segunda frequências naturais $\left(f_{1}\right.$ e $\left.f_{2}\right)$ de uma viga suportada nas extremidades em função da relação dos fatores $a_{1}$ e $a_{2}$. Adaptado de Meske, Lauber e Schnack (2005).

Figura 7 - Chapa de estudo do método de Park, Park e Park (2007) 14

Figura 8 - Evolução das bossas pelo método de Park, Park e Park (2007) comparando os resultados quando a análise de sensibilidade é conduzida na área total da chapa ou somente nas regiões vizinhas de áreas previamente deformadas. 15

Figura 9 - Aumento da primeira frequência por iteração (a) e tempo computacional de análise do método (b), considerando ambos os casos de análise de sensibilidade (área total da chapa ou somente áreas vizinhas das previamente deformadas). Adaptado de Park, Park e Park (2007).

Figura 10 - Estrutura de estudo, adaptado de Rebillard e Guyader (1997).

Figura 11 - Média quadrática da velocidade transversal da estrutura da Figura 10, com força aplicada nas coordenadas $x=0,3$ e $y=0,17$, sendo a linha tracejada placas com 
ângulo de conexão 0o e a linha contínua com ângulo de 4ㅇ․ Adaptado de Rebillard e Guyader (1997).

Figura 12 - Média quadrática da velocidade transversal da estrutura da Figura 10, com força aplicada nas coordenadas $x=0,3$ e $y=0,17$, sendo a linha tracejada placas com ângulo de conexão 30 e a linha contínua com ângulo de 60․ Adaptado de Rebillard e Guyader (1997). 18

Figura 13 - Razão das médias quadráticas das velocidades (em plano/transversal) para a força F localizada em x=0,3 e y=0,17 em uma excitação de frequência $500 \mathrm{~Hz}$. Adaptado de Rebillard e Guyader (1997). 19

Figura 14 - Fluxo de trabalho para cálculo do padrão deformado. O valor absoluto de cada modo é calculado e multiplicado por um fator de ponderação para ser somado ao padrão final de deformação a ser aplicado na chapa. O exemplo mostra a combinação de três modos. Adaptador de (FREDÖ e HEDLUNG, 2005)............... 20

Figura 15 - Exemplo de aplicação de otimização por Padrões de Bossas por formas modais em assoalho de caminhão comercial. (FREDÖ e HEDLUNG, 2005) 21

Figura 16 - Ganho de rigidez na função de transferência acústica entre os assoalhos da Figura 15. A curva vermelha mostra a função transferência original, enquanto a curva azul mostra o resultado do assoalho deformado, com aumento do valor da frequência onde ocorrem picos de ressonância com a cavidade acústica e a redução do número de picos. (FREDÖ e HEDLUNG, 2005)

Figura 17 - Chapa de aço usada para estudar os efeitos do método de deformação por padrões de bossas, de dimensões 300 por $100 \mathrm{~mm}$, engastada nas duas arestas de $100 \mathrm{~mm}$.

Figura 18 - Chapa deformada conforme o primeiro formato modal de flexão. ….................. 25

Figura 19 - Segundo o modo de flexão da chapa original com um nó modal......................... 26

Figura 20 - Primeiro modo de flexão da chapa deformada, exibindo um nó modal (semelhante ao formato modal da Figura 19)....................................................................... 26

Figura 21 - Segundo modo de flexão da chapa deformada................................................ 26

Figura 22 - Chapa deformada conforme o primeiro formato modal de torção. .................... 27

Figura 23 - Primeiro formato modal da chapa deformada (similar ao primeiro formato da chapa não deformada). 
Figura 24 - Segundo formato modal da chapa deformada (similar ao segundo formato modal da chapa não deformada).

Figura 25 - Terceiro formato modal da chapa deformada (semelhante ao quinto formato

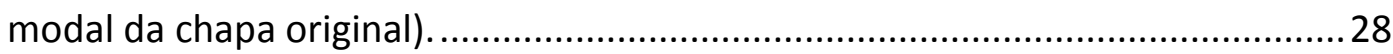

Figura 26 - Chapa deformada conforme o segundo formato modal de flexão.......................29

Figura 27 - Terceiro formato modal de flexão da chapa original. .........................................30

Figura 28 - Segundo modo de flexão da chapa deformada (semelhante ao terceiro formato modal de flexão da chapa original).

Figura 29 - Primeiro formato modal de flexão da chapa deformada (semelhante ao primeiro formato modal de flexão da chapa original)................................................... 30

Figura 30 - Chapa deformada conforme o módulo do segundo formato modal.................... 31

Figura 31 - Primeiro formato modal de flexão da chapa deformada...................................... 32

Figura 32 - Segundo formato modal de flexão da chapa deformada..................................... 33

Figura 33 - Terceiro formato modal de flexão da chapa deformada. ................................... 33

Figura 34 - Formato original (a) e formato deformado (b) seguindo o primeiro formato modal da chapa livre-livre. 34

Figura 35 - Formato original (a) e formato deformado (b) seguindo o primeiro formato modal da chapa engastada em uma aresta. 35

Figura 36 - Formato original (a) e formato deformado (b) seguindo o primeiro formato modal da chapa engastada nas quatro arestas.

Figura 37 - Formato original (a) e formato deformado (b) seguindo o primeiro formato modal da chapa engastada nos quatro vértices 38

Figura 38 - Formato original (a) e formato deformado (b) seguindo o primeiro formato modal da chapa engastada em três vértices, com plano de simetria indicado.... 40

Figura 39 - Formato original (a) e formato deformado (b) seguindo o primeiro formato modal da chapa engastada em três vértices, sem plano de simetria

Figura 40 - Formato original (a) e formato deformado (b) seguindo o primeiro formato modal da chapa engastada em dois vértices no ponto central das arestas de $100 \mathrm{~mm} \mathrm{..} 42$

Figura 41 - Valores de frequência para o primeiro modo em $\mathrm{Hz}$ comparado com a razão entre o comprimento e a largura (C/L) da chapa. 
Figura 42 - Primeira frequência natural da chapa deformada em função do máximo ângulo entre os elementos da chapa.

Figura 43 - Frequências naturais da chapa deformada por tipo de formato modal utilizado na deformação (chapa de 100 por 300 mm engastada nas arestas de $100 \mathrm{~mm}$ ) ..... 47

Figura 44 - Valores da primeira frequência natural da chapa deformada por tipo de engaste presente na chapa.

Figura 45 - Ilustração do processo de composição da formato deformado da chapa utilizando os três primeiros formatos de flexão.

Figura 46 - Ângulos entre os elementos $\alpha$ (a) e $\beta$ (b) utilizados para avaliar a condição de hipersensibilidade na chapa após a deformação ser aplicada. 52

Figura 47 - Fluxograma simplificado do programa de otimização adotado. 54

Figura 48 - Chapa apoiada nos quatro vértices original (a) e deformada pelo programa de otimização utilizando somente formatos de flexão (b) e deformada pelo programa utilizando tanto modos de flexão quanto de torção (c).

Figura 49 - Evolução da primeira frequência natural da chapa otimizada em cada avaliação da função objetivo realizada durante a otimização. 59

Figura 50 - Ganho percentual da primeira frequência natural da chapa otimizada em função do valor do de ponderação inicial $C 1$. 61 


\section{Índice de tabelas}

Tabela 1 - Valores de frequência em $\mathrm{Hz}$ para as primeiras cinco frequências naturais da chapa original e da chapa deformada com o primeiro formato modal de flexão. 25

Tabela 2 - Valores de frequência em $\mathrm{Hz}$ para as primeiras cinco frequências naturais da chapa original e da chapa deformada conforme o primeiro formato modal de torção .27

Tabela 3 - Valores de frequência em $\mathrm{Hz}$ para as primeiras cinco frequências naturais da chapa original e da chapa deformada conforme o segundo formato modal de flexão .. 29

Tabela 4 - Valores de frequência em $\mathrm{Hz}$ para as primeiras cinco frequências naturais da chapa original e da chapa deformada conforme o módulo do segundo formato modal de flexão 32

Tabela 5 - Frequências em $\mathrm{Hz}$ das primeiras cinco frequências naturais da chapa original e da chapa deformada conforme o primeiro formato modal de flexão na condição livrelivre. 35

Tabela 6 - Valores de frequência em $\mathrm{Hz}$ para as primeiras cinco frequências naturais da chapa original e da chapa deformada conforme o primeiro formato modal de flexão na condição de chapa engastada em uma aresta. 36

Tabela 7 - Valores de frequência em $\mathrm{Hz}$ para as primeiras cinco frequências naturais da chapa original e da chapa deformada conforme o primeiro formato modal de flexão na condição engastada em todas as arestas. .38

Tabela 8 - Valores de frequência em $\mathrm{Hz}$ para as primeiras cinco frequências naturais da chapa original e da chapa deformada conforme o primeiro formato modal de flexão na condição engastada nos vértices. 39

Tabela 9 - Valores de frequência em $\mathrm{Hz}$ para as primeiras cinco frequências naturais da chapa original e da chapa deformada conforme o primeiro formato modal de flexão na condição de engaste em três pontos com plano de simetria .40

Tabela 10 - Valores de frequência em $\mathrm{Hz}$ para as primeiras cinco frequências naturais da chapa original e da chapa deformada conforme o primeiro formato modal de flexão na condição de engaste em três pontos sem plano de simetria. 
Tabela 11 - Valores de frequência em $\mathrm{Hz}$ para as primeiras cinco frequências naturais da chapa original e da chapa deformada conforme o primeiro formato modal de flexão na condição de engaste em dois pontos no centro das arestas.

Tabela 12 - Resultados da otimização somente com modos de flexão e com modos de flexão e torção comparados à chapa original.

Tabela 13 - Comparação dos resultados da otimização utilizando-se coeficientes iniciais positivos e negativos. 60

Tabela 14 - Comparação dos coeficientes de ponderação otimizados para diferentes valores do coeficiente de ponderação inicial $C 1$.

Tabela 15 - Resultados obtidos para os diferentes valores de coeficientes de ponderação iniciais

Tabela 16 - Resultados da otimização comparados à chapa original na otimização da primeira frequência natural, com o mínimo impacto no valor da terceira frequência. ..... 64

Tabela 17 - Resultados da otimização comparados à chapa original na otimização da quinta frequência natural, com o posicionamento da terceira frequência. 65 


\section{Lista de variáveis}

$\alpha_{i}$ : ângulo entre os elementos da malha de elementos finitos na direção X:

$\beta_{\mathrm{i}}$ : ângulo entre os elementos da malha de elementos finitos na direção Y:

$\varphi_{\mathrm{n}}:$ n-ésimo modo de vibrar da chapa ou estrutura

$\boldsymbol{\varphi}_{\text {total }}$ : formato deformado da chapa baseado na combinação dos formatos modais

Alfa : Fator de escala utilizado no programa em Matlab para ajustar a geometria da chapa deformada aos limites da hipersensibilidade

C : comprimento da chapa

$\boldsymbol{C}_{\boldsymbol{j}}$ : Fator de ponderação do j-ésimo formato modal para compor a chapa otimizada

fi : i-ésima frequência natural da chapa original

$f^{\prime}{ }_{i}$ : i-ésima frequência natural da chapa deformada

$\boldsymbol{i}$ : i-ésima iteração da otimização

J : Função objetivo da otimização

$L$ : Largura da chapa

$\boldsymbol{n}$ : número do nó na malha de elementos finitos

$X_{i}$ : coordenada na direção " $X$ " da chapa do nó "n" da malha de elementos finitos

$Y_{i}$ : coordenada na direção " $\mathrm{Y}$ " da chapa do nó " $\mathrm{n}$ " da malha de elementos finitos

$Z_{i}$ : coordenada na direção " $Z$ " da chapa do nó " $\mathrm{n}$ " da malha de elementos finitos 



\section{Introdução}

Vibrações de natureza mecânica são parte frequente dos fenômenos físicos que circundam nosso dia a dia, presentes desde aparelhos de uso doméstico como a máquina de lavar roupas até veículos de transporte terrestre como automóveis. Nestes produtos pode-se vivenciar os efeitos induzidos pelo movimento mecânico e acelerações gerados pela condição de operação dos produtos, que podem causar sensações desagradáveis ao consumidor e até mesmo provocar fadiga física após certo tempo de exposição (SOTELO e FRANÇA, 2006).

Por conta disso, considerável volume de recursos é despendido anualmente no aprimoramento de produtos e projetos de modo a reduzir os efeitos da vibração mecânica nestes produtos. Tal esforço se deve não somente aos aspectos da percepção dos consumidores quanto ao produto em si, mas também visa prevenir falhas prematuras de equipamentos e máquinas, tanto devido a carregamentos dinâmicos elevados quanto a problemas de fadiga em materiais por carregamentos cíclicos (SOTELO e FRANÇA, 2006). Desta forma, a melhoria do comportamento das estruturas sujeitas a carregamentos dinâmicos, ou seja, suas características dinâmicas, é uma busca da engenharia moderna. Essa busca visa atender tanto necessidades técnicas, quanto a maior exigência de consumidores por produtos silenciosos, confiáveis e de custo reduzido. Nesse âmbito, o estudo da vibração em chapas metálicas se torna importante, pois elas são parte integrante em uma grande gama de produtos.

De forma a melhorar as características dinâmicas de estruturas, diversas técnicas se tornaram disponíveis no correr das décadas. A partir do fim da década de 1970 as modificações dinâmicas estruturais (Structural Dynamic Modifications - SDM) se tornaram ferramentas populares graças aos desenvolvimento e implementação de programas para computadores pessoais. Os esforços inicias focaram a implementação de uma técnica de modelagem eficiente que determinasse os efeitos de mudanças estruturais a partir de dados modais, tanto de elementos finitos quanto de medições, como base para um método de predição do comportamento da estrutura (AVITABILE, 2003). Tais mudanças estruturais eram obtidas pela modificação ou adição de molas, massas, amortecedores, barras ou placas nas 
estruturas, sendo que tais mudanças são definidas através de análises de sensibilidade e perturbação modal (PARK e PARK, 2000). Nad (2007) apresenta em seu estudo as abordagens e formulações essenciais para conduzir um trabalho de SDM em estruturas dinâmicas, incluindo exemplos numéricos.

Os métodos de SDM são atualmente considerados alternativas ao processo de otimização quando se deseja evitar processos de modelação numéricas demorados, porém são métodos cujo resultado obtido difere da solução ótima real quando grandes mudanças modais estão envolvidas (PARK e PARK, 2000). Conforme computadores mais rápidos e programas de análise estrutural e otimização mais capazes tornaram-se disponíveis, a integração entre a análise e a otimização em projetos de engenharia tornou-se um objetivo realista (HSU, 1994). Para este fim, diversos métodos de otimização foram desenvolvidos, como levantado por Saito, et. al. (2005), entre os quais a otimização de parâmetros, utilizada em ajustes finos de projeto; a otimização topológica, mais complexa e limitada pelos processos de fabricação disponíveis; e a otimização de forma utilizada em chapas estruturais, entre outros.

Dentre os trabalhos mais recentes na área de otimização de forma, visando a melhoria das características dinâmicas da estrutura, temos a metodologia de otimização por Padrões de Bossas por formas modais (Embossed Pattern) apresentada por Fredö e Hedlung (2004). Este método permite a criação de formas geométricas com pequenas deformações, que aplicadas em superfícies de chapas atenuam a vibração causada pelo carregamento dinâmico na estrutura. Isto ocorre porque as deformações no formato da chapa alteram as frequências naturais da chapa em relação ao formato original, deslocando-a da faixa de atuação do dito carregamento (aumentando a rigidez da chapa), ou seja, alteram a interação entre o carregamento e o comportamento modal da estrutura. Entretanto, tal método ainda tem sua aplicabilidade restrita, pois depende de fatores de ponderação para obter a geometria de bossas a ser aplicada na chapa cujo critério de escolha não foi explorado pelos autores. 


\subsection{Motivação e Objetivo}

O trabalho desenvolvido por Fredö e Hedlung (2004), apesar de demonstrar os benefícios da aplicação da otimização por Padrões de Bossas por Formas Modais em estruturas, não demonstra como determinar os coeficientes de ponderação fundamentais para o método, restringindo sua ampla aplicação em projetos de engenharia.

O presente trabalho foca, portanto, na otimização estrutural de forma aplicada a problemas de dinâmica estrutural de chapas (posicionamento de frequências naturais), com o objetivo de contribuir com o método de otimização por Padrões de Bossas por Formas Modais desenvolvido por Fredö e Hedlung (2004).

Desta forma, o objetivo deste trabalho é desenvolver uma metodologia para a escolha dos coeficientes de ponderação utilizados no método de Fredö e Hedlung (2004). Com isto, poder-se-á aplicar o método de maneira prática na otimização e posicionamento de frequências naturais de chapas metálicas.

\subsection{Conteúdo da Dissertação}

O presente trabalho aborda o tema da otimização de chapa metálicas com o objetivo de reposicionar as suas frequências naturais. 0 procedimento é realizado através de um algoritmo implementado no software de simulação matemática comercial Matlab ${ }^{\circledR}$ para condução do processo de otimização em conjunto com o software de simulação por elementos finitos comercial Nastran ${ }^{\circledR}$ para condução das análises para levantamento de autovetores e autovalores da chapa. O processo de otimização fornece um conjunto de coeficientes de ponderação que permitem a combinação de diversos formatos modais da chapa para criação de um padrão de bossas por formas modais para ser aplicado na chapa. Assim, após deformar a chapa com o padrão de bossas otimizado, obtém-se uma estrutura com novas características dinâmicas desejadas. 
Esta dissertação está dividida nos seguintes capítulos:

Capítulo 1 - Introdução: Introduz o tema abordado na dissertação, contextualizando o problema, mostrando as motivações do estudo e indicando os objetivos do trabalho.

Capítulo 2 - Revisão Bibliográfica: Apresenta uma breve revisão e visão geral da otimização estrutural dinâmica, apresentando trabalhos recentes na área e analisando as vantagens e limitações dos mesmos. Aborda-se em mais detalhes o trabalho que motivou o desenvolvimento deste estudo e os conceitos que embasam a metodologia utilizada no desenvolvimento do programa de otimização proposto.

Capítulo 3 - Estudo Preliminar: Apresenta um estudo dos efeitos que a imposição de formas modais em chapas causa nas suas frequências naturais. Este capítulo permite analisar também os efeitos das condições de contorno da chapa nos resultados obtidos.

Capítulo 4 - Estrutura do Programa de Otimização: Descreve os detalhes do algoritmo de otimização utilizado para obter os padrões de bossas a serem adotados na chapa em função dos requisitos de projeto (função objetivo e restrições). Apresenta-se também o fluxograma do algoritmo de otimização.

Capítulo 5 - Estudo de Casos: Mostra os resultados obtidos com a metodologia proposta em um modelo matemático de chapa metálica, abordando diferentes condições iniciais da otimização e funções objetivo, além de incluir uma discussão sobre os resultados otimizados em relação aos resultados obtidos no estudo preliminar (Capítulo 3).

Capítulo 6 - Conclusões: Apresenta as conclusões resultantes do trabalho, sugerindo possíveis extensões deste trabalho na interação entre os formatos deformados e o comportamento modal das chapas. 


\section{Revisão Bibliográfica}

\subsection{Visão geral da otimização}

Segundo Rao (2009), a otimização é o ato de se obter o melhor resultado possível dadas circunstâncias definidas. No projeto, construção e manutenção de qualquer sistema de engenharia, diversas decisões são tomadas visando minimizar o esforço ou maximizar os resultados desejados. Se o esforço requerido ou o benefício alcançado em qualquer situação for expresso como uma função de variáveis de decisão, a otimização pode ser definida como o processo de encontrar as condições que forneçam o máximo ou mínimo de uma dada função. Nocedal e Wright (2006) definem o processo de identificação da função objetivo da otimização, das variáveis envolvidas e das restrições como modelamento do problema, e que uma vez formulado pode ser resolvido com o uso de algoritmos de otimização.

O presente trabalho aborda o ramo da otimização estrutural o qual soluciona um dado problema a partir de uma função objetivo e uma série de restrições que devem ser atendidas através de sucessivas análises estruturais iterativas, geralmente utilizando métodos de elementos finitos, nos quais se avaliam os impactos de alterações estruturais específicas no comportamento da estrutura que se deseja otimizar. Segundo Saitou, et. al. (2005), entre os principais métodos de otimização estrutural tem-se a otimização de parâmetros, a otimização de forma e a otimização topológica, distinguindo-os da seguinte maneira:

- Otimização de parâmetros

A otimização de parâmetros é um processo que consiste basicamente na busca da combinação ideal de parâmetros da estrutura (propriedades geométricas e de material), sem alteração de formato, focando em ajustes finos de projeto através de alterações pequenas da estrutura, obtidas através da otimização das variáveis de projeto definidas como a série de parâmetros que descrevem as propriedades e geometria da estrutura.

Atualmente esse processo já pode ser realizado de maneira direta dentro dos próprios pacotes computacionais de CAD/CAE (Computer Aided Design/Computer Aided Engineering) que incluem módulos de análise por elementos finitos. Neste processo, a maior 
dificuldade que pode surgir é quando modelos muitos grandes ou com não-linearidades são analisados, pois estas condições podem significar altos custos computacionais (SAITOU, et. al. 2005). Um estudo recente na otimização de parâmetros foi apresentado por Vu (2015) no qual a seção transversal e as coordenadas dos nós dos elementos de uma treliça são otimizadas através de um método diferencial evolutivo associado à análise por elementos finitos.

- Otimização topológica

Segundo Saitou, et. al. (2005) a otimização topológica atua na forma que a estrutura se conecta com suas regiões adjacentes em um domínio de estudo controlado, atuando nos elementos de forma discreta ou contínua. No caso discreto, a espessura e o comprimento dos elementos que compõem o domínio da estrutura são variados. Já no caso contínuo, varia-se a densidade do material em diferentes regiões da estrutura. O caso discreto da otimização topológica é recomendado usualmente para estudos conceituais de design, sendo que as topologias factíveis em um dado domínio de projeto são limitadas pelo número e pelo posicionamento possível para os componentes da estrutura. Por outro lado, a abordagem contínua não possui essa limitação, acarretando, porém, custos computacionais maiores.

Neste processo as maiores dificuldades envolvem a não-linearidade das estruturas, restrições para se trabalhar com modelos grandes e limitações da parametrização topológica convencional. Para resolver o último problema, estudos recentes têm investigado novos métodos de otimização, trabalhando em conjunto com a otimização por tamanho e de forma (SAITOU, et. al., 2005). Atualmente a otimização topológica tem tido muito uso em estruturas do tipo treliça, componentes automotivos e estruturas reticuladas. Rozvany (2008) faz uma revisão dos diversos métodos numéricos estabelecidos para a otimização topológica estrutural, com enfoque nos métodos de interpolação SIMP (Simple Isotropic Material with Penalization) e nos métodos de otimização estrutural evolucionária.

Entre os trabalhos publicados de otimização topológica para problemas dinâmicos de frequência natural tem-se o trabalho de Ma, Kikuchi e Hagiwara (1993), que transformam o problema de otimização em um problema de Distribuição Ótima de Material associado a um processo de homogeneização. Outro trabalho é o de Zhao, Xie e Steven (1996), que utiliza um método evolucionário para otimizar a frequência natural, dada uma restrição de peso na estrutura, ou minimizar o peso da estrutura dado uma restrição nas frequências naturais. Yang 
(1997) apresenta um trabalho de otimização no qual a minimização do peso é definida como a função objetivo e as frequências naturais são consideradas as restrições. Xie e Steven (1996) apresentam uma abordagem do problema que combina um algoritmo evolucionário a um estudo de sensibilidade para cada elemento da malha, a fim de determinar quais devem ser removidos durante a otimização.

- Otimização de forma

Esta metodologia trabalha com a otimização dos parâmetros da geometria externa da estrutura, usualmente representadas por curvas suaves, podendo ser dividida em manipulação direta e indireta da geometria. Na manipulação direta a variável de projeto é um vetor dos parâmetros que representam a fronteira do componente, tais como pontos de controle da superfície, coeficientes de polinômios ou coordenadas de nós da estrutura que podem ser movimentados. Já no caso da manipulação indireta, a variável de projeto é um vetor de parâmetros que definem indiretamente a geometria, tais como cargas fictícias aplicadas na fronteira da estrutura (SAITOU, et. al., 2005).

No decorrer dos anos, diversos trabalhos na área de otimização de forma foram desenvolvidos, sendo possível destacar alguns. O trabalho de Liu e Shimoda (2013) utiliza reforços estruturais perpendiculares à chapa, em um processo de otimização para definir a quantidade mínima de reforços para atingir o objetivo da otimização. Chen, et. al. (2006) apresentam um trabalho no qual a otimização de forma é abordada através da representação implícita do espaço de projeto através de $B$-splines e funções paramétricas, que podem ser otimizadas através de multiplicadores de Lagrange associada a análise de sensibilidade. Lee, Kim e Park (2005) utilizam uma estratégia evolucionária para determinar a melhor combinação de tamanho e posição de reforços a serem aplicados na estrutura. Já o trabalho de Meske, Lauber e Schnack (2005) se baseia em critérios de otimalidade, enquanto o trabalho de Park, Park e Park (2007) aplica um padrão de deformação por bossas na estrutura através da análise das regiões com maior energia de deformação modal. Por fim, Fredö e Hedlung (2004) desenvolveram outro método de padrões de bossas, cujo formato deformado é baseado nas formas modais da chapa sendo otimizada.

Uma das desvantagens do método de otimização de forma é a escolha do melhor método de otimização para cada caso, pois há uma grande quantidade de métodos de 
otimização implementados como ferramentas de suporte em diversos aplicativos de engenharia comerciais (NASTRAN $^{\circledR}$, ABAQUS $^{\circledR}$, Optistruct $^{\circledR}$, entre outros). Além disso, o processo de otimização pode gerar superfícies difíceis de fabricar ou problemáticas em quesitos de design e estética do produto, inviabilizando sua aplicação. Atualmente a otimização de forma tem sido amplamente utilizada na determinação da geometria de chapas na indústria de bens de consumo, automobilística e aeroespacial.

\subsection{Otimização estrutural de frequências naturais}

Focando especificamente na otimização de frequências naturais, que cobrem uma vasta gama de aplicações de engenharia que vão desde o controle de flutter em aeronaves até o controle estrutural em projeto, casos nos quais se deseja evitar a presença de ressonâncias estruturais nas regiões de operação do produto, diversos métodos de otimização já foram desenvolvidos, conforme mostrado por Grandhi (1993). Grandhi (1993) classifica os tipos de métodos por suas características, sendo que alguns utilizam elementos de mais de uma dessas características:

- Técnicas de programação matemática

São técnicas baseadas na solução através de métodos matemáticos de programação, incluindo métodos de função penalidade, projeção de gradientes, multiplicadores e programação sequencial linear e quadrática, para citar alguns. Nestes tipos de otimização, o resultado final usualmente sofre grande influência dos tipos de restrições impostas ao projeto inicialmente. Esta técnica é a mais comumente encontrada e utilizada em programas

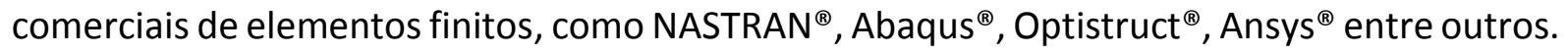
O trabalho de Germano e Nicoletti (2012) é um exemplo de otimização por forma através da aplicação de técnicas de programação matemática, onde o problema de otimização das espessuras da chapa para maximização das frequências naturais é resolvido com suporte das ferramentas do programa NASTRAN ${ }^{\circledR}$. 
- Métodos de critérios de otimalidade

Usualmente, estes métodos podem ser divididos em duas abordagens, a discreta e a contínua. Na abordagem contínua, a solução é representada por uma série de equações diferenciais, cujas soluções representam o caminho ótimo ou todos os pontos ótimos do domínio, sendo usualmente não-lineares. As equações podem, em alguns casos, serem resolvidas numericamente por diferenças finitas, mas usualmente encontrar a solução das equações é muito complicado para ser realizado em aplicações práticas.

Por outro lado, a abordagem discreta do OCM pode ser implementada utilizando-se métodos de elementos finitos, através de etapas envolvendo análise estrutural e alteração da estrutura, sendo que uma relação de recorrência derivada do critério de otimalidade é usada para modificar as variáveis de projeto, sendo o critério de otimalidade obtido por diferenciação do Lagrangeano em relação às variáveis de projeto. Neste caso a essência do processo é que, no ponto ótimo, a soma ponderada do Lagrangeano da densidade de energia é o mesmo para todos os elementos e a condição ótima consiste dos gradientes e multiplicadores de Lagrange.

Em seu trabalho, Grandhi (1993) também ressalta alguns problemas comuns na otimização de frequência, com destaque no fenômeno da inversão na sequência dos modos de vibrar e no impacto causado pelo acréscimo de massa em algumas regiões da estrutura para se alcançar o comportamento dinâmico desejado, podendo atingir níveis que tornam o formato otimizado impraticável em termos de engenharia. Esse último fenômeno é crítico principalmente na otimização topológica.

\subsection{Trabalhos recentes de otimização de forma para posicionamento de frequências naturais}

Com a popularização dos sistemas computacionais de alta capacidade aliados a aplicativos de análise numéricas com mais recursos, e impulsionado pela crescente demanda de soluções técnicas melhores e mais baratas para os requisitos de projeto de dinâmica estrutural, diversos métodos de otimização estrutural visando melhorar a dinâmica da estrutura foram desenvolvidos no correr dos últimos anos. Dentre esses métodos, pode-se 
citar os métodos de acréscimo de reforços desenvolvido por Liu e Shimoda (2013) e o método de acréscimo de reforços baseado em estratégias de evolução de Lee, Kim e Park (2005); o método de otimalidade de Meske, Lauber e Schnack (2005); o método de aplicação de bossas de Park et. al. (2005), e o método por padrões de bossas por formas modais de Fredö e Hedlung (2004).

- Método de acréscimo de reforços

Na metodologia apresentada por Liu e Shimoda (2013), as características dinâmicas das estruturas são melhoradas através da inclusão de reforços estruturais perpendiculares à chapa, cuja posição é definida através de processos de otimização para se obter a menor quantidade de reforços necessários. O processo de otimização é conduzido sem o uso de parametrização, sendo formulado em duas etapas. A primeira como um problema de maximização das frequências naturais sujeito a uma restrição de volume da estrutura e a segunda como um problema recíproco de minimização do volume sujeito a restrições nas frequências naturais. Essa tratativa permite a definição de reforços que maximizem a frequência natural com o menor tamanho possível.

As Figuras 1 e 2 mostram um exemplo de aplicação da metodologia de Liu e Shimoda (2013) mostrando a chapa original, o processo iterativo que mostra o ganho em rigidez com o acréscimo de reforços seguido do processo iterativo de minimização do volume dos reforços mantendo a rigidez inalterada.
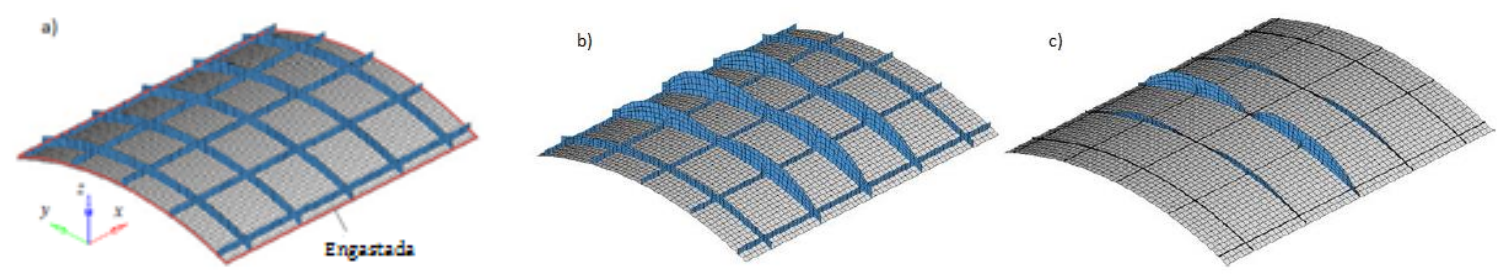

Figura 1 - Processo de otimização proposto por Liu e Shimoda (2013). a) chapa original. b) chapa otimizada para frequências naturais. c) chapa final otimizada para mínimo volume. Adaptado de Liu e Shimoda (2013). 


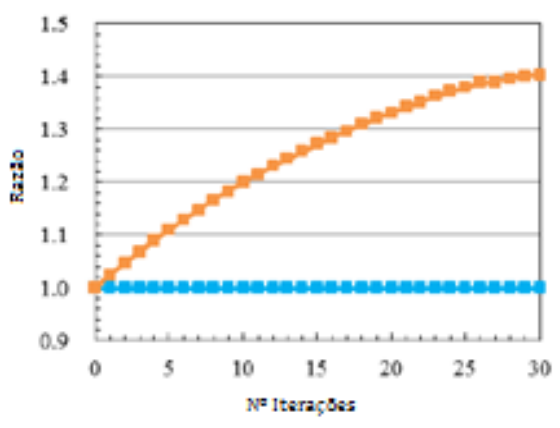

a)

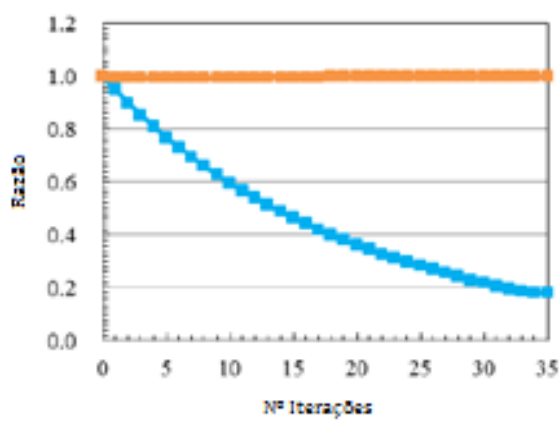

b)

Figura 2 - Ganho de rigidez (laranja) pelo aumento da primeira frequência com a manutenção do volume (azul) da chapa (a) e a posterior minimização do volume com a manutenção da primeira frequência natural (b). Adaptado de Liu e Shimoda (2013).

- Método de acréscimo de reforços evolucionário

Outro método baseado em reforços foi o proposto por Lee, Kim e Park (2005), no qual o foco da otimização é a posição e o comprimento dos reforços a serem acrescentados na estrutura, com restrições aplicadas aos locais nos quais os reforços podem ser aplicados. Para tal, a variável de projeto inclui as coordenadas de uma extremidade do reforço $(X, Y)$, o ângulo de inclinação do reforço no plano X-Y e o comprimento do reforço, com a restrição geométrica dos locais possíveis para o reforço também aplicada, conforme a Figura 3. Para realizar o processo de otimização dos reforços são utilizados programas de otimização baseados em estratégias de evolução (técnicas de otimização baseadas em uma população probabilística). Estes programas avaliam uma população de soluções dentro do espaço de variáveis baseado nos princípios da evolução biológica natural. As Figuras 3 e 4 ilustram o método de Lee, Kim e Park (2005), mostrando a definição da chapa otimizada e os ganhos obtidos com diversas propostas de reforços.

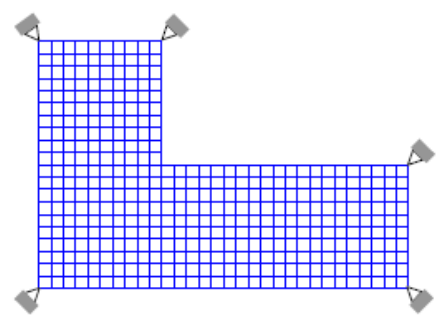

(a)

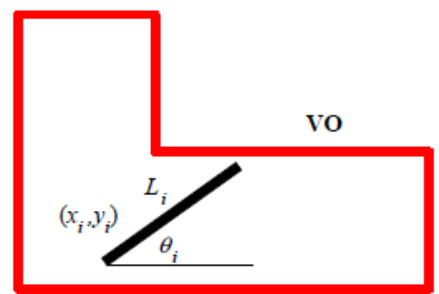

(b)

Figura 3 - Modelo de estudo (a) e região permissível para colocação dos reforços (b). Adaptado de Lee, Kim e Park (2005). 


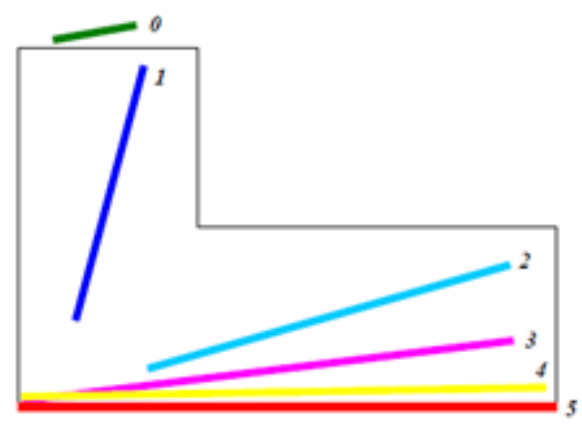

a)

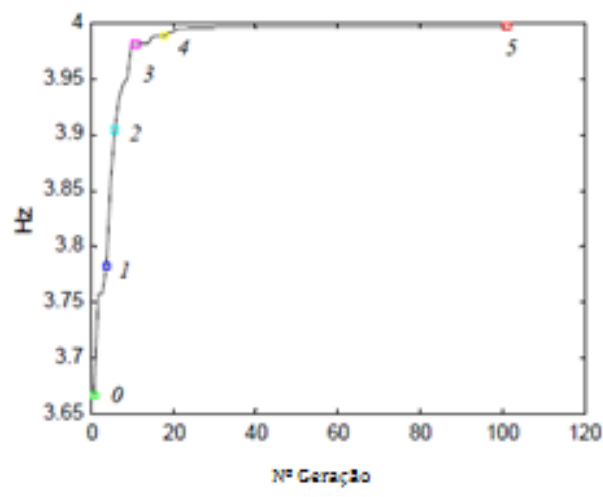

b)

Figura 4 - Resultados de posição do reforço (a) e aumento da frequência com as gerações da otimização (b). Adaptado de Lee, Kim e Park (2005).

Ambos os métodos apresentados de acréscimo de reforços apresentaram resultados positivos na otimização, porém possuem uma restrição importante relacionada à manufaturabilidade do componente resultante da otimização, restringindo os métodos de fabricação que podem ser aplicados. Isso acarreta em custos de manufatura adicionais (e.g.: em nenhum dos dois casos as chapas otimizadas podem ser produzidas através de estampagem), além de terem aplicação restrita em componentes com função estética no produto.

- Método de otimalidade

Meske, Lauber e Schnack (2005) apresentaram uma abordagem de otimização de forma para posicionamento de frequências naturais baseado num critério de otimalidade derivado para a maximização da frequência natural com restrições do volume, sendo a otimização alcançada através da alteração das fronteiras da estrutura, limitada pelas condições de contorno impostas em cada caso.

O critério de otimalidade deste método é baseado no Lagrangeano do problema de maximização da frequência dentro do espaço de modificações permitido da fronteira da estrutura, sendo que a frequência natural da estrutura é máxima se o lagrangeano da densidade de energia do modo for constante na fronteira de projeto. Nesta condição, a fronteira obtida é a ótima. No método, cada nó da fronteira da estrutura é tratado como uma variável de projeto, e a regra para o cálculo iterativo das novas posições dos nós é baseado na diferença entre o Lagrangeano da densidade de energia no nó e o valor médio do Lagrangeano na fronteira. As Figuras 5 e 6 mostram, respectivamente, o formato otimizado e os ganhos em 
frequência obtidos com a otimização para diversos fatores de peso entre a primeira e a segunda frequências naturais.

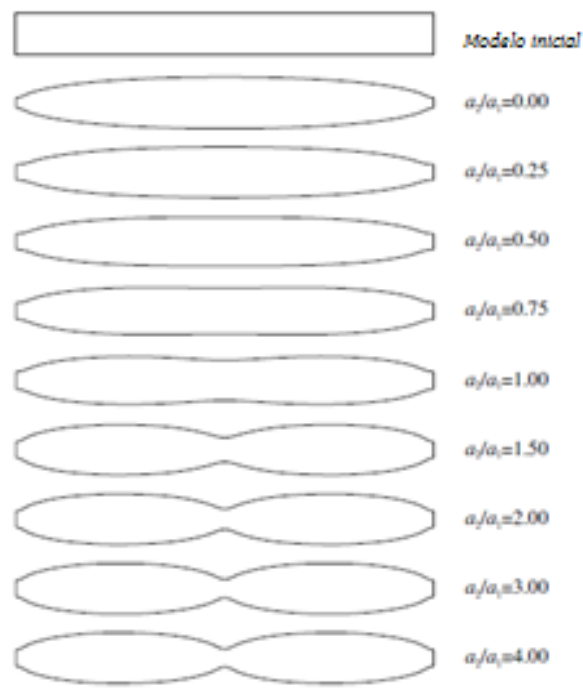

Figura 5 - Resultados da otimização para diversos fatores de peso entre a primeira frequência $\left(a_{1}\right)$ e a segunda frequência $\left(a_{2}\right)$ de uma viga apoiada nas extremidades. Adaptado de Meske, Lauber e Schnack (2005).

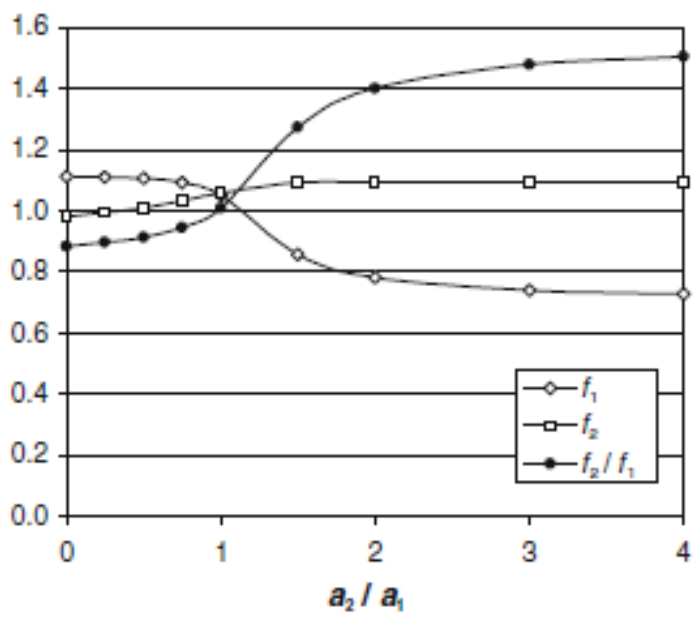

Figura 6 - Aumento da primeira e da segunda frequências naturais $\left(f_{1}\right.$ e $\left.f_{2}\right)$ de uma viga suportada nas extremidades em função da relação dos fatores $a_{1}$ e $a_{2}$. Adaptado de Meske, Lauber e Schnack (2005).

Este método apresenta convergência rápida da otimização e não necessita de parametrização da fronteira da estrutura. Entretanto, sua aplicação e seus resultados são limitados pela liberdade de projeto disponível para alterações da fronteira da estrutura, ou seja, em casos com liberdade de alterações o aumento da rigidez será elevado, porém em 
casos de liberdade reduzida os resultados serão mínimos (ou mesmo nenhum num caso de fronteiras fixas).

- Método da aplicação de bossas

Park, Park e Park (2007) propuseram um método de otimização das frequências naturais baseado na aplicação de bossas na estrutura, caracterizadas pelo deslocamento vertical de regiões da estrutura que mostram ter mais impacto no aumento da frequência natural visando maximizar a primeira frequência natural.

O passo inicial do método é a aplicação de bossas nas regiões com maior energia de deformação modal, seguido então da aplicação de bossas nas regiões vizinhas para verificar quais dessas produz mais impacto na rigidez da estrutura (análise de sensibilidade). As regiões com mais impacto recebem então o deslocamento vertical, e o processo se estende às demais regiões vizinhas destas até que o critério de convergência seja atingido.

A definição da altura da bossa no método é escolhida caso a caso, não sendo o fator mais importante no aumento da frequência da estrutura, segundo Park, Park e Park (2007). O principal fator considerado é somente a localização das bossas. As Figuras 7, 8 e 9 mostram os resultados da aplicação do método de otimização de Park, Park e Park (2007) comparando os resultados obtidos analisando somente as regiões vizinhas e a chapa inteira durante as otimizações.
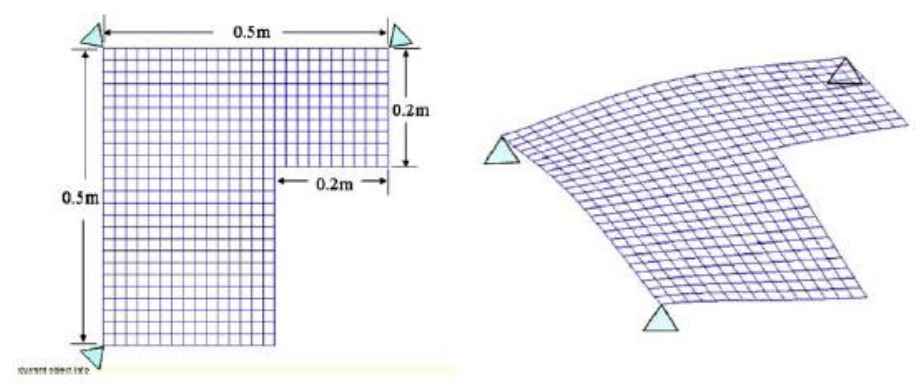

Figura 7 - Chapa de estudo do método de Park, Park e Park (2007). 


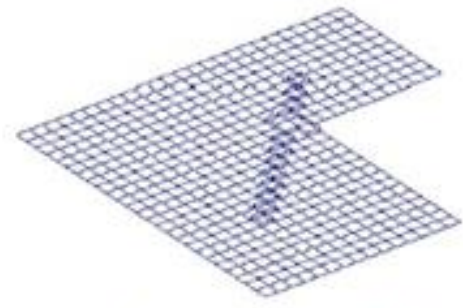

a Etapa : 10, área total

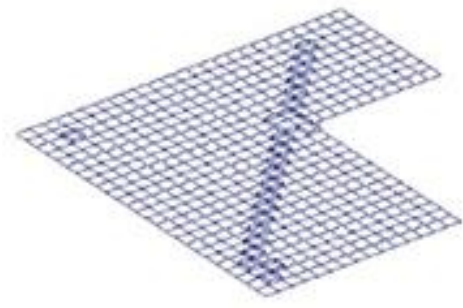

c Etapa : 20, área total

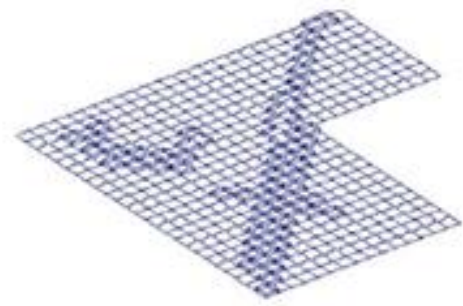

e Etapa : 50,área total

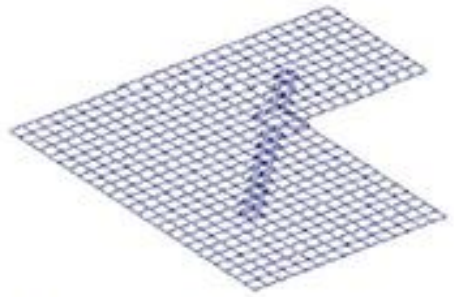

b Etapa : 10, regiões vizinhas

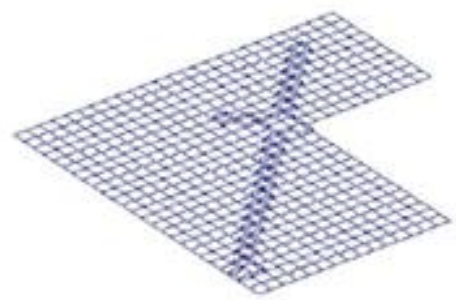

d Etapa : 20, regiões vizinhas

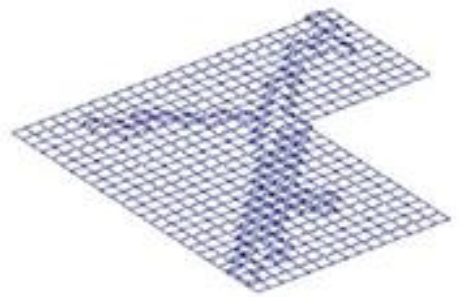

f Etapa : 50, regiões vizinhas

Figura 8 - Evolução das bossas pelo método de Park, Park e Park (2007) comparando os resultados quando a análise de sensibilidade é conduzida na área total da chapa ou somente nas regiões vizinhas de áreas previamente deformadas.

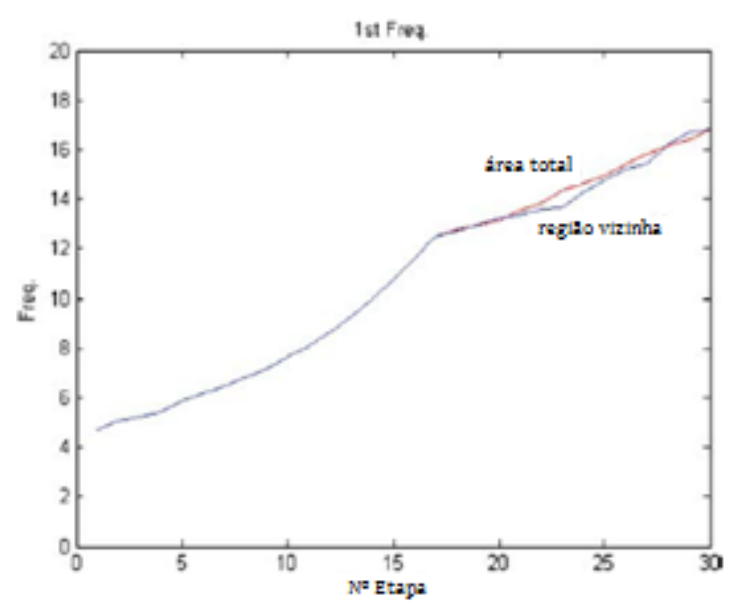

a)

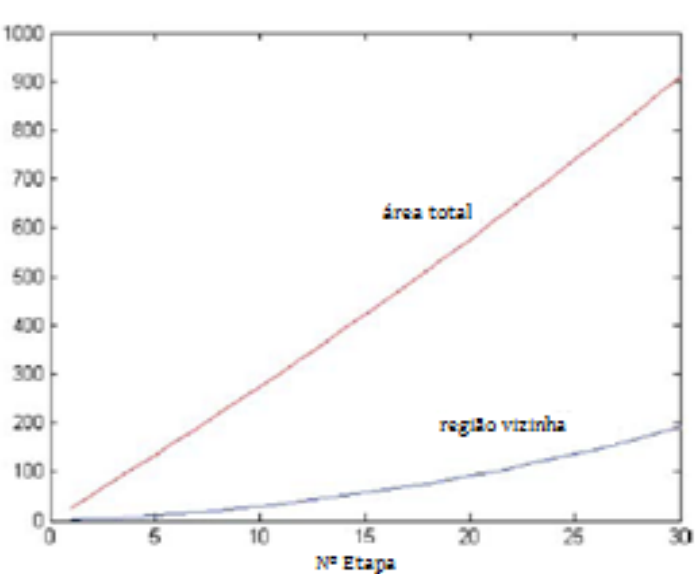

b)

Figura 9 - Aumento da primeira frequência por iteração (a) e tempo computacional de análise do método (b), considerando ambos os casos de análise de sensibilidade (área total da chapa ou somente áreas vizinhas das previamente deformadas). Adaptado de Park, Park e Park (2007). 
Este método apresenta rápida convergência, baixo consumo computacional e simplicidade de implementação. Entretanto, não existe no método uma definição precisa ou mesmo uma análise de qual a profundidade ideal das bossas para a otimização, deixando essa definição para o projetista que utilizará o método. Adicionalmente, as superfícies geradas podem causar problemas estéticos em aplicações reais, sendo necessário o retrabalho da superfície gerada suavizando o formato das bossas (com possível impacto nos ganhos apresentados) ou mesmo inviabilizando a solução otimizada.

- Método da otimização por padrões de deformação

No método de otimização por Padrões de Bossas por Formas Modais apresentado por Fredö e Hedlung (2004), a otimização das propriedades dinâmicas da chapa é atingida através da criação de formas geométricas com pequenas deformações, que aplicadas em superfícies de chapas atenuam a vibração causada pelo carregamento dinâmico em determinadas faixas de frequência. Tal efeito ocorre porque as pequenas deformações alteram as frequências naturais da chapa deslocando-a da faixa de atuação do carregamento (aumentando a rigidez da chapa) retirando a interação entre o carregamento e o comportamento modal da estrutura. Para tal, o método utiliza os próprios formatos modais da estrutura como base para definição da nova geometria, combinando esses formatos modais em um padrão de pequenas deformações a ser aplicado na estrutura, acarretando ganhos sensíveis nas frequências naturais e na rigidez.

Esse ganho de rigidez com o uso de pequenas deformações é possível devido ao fenômeno de hipersensibilidade ao ângulo de conexão apresentado por Rebillard e Guyader (1997), que demonstra que uma pequena alteração dos ângulos entre chapas de aço (entre $2^{\circ}$ e $5^{\circ}$ ) produzem grandes alterações na rigidez do conjunto. Adicionalmente, as estruturas otimizadas por esse método possuem geometrias suaves, que não acarretam impactos no processo produtivo (podendo facilmente serem produzidas por processos de estampagem) além de terem poucos impactos estéticos na estrutura, sendo dos métodos apresentados um dos mais viáveis para aplicação em bens de consumo. 


\subsection{A hipersensibilidade ao ângulo de conexão}

O trabalho de Rebillard a Guyader (1997), que apresentou o conceito de hipersensibilidade, originou-se do estudo sobre a causa de diferentes comportamentos dinâmicos em sistemas aparentemente idênticos (fabricados em uma mesma linha de produção, por exemplo). No estudo, foi analisado o movimento em plano e flexional das conexões de placas de uma estrutura de estudo, composta por uma série de placas finas isotrópicas de mesma espessura e largura, com comprimentos distintos, conectadas por ângulos diferentes, apoiadas nas extremidades e sob efeito de uma força $F$, conforme mostrado na Figura 10. Como parâmetros de controle para o comportamento vibracional, foram utilizadas a média quadrática da velocidade transversal de uma placa da estrutura e a média quadrática da velocidade transversal da estrutura inteira.
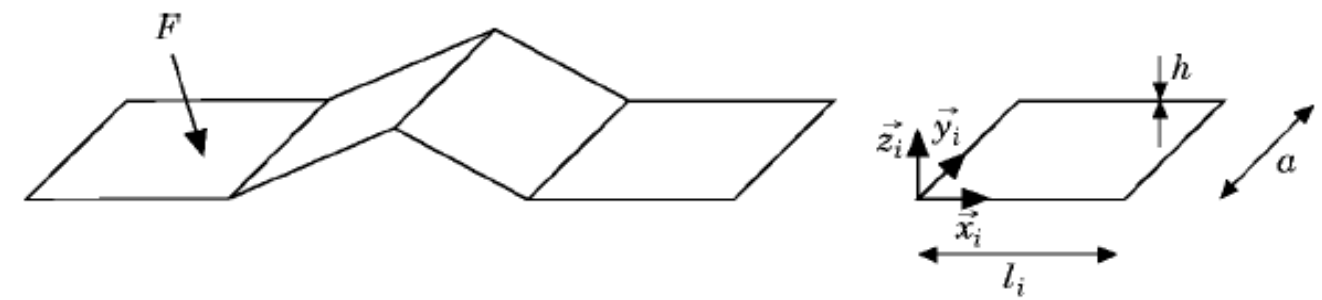

Figura 10 - Estrutura de estudo, adaptado de Rebillard e Guyader (1997).

Considerando duas placas idênticas conectadas e observando o comportamento vibracional das mesmas para diferentes ângulos de conexão, medido pela média quadrática da velocidade transversal, tem-se dois resultados distintos dependendo da variação do ângulo de conexão. Para pequenos ângulos de conexão, a velocidade quadrática tem diferenças sensíveis de picos em relação à frequência, como pode ser visto na Figura 11 que compara a velocidade calculada em placas conectadas em ângulos de $0^{\circ}$ e $4^{\circ}$. Na Figura 12 são comparadas as velocidades de chapas conectadas com grandes ângulos, no caso $30^{\circ}$ e $60^{\circ}$. 


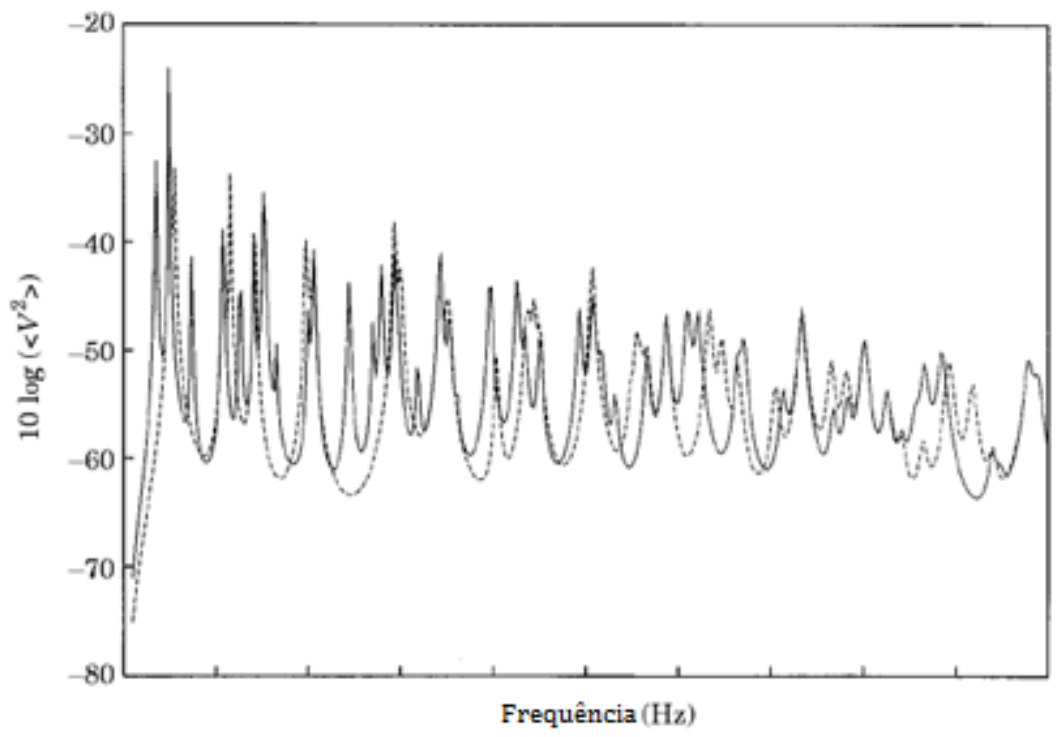

Figura 11 - Média quadrática da velocidade transversal da estrutura da Figura 10, com força aplicada nas coordenadas $x=0,3$ e $y=0,17$, sendo a linha tracejada placas com ângulo de conexão $0^{\circ}$ e a linha contínua com ângulo de 4‥ Adaptado de Rebillard e Guyader (1997).

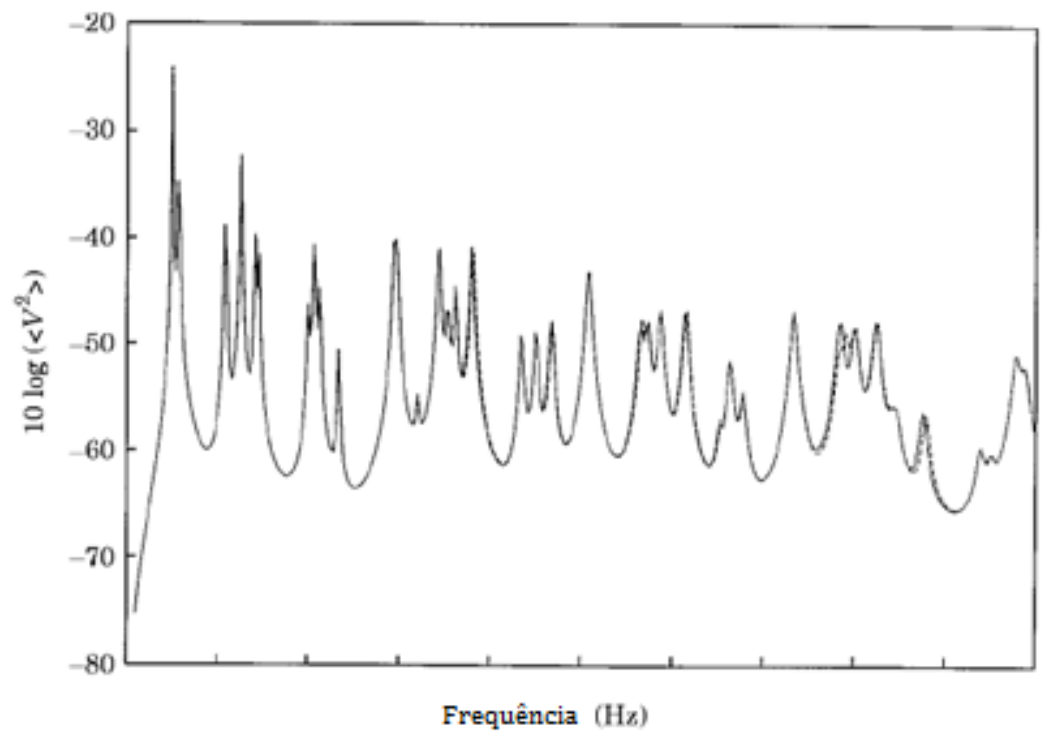

Figura 12 - Média quadrática da velocidade transversal da estrutura da Figura 10, com força aplicada nas coordenadas $x=0,3$ e $y=0,17$, sendo a linha tracejada placas com ângulo de conexão $30^{\circ}$ e a linha contínua com ângulo de 60․ Adaptado de Rebillard e Guyader (1997).

Nota-se que no segundo caso, ao contrário do caso anterior, as velocidades são praticamente as mesmas, com pouca diferença entre os ângulos. Isso significa que, fisicamente, uma pequena variação do ângulo de conexão pode causar grandes variações na média quadrática da velocidade transversal, levando a variações de comportamento 
dinâmico. A explicação desse fenômeno está relacionada ao acoplamento do movimento no plano com o movimento perpendicular ao plano, conforme mostra a Figura 13, na qual a razão da velocidade quadrática em plano por velocidade flexural quadrática é mostrada. $\mathrm{O}$ valor máximo ocorre para pequenos ângulos, nos quais a variação do ângulo acarreta grande impacto na razão de velocidades.

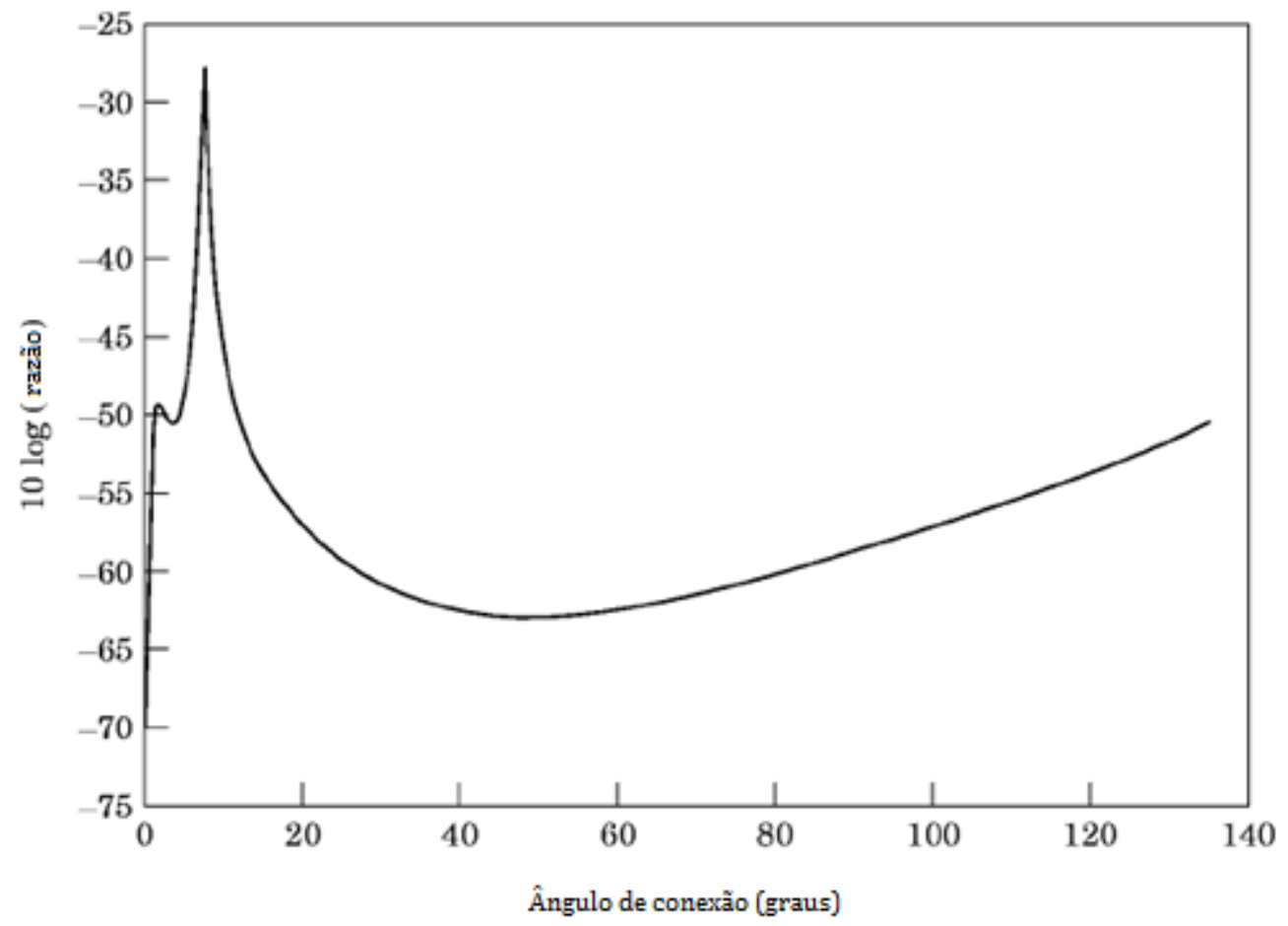

Figura 13 - Razão das médias quadráticas das velocidades (em plano/transversal) para a força $F$ localizada em $x=0,3$ e y=0,17 em uma excitação de frequência $500 \mathrm{~Hz}$. Adaptado de Rebillard e Guyader (1997).

\section{5 método de Fredö e Hedlung (2004)}

A metodologia de Fredö e Hedlung (2004) foi desenvolvida considerando duas premissas. A primeira refere-se ao fenômeno de hipersensibilidade ao ângulo de conexão, restringindo o ângulo entre os elementos das chapas na faixa de $2^{\circ}$ a $5^{\circ}$, e a segunda considera que a curvatura da chapa altera seu comportamento dinâmico quando o comprimento de onda da curvatura coincide com o comprimento de onda do modo de vibrar da estrutura. A partir de tais premissas, a metodologia de otimização por formato baseia-se no levantamento 
dos modos de vibrar da estrutura na condição de operação $([\Phi] n)$, que combinados por um somatório ponderado por fatores $C_{j}$ criam um novo formato deformado da chapa $([\Phi]$ total) que produza resultados otimizados de rigidez na condição de operação. A Figura 14 ilustra o processo de combinação dos modos descrito na metodologia.

A Figura 15 mostra um exemplo de aplicação da metodologia em assoalho de caminhão comercial, no qual os autores modificaram as frequências naturais do assoalho que apresentavam alinhamento modal com as frequências de ressonância da cavidade acústica do veículo. A Figura 16 mostra o ganho em rigidez na função de transferência comparando os respectivos assoalhos, com o aumento das frequências naturais de ressonância do assoalho com a cavidade acústica do veículo no assoalho otimizado e a supressão do pico existente na região entre 60 e $70 \mathrm{~Hz}$ no assoalho original.
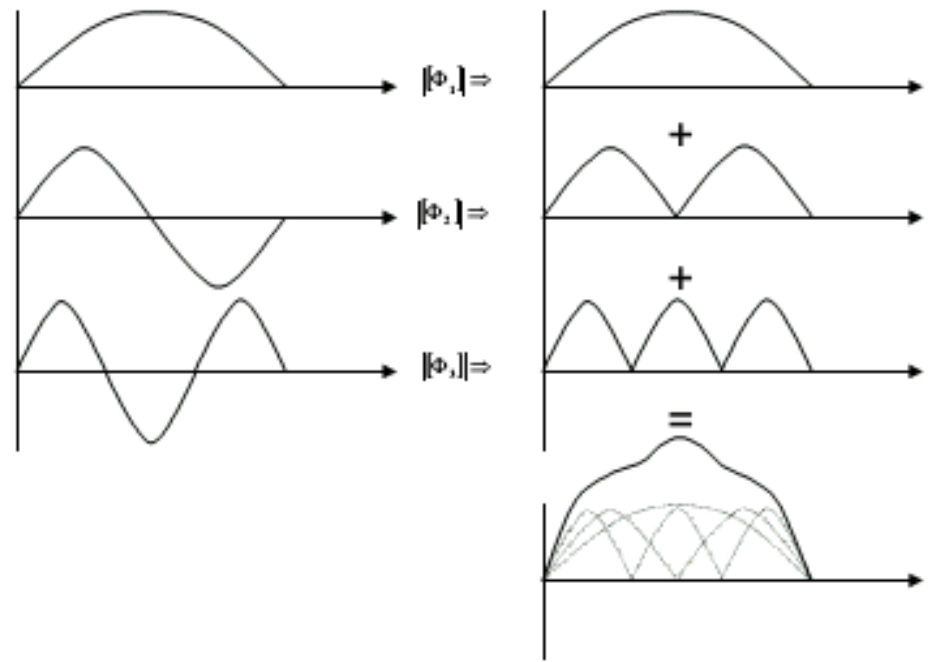

$C_{1} \cdot \mid\left[\Phi_{1}\right]$

$C_{2} \cdot \mid\left[\Phi_{2}\right]$

$C_{3} \cdot \mid\left[\Phi_{3}\right]$

$\left[\Phi_{\text {total }}\right]$

$$
[\Phi]_{\text {total }}=C_{1} \cdot\left|\left[\Phi_{1}\right]\right|+C_{2} \cdot\left|\left[\Phi_{2}\right]+\ldots \ldots C_{n} \cdot\right|\left[\Phi_{n}\right] \mid
$$

Figura 14 - Fluxo de trabalho para cálculo do padrão deformado. 0 valor absoluto de cada modo é calculado e multiplicado por um fator de ponderação para ser somado ao padrão final de deformação a ser aplicado na chapa. 0 exemplo mostra a combinação de três modos.

Adaptador de (FREDÖ e HEDLUNG, 2005). 


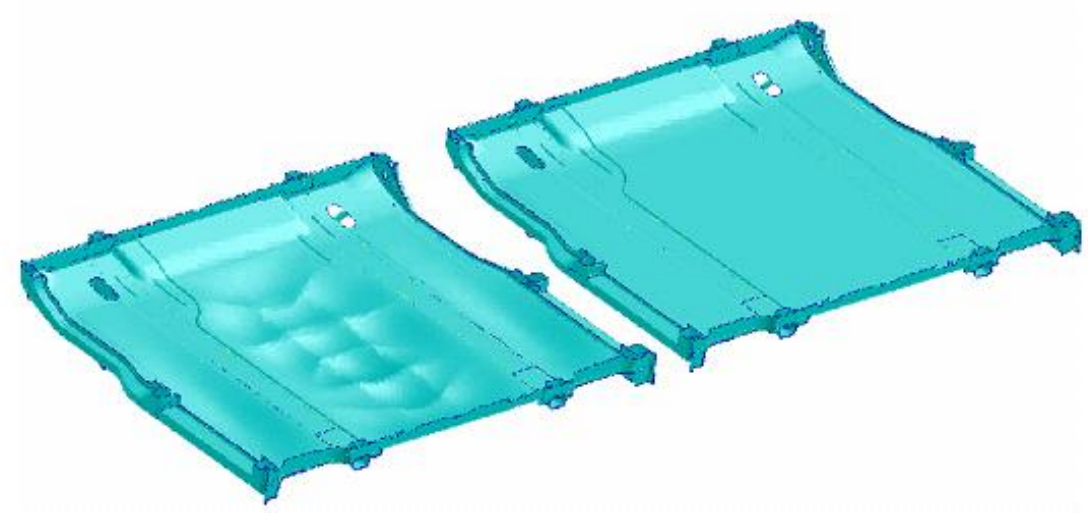

Figura 15 - Exemplo de aplicação de otimização por Padrões de Bossas por formas modais em assoalho de caminhão comercial. (FREDÖ e HEDLUNG, 2005)

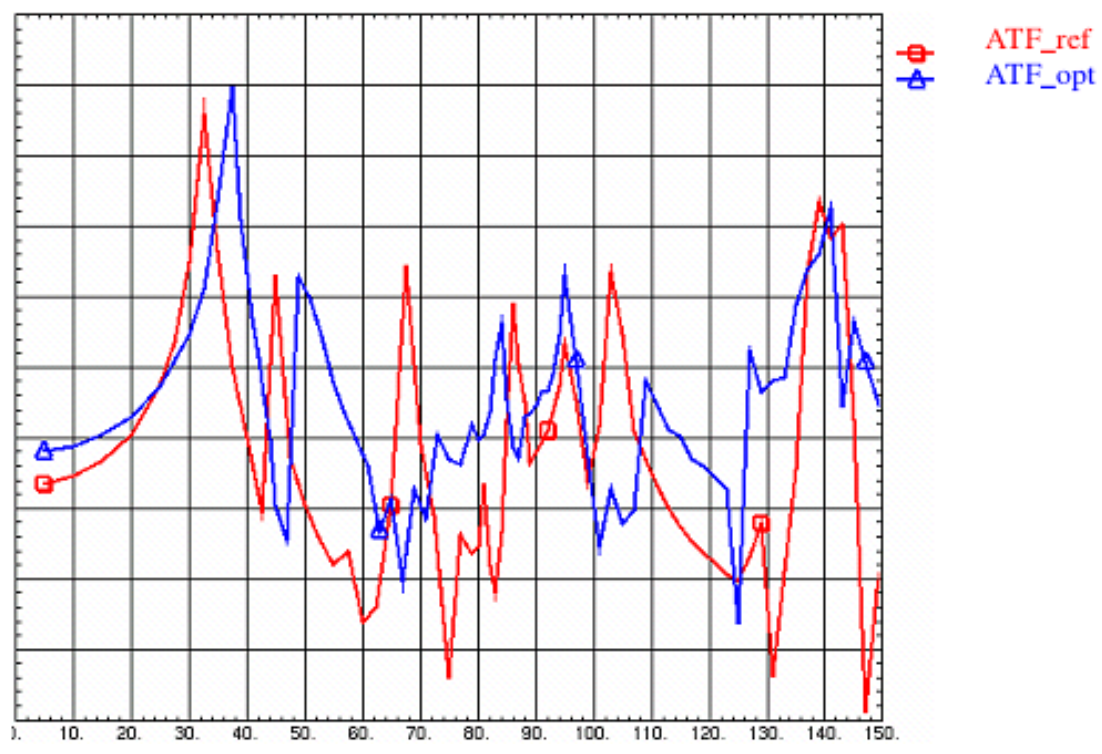

Frequência $(\mathrm{Hz})$

Figura 16 - Ganho de rigidez na função de transferência acústica entre os assoalhos da Figura 15. A curva vermelha mostra a função transferência original, enquanto a curva azul mostra o resultado do assoalho deformado, com aumento do valor da frequência onde ocorrem picos de ressonância com a cavidade acústica e a redução do número de picos.

(FREDÖ e HEDLUNG, 2005)

Um dos diferenciais da metodologia desenvolvida por Fredö e Hedlung (2004) é a possibilidade de dispensar reforços estruturais ou uso de componentes especiais no projeto, reduzindo a custo e o peso das estruturas. Entretanto, a metodologia apresentada por Fredö e Hedlung (2004) não permite uma aplicação abrangente, pois não aprofunda o procedimento de definição dos coeficientes de ponderação $C_{j}$ necessários para sua implementação, dependendo de metodologias de Planejamento de Experimentos ou na experiência do analista para definir tais coeficientes. 


\subsection{Conclusão}

Como se pode observar, existem diferentes métodos de reposicionamento das frequências naturais de chapas metálicas. Entretanto, o método que se mostra mais adequado ao processo de estampagem e que, portanto, tem a maior possibilidade de aplicação na indústria, é o método apresentado por Fredö e Hedlung (2004). O trabalho desenvolvido por Fredö e Hedlung (2004), apesar de demonstrar os benefícios da aplicação da otimização por Padrões de Bossas por Formas Modais em estruturas de engenharia, não demonstra como determinar os coeficientes de ponderação $C_{j}$ fundamentais para o método, restringindo sua ampla aplicação em projetos de engenharia. Com isso, surge a oportunidade de se estabelecer um critério para definir esses parâmetros de ponderação, possibilitando então uma maior aplicabilidade do método de otimização por Padrões de Bossas por formas modais através de um programa de otimização. 


\section{Estudo Preliminar}

O primeiro passo para desenvolver um método para a definição dos coeficientes de ponderação foi investigar o método de deformação por padrões de bossas sob condições conhecidas, com um chapa de teste de aço de dimensões 100 por 300 mm, engastada em diversas condições a serem estudadas. A Figura 17 ilustra a chapa com engastes nas duas arestas de $100 \mathrm{~mm}$.

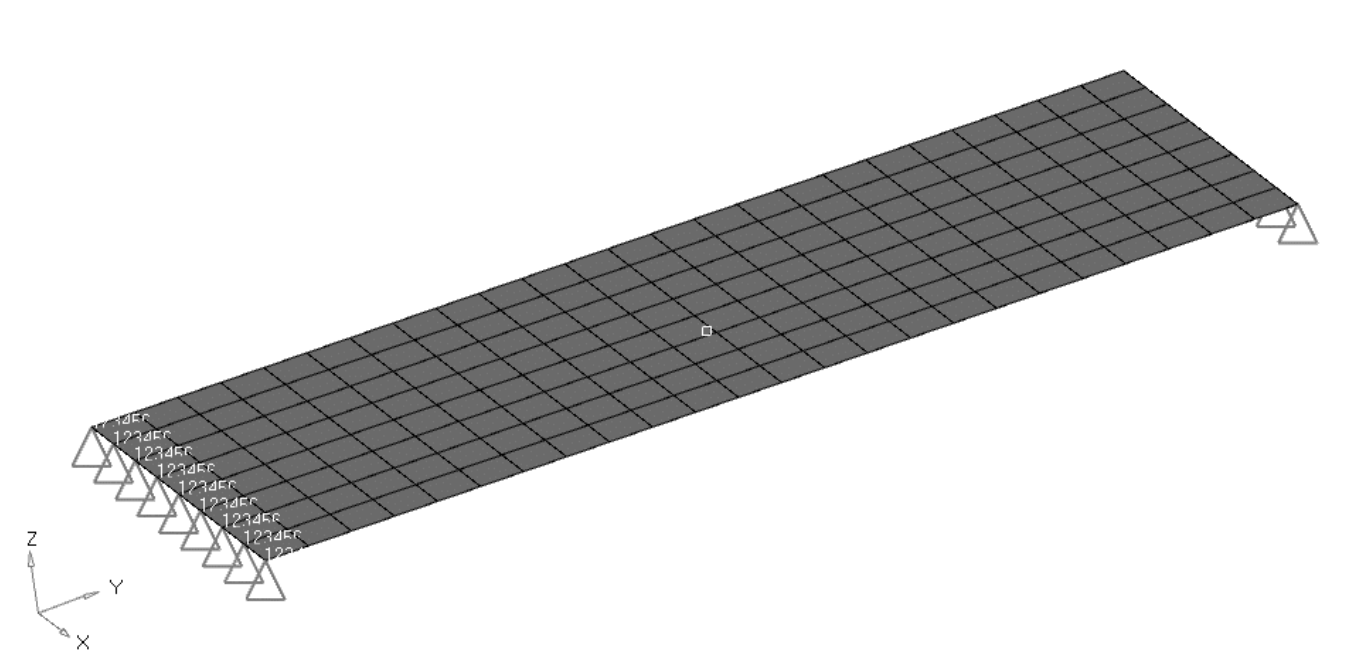

Figura 17 - Chapa de aço usada para estudar os efeitos do método de deformação por padrões de bossas, de dimensões 300 por $100 \mathrm{~mm}$, engastada nas duas arestas de $100 \mathrm{~mm}$.

Por simplicidade, as deformações (bossas) para obter o novo formato da chapa foram sempre aplicadas deslocando os elementos da malha na direção vertical dos nós do modelo de elementos finitos, sendo baseadas nos formatos modais da chapa não deformada.

As propriedades do modelo da chapa em estudo são:

- Tipo de elemento: placa fina isoparamétrica baseada na teoria de Mindlin (OJALVO e PILON, 1987)

- Espessura: 0,7 mm

- Tamanho de elemento: $12,5 \mathrm{~mm}$ por $12,5 \mathrm{~mm}$

- Densidade do material: $7860 \mathrm{~kg} / \mathrm{m}^{3}$

- Módulo de Young: 2,07 x 1011 GPa

- Módulo de elasticidade transversal: 7,93 x $10^{10} \mathrm{GPa}$

- Coeficiente de Poisson: 0.3 


\subsection{Efeito da deformação em forma modal na frequência natural}

Este estudo foi dividido em quatro etapas, cada qual utilizando um formato modal distinto como padrão de deformação, segundo a ordem a seguir:

1. Forma do primeiro modo de flexão como padrão de deformação

2. Forma do primeiro modo de torção como padrão de deformação

3. Forma do segundo modo de flexão como padrão de deformação

4. Módulo do segundo modo de flexão como padrão de deformação

Para este estudo as condições de contorno da chapa foram mantidas constantes, com as duas arestas de $100 \mathrm{~mm}$ fixas em todas as direções de translação e rotação. Todas as deformações das chapas (deformações por bossas) nos casos listados foram obtidas através da aplicação dos deslocamentos verticais nos nós da chapa. Esses deslocamentos foram definidos conforme o formato modal escolhido para cada condição, ponderado para que o ângulo entre os elementos esteja dentro do limite máximo de $5^{\circ}$, atendendo os requisitos da hipersensibilidade. Os formatos modais e frequências naturais foram obtidos através de metodologias de extração de autovalores e autovetores por simulação de elementos finitos, implementadas pelo método Lanczos através do software MD Nastran ${ }^{\circledR}$ 2010SE (MSC, 2010).

\subsubsection{Impacto do primeiro formato modal de flexão na frequência natural}

Nesta etapa, o primeiro modo de vibração de flexão foi aplicado como padrão de deformação por bossas na chapa (Figura 18), para verificar o impacto nas frequências naturais. A Tabela 1 mostra os resultados das primeiras cinco frequências naturais comparando a chapa original com a chapa deformada com o primeiro formato modal. 


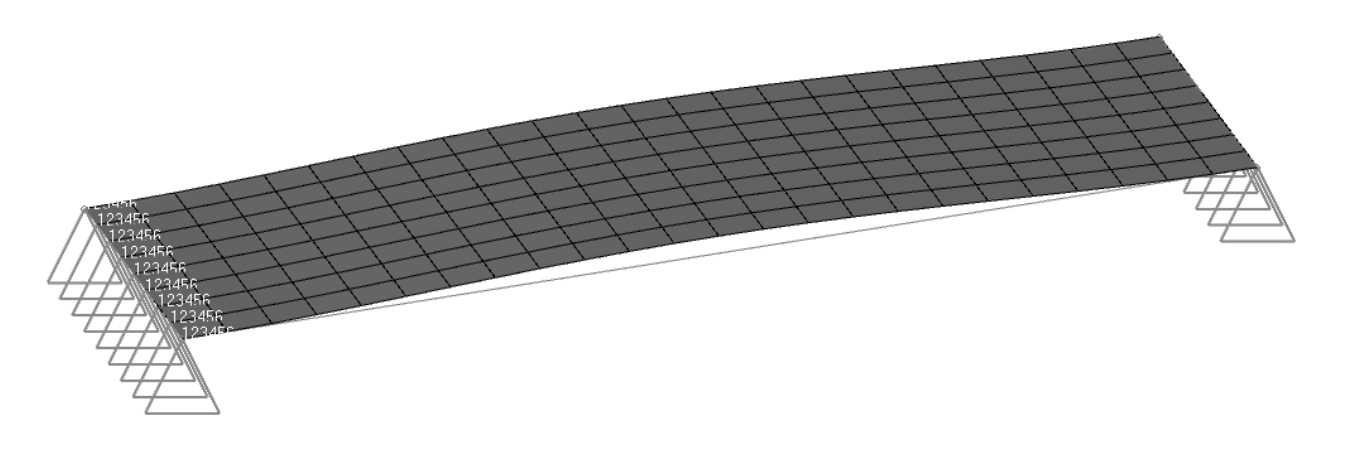

Figura 18 - Chapa deformada conforme o primeiro formato modal de flexão.

Tabela 1 - Valores de frequência em $\mathrm{Hz}$ para as primeiras cinco frequências naturais da chapa original e da chapa deformada com o primeiro formato modal de flexão.

\begin{tabular}{|c|c|c|c|c|c|c|}
\hline \multicolumn{2}{|r|}{ Frequência natural } & 1 & 2 & 3 & 4 & 5 \\
\hline \multirow{3}{*}{ 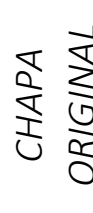 } & Geometria original $(\mathrm{Hz})$ & 42,2 & 89,3 & 116 & 192 & 229 \\
\hline & Formato modal & Flexão & Torção & Flexão & Torção & Flexão \\
\hline & Número de nós modais & 0 & 0 & 1 & 1 & 2 \\
\hline \multirow{4}{*}{ 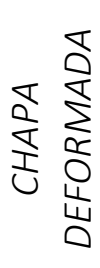 } & Geometria deformada $(\mathrm{Hz})$ & 116 & 165 & 194 & 208 & 381 \\
\hline & Ganho em frequência (\%) & 174,8 & 84,7 & 67,2 & 8,3 & 66,3 \\
\hline & Formato modal & Flexão & Flexão & Torção & Torção & Flexão \\
\hline & Número de nós modais & 1 & 2 & 1 & 2 & 3 \\
\hline
\end{tabular}

Quando o padrão de bossas da chapa foi o formato modal do primeiro modo de flexão, essa forma modal desapareceu nas análises modais da chapa deformada até $3000 \mathrm{~Hz}$, confirmando a hipótese de Fredö e Hedlung (2004) da interação do comprimento de onda da curvatura da chapa deformada com o formato modal da chapa original. Também se observa a inversão da ordem dos modos de flexão e torção em relação à chapa original, conforme indicado por Grandhi (1993).

As Figuras 19, 20 e 21 mostram, respectivamente, o segundo modo de flexão para a chapa original, o primeiro modo de flexão da chapa deformada (que tem formato semelhante) e o segundo modo de flexão da chapa deformada (que se assemelha ao terceiro formato modal de flexão da chapa original). 


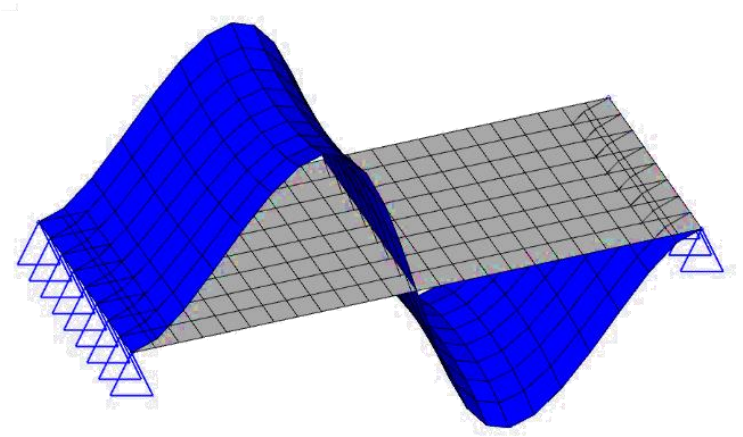

Figura 19 - Segundo o modo de flexão da chapa original com um nó modal.

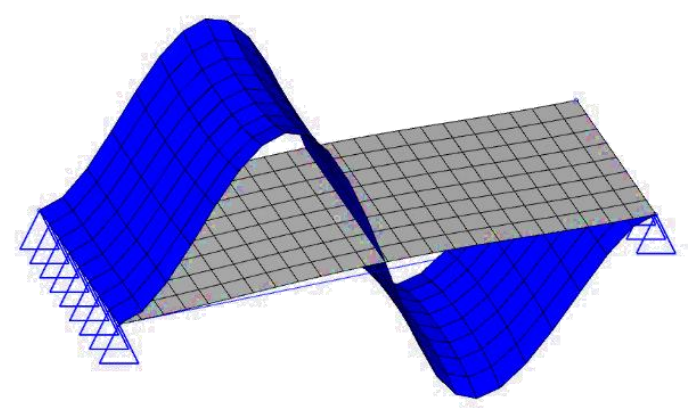

Figura 20 - Primeiro modo de flexão da chapa deformada, exibindo um nó modal (semelhante ao formato modal da Figura 19).

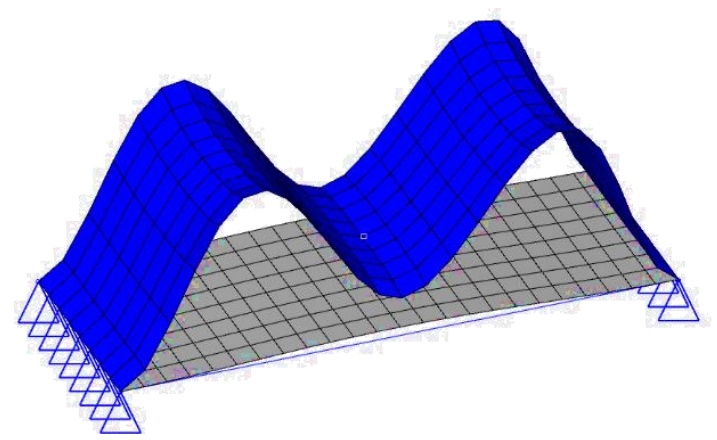

Figura 21 - Segundo modo de flexão da chapa deformada.

\subsubsection{Impacto do primeiro formato modal de torção na frequência natural}

Nesta etapa, o primeiro modo de vibração de torção foi aplicado como padrão de deformação na chapa (Figura 22), para verificar o impacto nas frequências naturais, utilizando o mesmo procedimento numérico do caso anterior. A Tabela 2 mostra os resultados das 
primeiras cinco frequências naturais comparando a chapa original com a chapa deformada conforme o primeiro formato modal de torção.

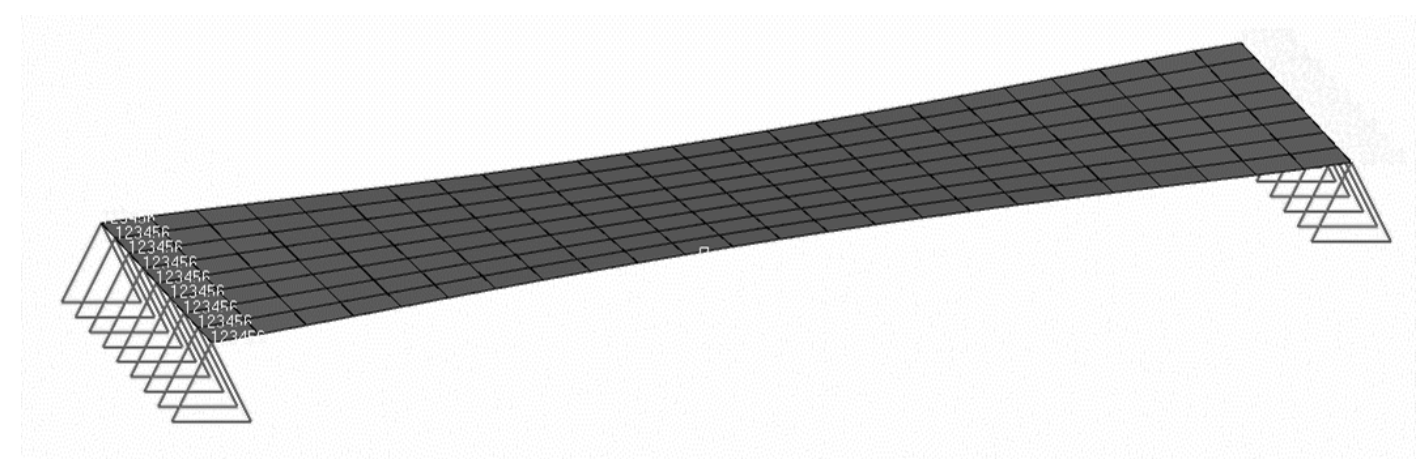

Figura 22 - Chapa deformada conforme o primeiro formato modal de torção.

Tabela 2 - Valores de frequência em Hz para as primeiras cinco frequências naturais da chapa original e da chapa deformada conforme o primeiro formato modal de torção

\begin{tabular}{|c|c|c|c|c|c|c|}
\hline & Frequência natural & 1 & 2 & 3 & 4 & 5 \\
\hline \multirow{3}{*}{ 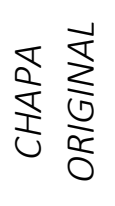 } & Geometria original $(\mathrm{Hz})$ & 42,2 & 89,3 & 116 & 192 & 229 \\
\hline & Formato modal & Flexão & Torção & Flexão & Torção & Flexão \\
\hline & Número de nós modais & 0 & 0 & 1 & 1 & 2 \\
\hline \multirow{4}{*}{ 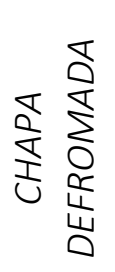 } & Geometria deformada $(\mathrm{Hz})$ & 138,5 & 207,9 & 230,5 & 258,5 & 270,8 \\
\hline & Ganho em frequência (\%) & 228 & 132,8 & 98,7 & 34,6 & 18,2 \\
\hline & Formato modal & Flexão & Torção & Flexão & Torção & Flexão \\
\hline & Número de nós modais & 0 & 0 & 2 & 1 & 1 \\
\hline
\end{tabular}

Quando o padrão de deformação da chapa foi o formato modal do primeiro modo de torção não ocorreu o fenômeno de supressão de forma modal, sendo o ganho nas frequências naturais superior ao fornecido pela utilização do primeiro formato modal de flexão para as primeiras quatro frequências naturais. Observou-se também a alteração da sequência dos formatos modais da chapa, em função do número de nós presentes, tal qual no caso do formato modal de flexão. As Figuras 23, 24 e 25 mostram o primeiro, o segundo e o terceiro formatos modais da chapa deformada. 


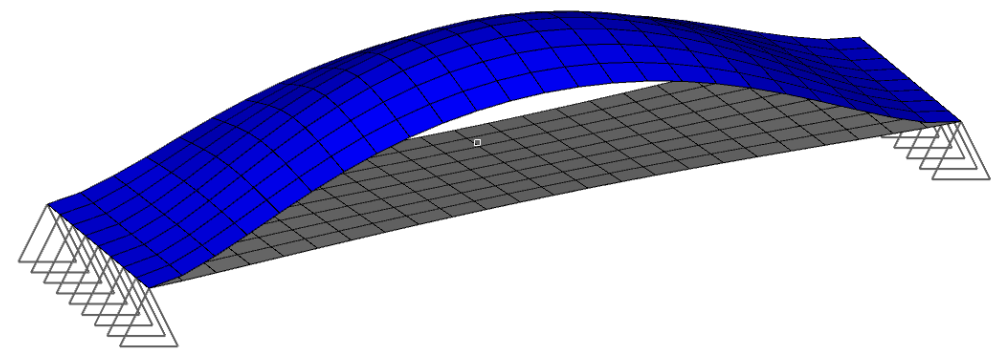

Figura 23 - Primeiro formato modal da chapa deformada (similar ao primeiro formato da chapa não deformada).

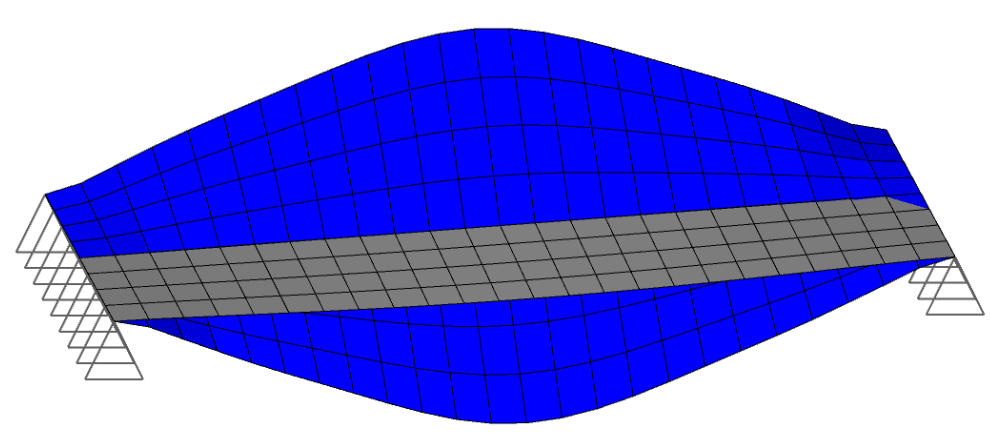

Figura 24 - Segundo formato modal da chapa deformada (similar ao segundo formato modal da chapa não deformada).

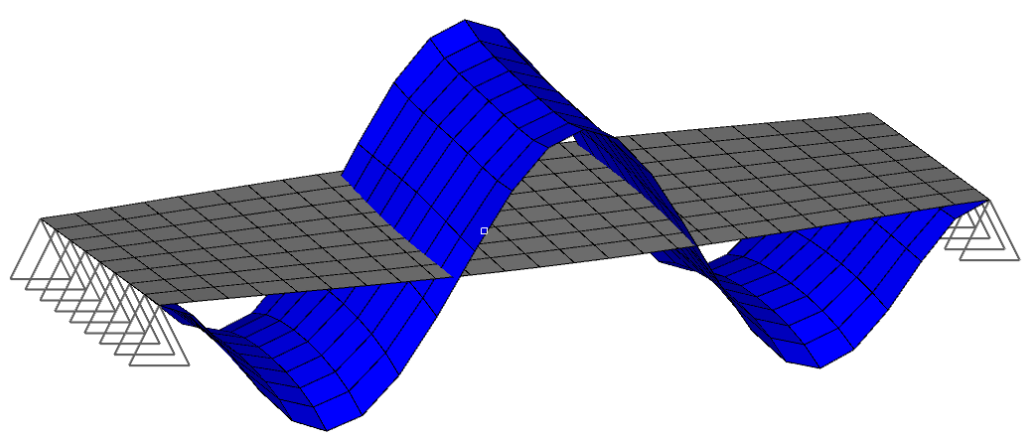

Figura 25 - Terceiro formato modal da chapa deformada (semelhante ao quinto formato modal da chapa original).

\subsubsection{Impacto do segundo formato modal de flexão na frequência natural}

Nesta etapa, o segundo modo de vibração de flexão foi aplicado como padrão de deformação na chapa (Figura 26), para verificar o impacto nas frequências naturais, utilizando o mesmo procedimento numérico dos casos anteriores. A Tabela 3 mostra os resultados das 
primeiras cinco frequências naturais comparando a chapa original com a chapa deformada conforme o segundo formato modal.

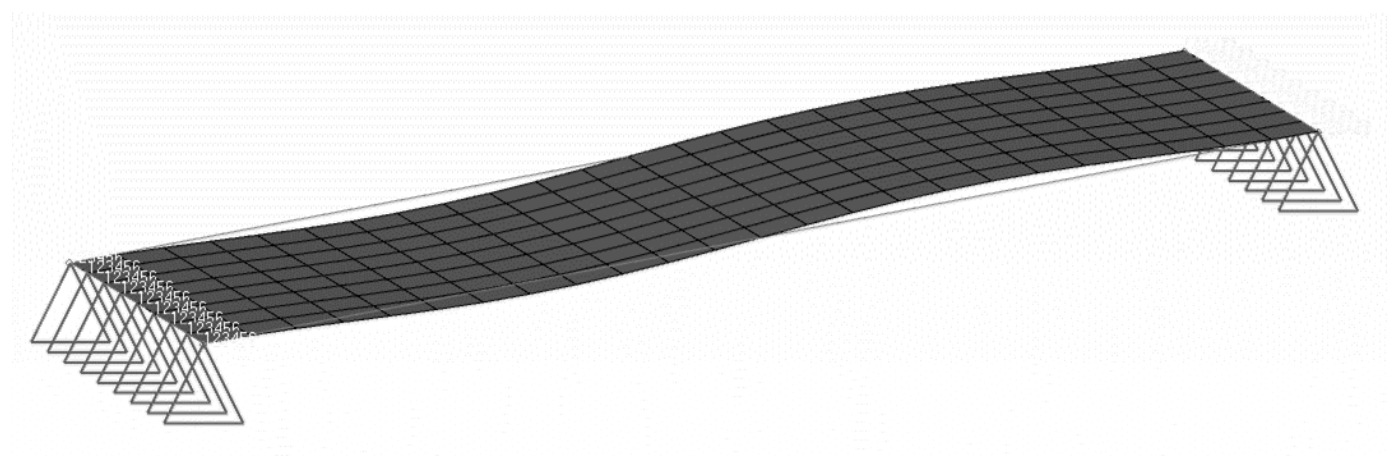

Figura 26 - Chapa deformada conforme o segundo formato modal de flexão.

Tabela 3 - Valores de frequência em $\mathrm{Hz}$ para as primeiras cinco frequências naturais da chapa original e da chapa deformada conforme o segundo formato modal de flexão

\begin{tabular}{|c|c|c|c|c|c|c|}
\hline & Frequência natural & 1 & 2 & 3 & 4 & 5 \\
\hline \multirow{3}{*}{ 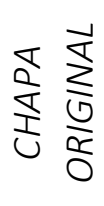 } & Geometria original $(\mathrm{Hz})$ & 42,2 & 89,3 & 116 & 192 & 229 \\
\hline & Formato modal & Flexão & Torção & Flexão & Torção & Flexão \\
\hline & Número de nós modais & 0 & 0 & 1 & 1 & 2 \\
\hline \multirow{4}{*}{ 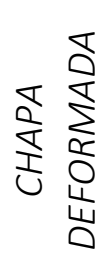 } & Geometria deformada $(\mathrm{Hz})$ & 42,4 & 229,4 & 253,4 & 352,3 & 399,8 \\
\hline & Ganho em frequência (\%) & 0,5 & 156,4 & 118,5 & 83,4 & 74,6 \\
\hline & Formato modal & Flexão & Flexão & Torção & Flexão & Torção \\
\hline & Número de nós modais & 0 & 2 & 1 & 3 & 2 \\
\hline
\end{tabular}

Observa-se nos resultados que novamente ocorreu a supressão de um formato modal, no caso o segundo formato modal de flexão da chapa original, sendo que não houve ganho significativo na primeira frequência natural da chapa deformada, criando uma faixa entre a primeira e a segunda frequências naturais da chapa deformada. Novamente observase também que a ordem dos modos de vibrar foi alterada em relação à chapa original (tanto a ordem flexão/torção quanto a quantidade de nós dos modos). 
As Figuras 27, 28 e 29 mostram, respectivamente, o terceiro modo de flexão para a chapa original, o segundo modo de flexão da chapa deformada (que tem formato semelhante) e o primeiro modo de flexão da chapa deformada (que se assemelha ao primeiro formato modal de flexão da chapa original), que não foi afetado pela deformação da chapa.

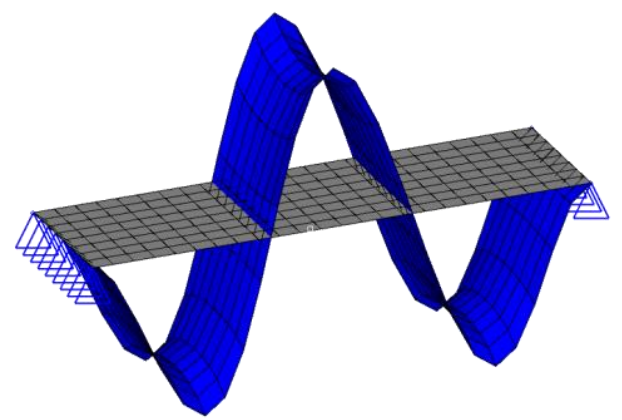

Figura 27 - Terceiro formato modal de flexão da chapa original.

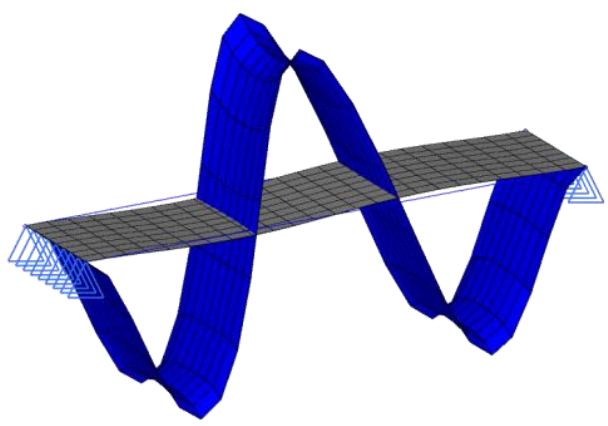

Figura 28 - Segundo modo de flexão da chapa deformada (semelhante ao terceiro formato modal de flexão da chapa original).

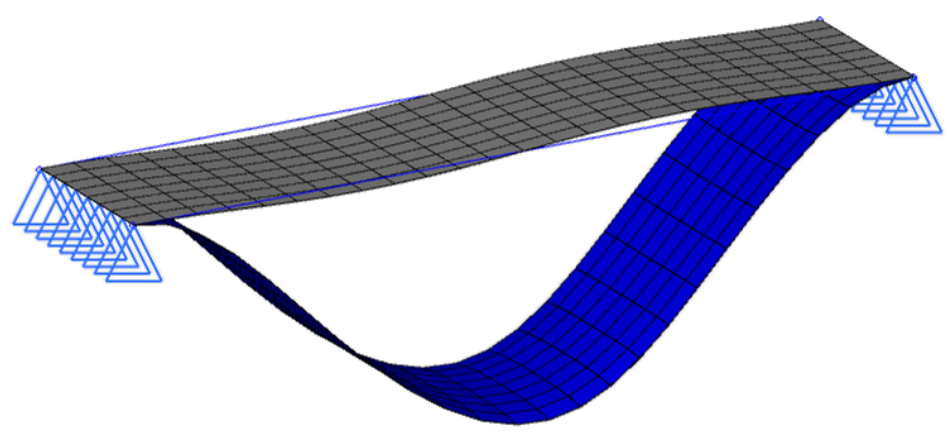

Figura 29 - Primeiro formato modal de flexão da chapa deformada (semelhante ao primeiro formato modal de flexão da chapa original). 


\subsubsection{Impacto do módulo do segundo formato modal de flexão na frequência natural}

O objetivo desse estudo é verificar se a interação do ganho de frequência e a alteração nos formatos modais está relacionada ao formato original da deformação (sendo necessário seguir o perfil original do formato modal, inclusive a direção da deformação dos elementos) ou se os ganhos podem ser obtidos com um formato mais simples, com todos os nós da malha de elementos finitos sendo deslocados na direção Z positiva (independente da direção dos nós no formato modal original) para gerar o formato deformado seguindo o processo descrito na Figura 14.

O módulo de um formato modal refere-se a forma geométrica obtida pela utilização do módulo dos deslocamentos verticais deste formato modal, como utilizado por Fredö e Hedlung (2004) e ilustrado na Figura 14. Neste caso, nenhum nó do modelo de elementos finitos é deslocado na direção negativa do eixo vertical ao se criar a superfície deformada da chapa, como pode ser observado na Figura 30, onde se impôs o módulo do segundo modo de flexão na chapa. A Tabela 4 mostra os resultados das primeiras cinco frequências naturais comparando a chapa original com a chapa deformada conforme o módulo do segundo formato modal.

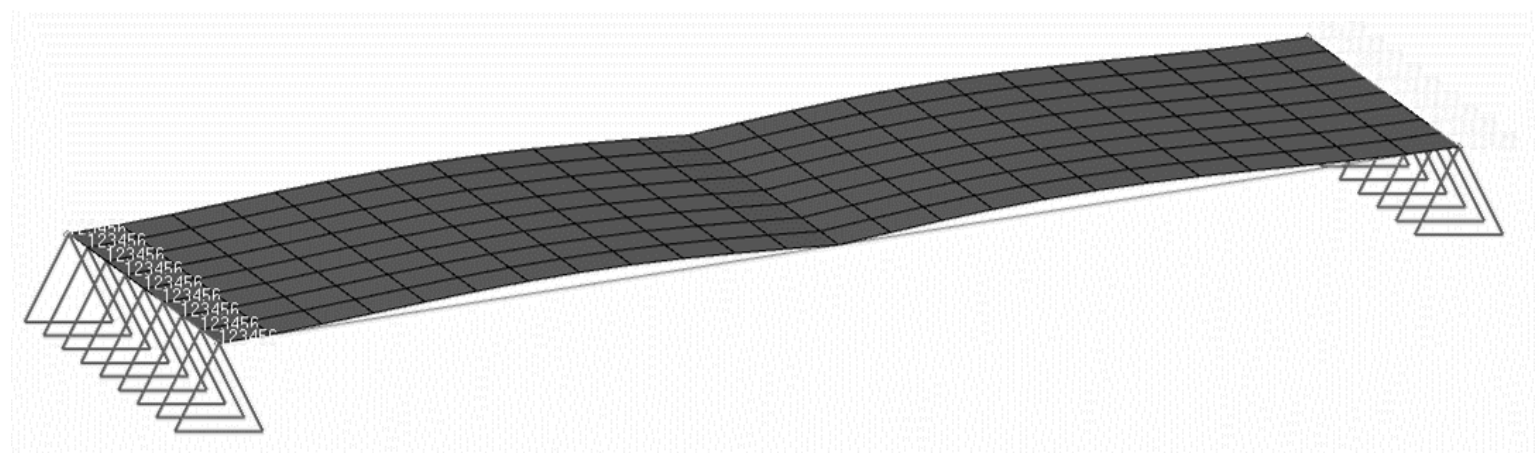

Figura 30 - Chapa deformada conforme o módulo do segundo formato modal. 
Tabela 4 - Valores de frequência em $\mathrm{Hz}$ para as primeiras cinco frequências naturais da chapa original e da chapa deformada conforme o módulo do segundo formato modal de flexão

\begin{tabular}{|c|c|c|c|c|c|c|}
\hline \multicolumn{2}{|r|}{ Frequência natural } & 1 & 2 & 3 & 4 & 5 \\
\hline \multirow{3}{*}{ 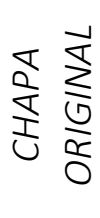 } & Geometria original $(\mathrm{Hz})$ & 42,2 & 89,3 & 116 & 192 & 229 \\
\hline & Formato modal & Flexão & Torção & Flexão & Torção & Flexão \\
\hline & Número de nós modais & 0 & 0 & 1 & 1 & 2 \\
\hline \multirow{4}{*}{ 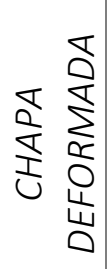 } & Geometria deformada $(\mathrm{Hz})$ & 48,9 & 98,7 & 117,3 & 382 & 385 \\
\hline & Ganho em frequência (\%) & 15,8 & 10,5 & 1,1 & 98,9 & 68,1 \\
\hline & Formato modal & Flexão & Torção & Flexão & Flexão & Flexão \\
\hline & Número de nós modais & 0 & 0 & 1 & 3 & 2 \\
\hline
\end{tabular}

Os resultados indicam que não ocorre a supressão do formato modal, bem como o ganho em frequências naturais ocorreu para frequências maiores (neste caso a partir da quarta frequência natural). Como nos demais casos, a sequência de formatos modais foi alterada na chapa deformada, sugerindo que esse comportamento será normal durante a aplicação dos formatos modais combinados para definir o formato deformado da chapa.

O resultado apresentado condiz com a hipótese apresentada por Fredö e Hedlung (2004), pois quando se toma o módulo do formato modal cria-se uma curvatura na chapa deformada com comprimento de onda diferente do comprimento de onda do formato modal utilizado. Como neste caso os elementos foram deformados somente na direção Z positiva, o formato deformado se repete num comprimento de onda inferior ao formato deformado original, induzindo que o ganho de rigidez tenha impacto em frequências mais altas (cujos formatos modais tenham comprimento de onda similar ao da curvatura da chapa). As Figuras 31, 32 e 33 mostram os três primeiros formatos de flexão da chapa deformada.

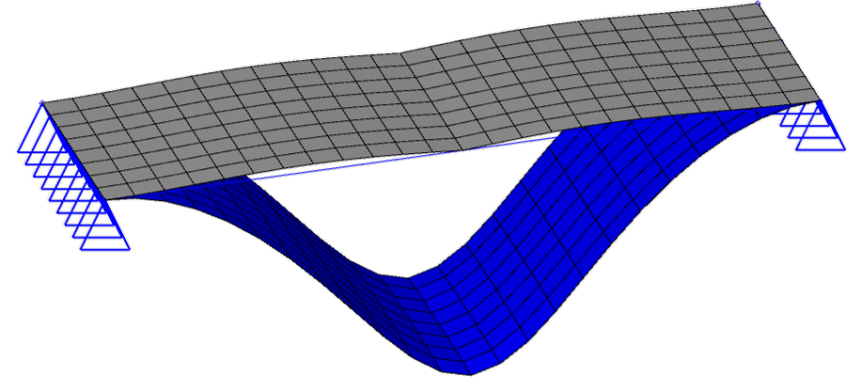

Figura 31 - Primeiro formato modal de flexão da chapa deformada. 


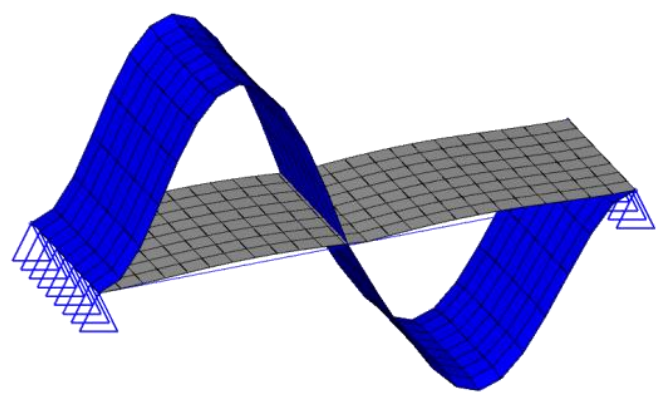

Figura 32 - Segundo formato modal de flexão da chapa deformada.

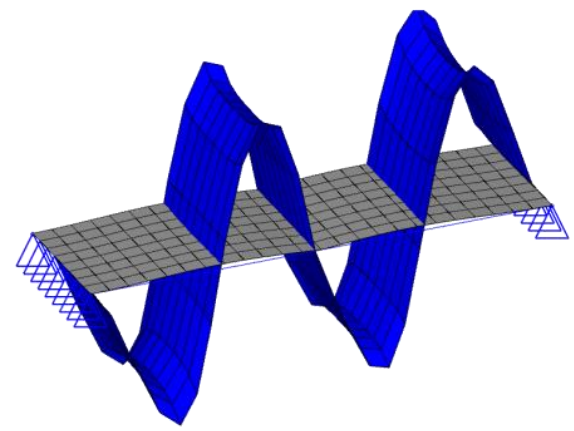

Figura 33 - Terceiro formato modal de flexão da chapa deformada.

\subsection{Efeito das condições de contorno da chapa}

Nesse estudo, variou-se a condição de contorno da chapa comparando as frequências naturais da chapa original com a chapa deformada conforme o primeiro formato modal de flexão, com as seguintes condições de contorno:

- Livre-livre-livre-livre

- Engastada em 1 aresta de $100 \mathrm{~mm}$

- Engastada nas 2 arestas de $100 \mathrm{~mm}$

- Engastada nas 4 arestas

- Engastada nos 4 vértices

- Engastada em 3 pontos, com plano de simetria

- Engastada em 3 pontos, sem plano de simetria

- Engastada nos pontos centrais das arestas de $100 \mathrm{~mm}$ 
O objetivo da variação das condições de contorno da chapa é identificar se os ganhos de frequência e a supressão dos modos de vibrar verificados no item 3.1 dependem das condições de contorno da chapa. Em todos os casos aqui estudados, a chapa utilizada tem dimensões 100 por 300 mm e mesmas propriedades de material dos estudos anteriores.

Por simplicidade, as deformações aplicadas para obter o novo formato da chapa foram sempre aplicadas somente na direção vertical dos nós do modelo de elementos finitos, sendo baseadas nos formatos modais da chapa não deformada.

\subsubsection{Livre-livre-livre-livre}

Neste caso, as chapas encontram-se livres no espaço, conforme a Figura 34 . Os resultados da tabela 5 indicam que, na condição livre-livre, a aplicação de padrões de bossas por formas modais não gerou o ganho esperado de rigidez na chapa. De fato, o resultado observado foi oposto, com redução das frequências naturais da chapa após a deformação, além de alteração na sequência de modos de vibrar. Uma possibilidade para essa queda de rigidez na chapa pode se dever à falta de restrições na chapa, que afetam a interação entre a curvatura do formato deformado e o formato modal da chapa.

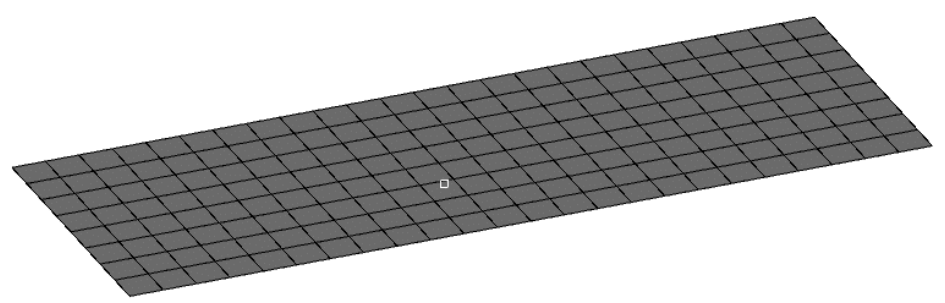

a)

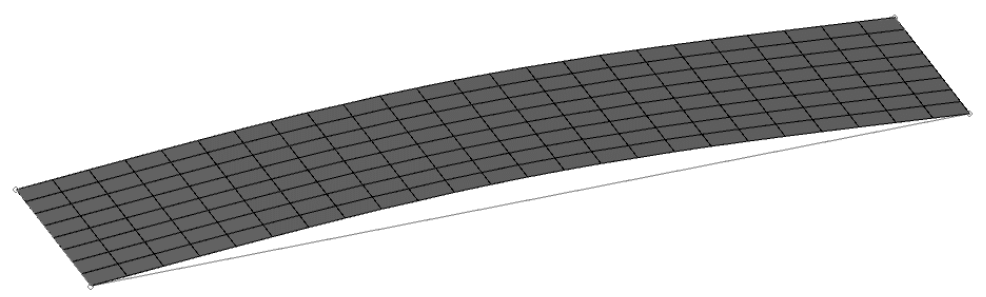

b)

Figura 34 - Formato original (a) e formato deformado (b) seguindo o primeiro formato modal da chapa livre-livre. 
Tabela 5 - Frequências em $\mathrm{Hz}$ das primeiras cinco frequências naturais da chapa original e da chapa deformada conforme o primeiro formato modal de flexão na condição livre-livre.

\begin{tabular}{|c|c|c|c|c|c|c|}
\hline & Frequência natural & 1 & 2 & 3 & 4 & 5 \\
\hline \multirow{3}{*}{ 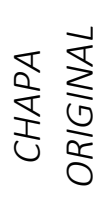 } & Geometria original $(\mathrm{Hz})$ & 43,4 & 82 & 116 & 173,3 & 232,8 \\
\hline & Formato modal & Flexão & Torção & Flexão & Torção & Flexão \\
\hline & Número de nós modais & 0 & 1 & 1 & 2 & 2 \\
\hline \multirow{4}{*}{ 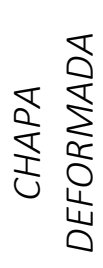 } & Geometria deformada $(\mathrm{Hz})$ & 41,6 & 73,8 & 114,3 & 155 & 223,4 \\
\hline & Ganho em frequência (\%) & $-4,2$ & -10 & $-1,5$ & $-10,6$ & $-4,1$ \\
\hline & Formato modal & Flexão & Torção & Flexão & Torção & Flexão \\
\hline & Número de nós modais & 0 & 1 & 2 & 2 & 3 \\
\hline
\end{tabular}

\subsubsection{Engastada em 1 aresta de $100 \mathrm{~mm}$}

Neste caso, as chapas receberam um engaste representado por uma restrição nos 6 graus de liberdade em uma das arestas de 100 mm, conforme a Figura 35 que mostra a chapa original e a chapa deformada conforme o primeiro formato modal de flexão.

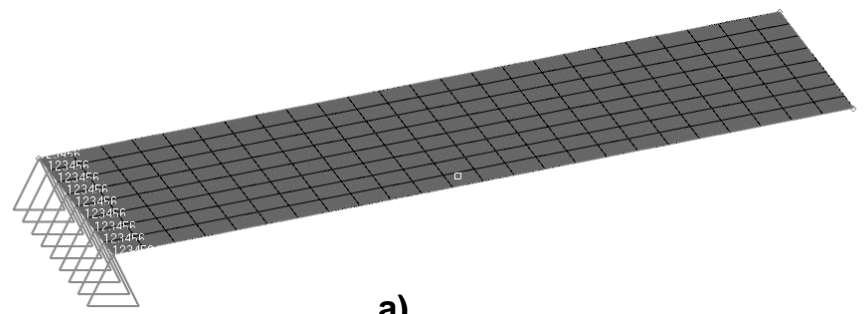

a)

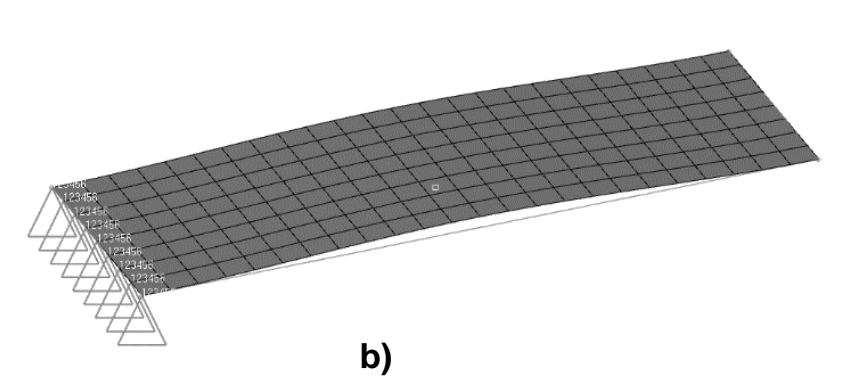

Figura 35 - Formato original (a) e formato deformado (b) seguindo o primeiro formato modal da chapa engastada em uma aresta. 
Os resultados da tabela 6 indicam que a condição de viga engastada somente em uma aresta também não fornece as condições de contorno mínimas necessárias para que o formato deformado aplicado produza ganhos na frequência natural da chapa. Neste caso não houve nenhuma alteração significativa nas frequências ou na sequência dos formatos modais.

Tabela 6 - Valores de frequência em $\mathrm{Hz}$ para as primeiras cinco frequências naturais da chapa original e da chapa deformada conforme o primeiro formato modal de flexão na condição de chapa engastada em uma aresta.

\begin{tabular}{|c|c|c|c|c|c|c|}
\hline & Frequência natural & 1 & 2 & 3 & 4 & 5 \\
\hline \multirow{3}{*}{ 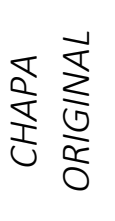 } & Geometria original (Hz) & 6,56 & 39,8 & 41 & 115 & 124,8 \\
\hline & Formato modal & Flexão & Torção & Flexão & Flexão & Torção \\
\hline & Número de nós modais & 0 & 0 & 1 & 2 & 1 \\
\hline \multirow{4}{*}{ 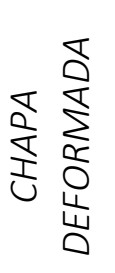 } & Geometria deformada $(\mathrm{Hz})$ & 6,61 & 39,2 & 41,2 & 115,4 & 122,1 \\
\hline & Ganho em frequência (\%) & 0,7 & $-1,6$ & 0,5 & 0,3 & $-2,2$ \\
\hline & Formato modal & Flexão & Torção & Flexão & Flexão & Torção \\
\hline & Número de nós modais & 0 & 0 & 1 & 2 & 1 \\
\hline
\end{tabular}

\subsubsection{Engastada nas 2 arestas de $100 \mathrm{~mm}$}

Neste caso, a chapa foi engastada através da aplicação de restrições nas duas arestas de $100 \mathrm{~mm}$ da chapa, nos 6 graus de liberdade, conforme explorado no item 3.1.1.

Os resultados da tabela 1 mostram que o engaste da chapa em duas arestas é suficiente para que a aplicação do padrão de bossas por formas modais para deformação da chapa produza resultados no aumento da frequência natural (neste caso aumentando em $174,8 \%$ a primeira frequência natural) bem como suprima os formatos modais que tenham o mesmo comprimento de onda da curvatura da chapa deformada, além de ocorrer alteração da sequência dos formatos modais. 


\subsubsection{Engastada nas 4 arestas}

Neste caso a chapa é engastada em todas as arestas (Figura 36) através da aplicação de restrições nos 6 graus de liberdade dos nós da borda da chapa, para verificar se esta condição de contorno (que simula diversas aplicações da indústria) afetaria o resultado obtido pela aplicação do primeiro formato modal como referência de deformação da chapa.
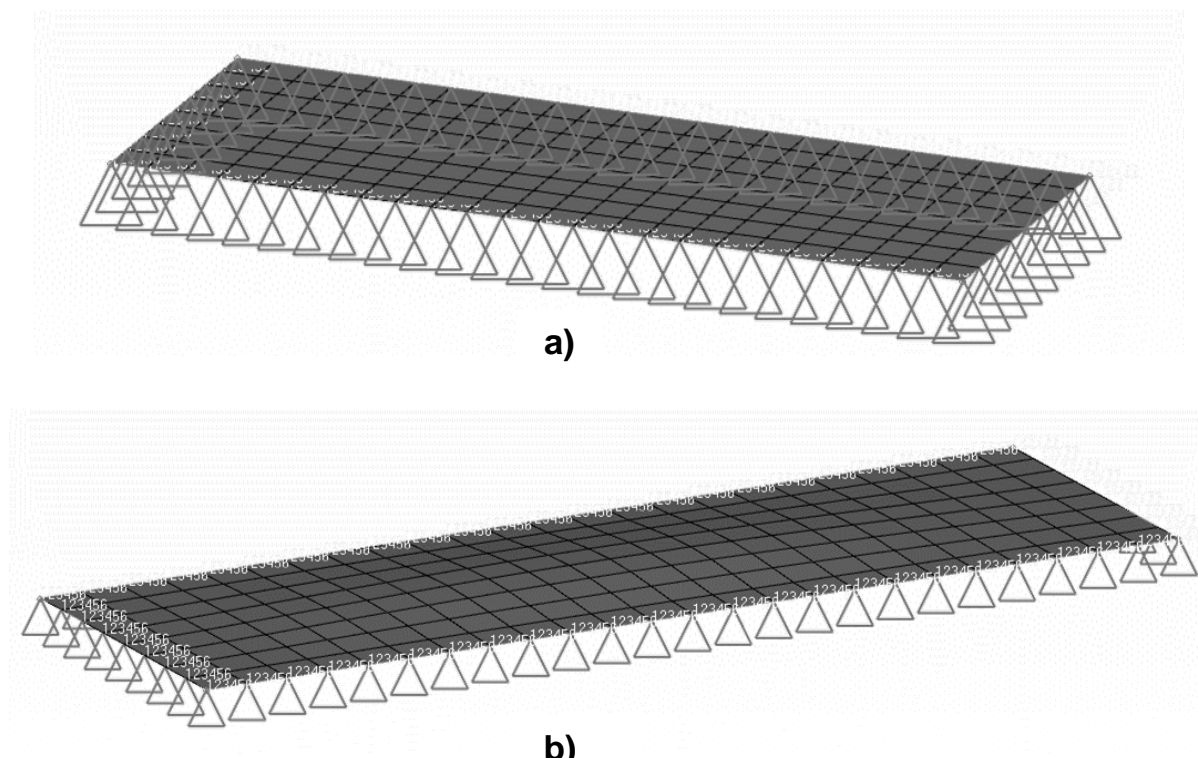

b)

Figura 36 - Formato original (a) e formato deformado (b) seguindo o primeiro formato modal da chapa engastada nas quatro arestas.

Os resultados da Tabela 7 mostram que o engaste da chapa em quatro arestas (todo o contorno da geometria), tendo a aplicação do formato modal do primeiro modo de flexão como referência para deformação da chapa, também produz resultados no aumento da frequência natural, com supressão do formato modal utilizado como referência na deformação da chapa e alteração da sequência de formatos modais e alteração da sequência dos formatos modais. 
Tabela 7 - Valores de frequência em $\mathrm{Hz}$ para as primeiras cinco frequências naturais da chapa original e da chapa deformada conforme o primeiro formato modal de flexão na condição engastada em todas as arestas.

\begin{tabular}{|c|c|c|c|c|c|c|}
\hline \multicolumn{2}{|r|}{ Frequência natural } & 1 & 2 & 3 & 4 & 5 \\
\hline \multirow{3}{*}{ 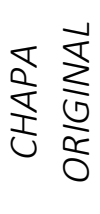 } & Geometria original (Hz) & 405,2 & 446,9 & 525,3 & 646,1 & 811,5 \\
\hline & Formato modal & Flexão & Flexão & Flexão & Flexão & Flexão \\
\hline & Número de nós modais & 0 & 1 & 2 & 3 & 4 \\
\hline \multirow{4}{*}{ 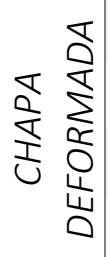 } & Geometria deformada $(\mathrm{Hz})$ & 882,2 & 883,7 & 1159,2 & 1233,7 & 1297,3 \\
\hline & Ganho em frequência (\%) & 117,1 & 97,7 & 120,6 & 90,9 & 59,8 \\
\hline & Formato modal & Flexão & Flexão & Torção & Torção & Torção \\
\hline & Número de nós modais & 1 & 2 & 0 & 1 & 2 \\
\hline
\end{tabular}

\subsubsection{Engastada nos 4 vértices}

Neste caso, a chapa é engastada apenas nos 4 vértices através da aplicação de restrições nos 6 graus de liberdade dos nós da borda da chapa (Figura 37), para verificar se esta condição de contorno seria suficiente para obter os resultados observados em outros casos pela aplicação do primeiro formato modal como referência de deformação da chapa.
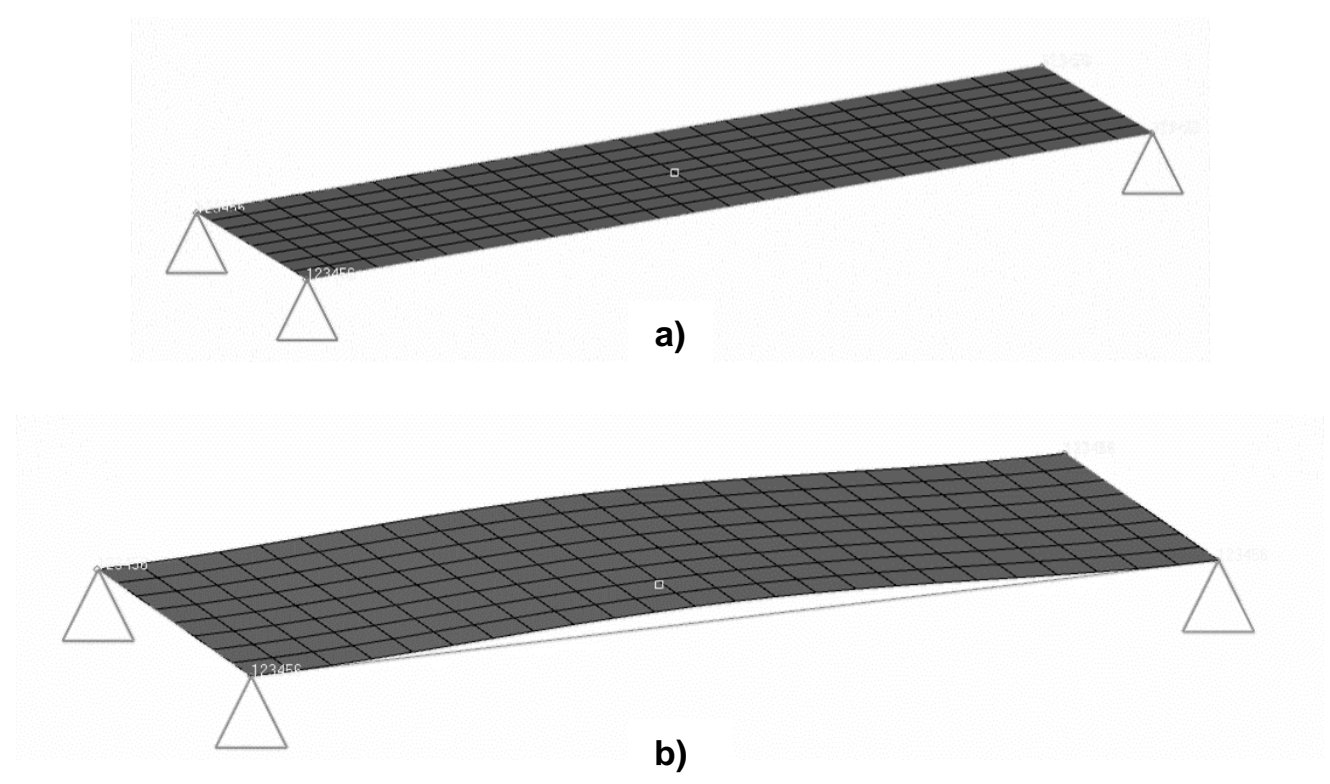

Figura 37 - Formato original (a) e formato deformado (b) seguindo o primeiro formato modal da chapa engastada nos quatro vértices 
Os resultados da Tabela 8 mostram que o engaste em quatro vértices, associado ao formato modal do primeiro modo de flexão como padrão de deformação da chapa, foi suficiente para produzir resultados no aumento da frequência natural (sendo estes superiores percentualmente ao caso da chapa engastada em duas arestas). Além disso, foi constatada a supressão do formato modal utilizado como referência na deformação da chapa, além da contraparte de torção do modo (ou seja, os modos sem nós foram suprimidos), associado à alteração da sequência de formatos modais.

Tabela 8 - Valores de frequência em $\mathrm{Hz}$ para as primeiras cinco frequências naturais da chapa original e da chapa deformada conforme o primeiro formato modal de flexão na condição engastada nos vértices

\begin{tabular}{|c|c|c|c|c|c|c|}
\hline & Frequência natural & 1 & 2 & 3 & 4 & 5 \\
\hline \multirow{3}{*}{ 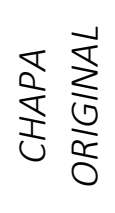 } & Geometria original $(\mathrm{Hz})$ & 28,1 & 83,2 & 86,9 & 175,1 & 179,2 \\
\hline & Formato modal & Flexão & Torção & Flexão & Flexão & Torção \\
\hline & Número de nós modais & 0 & 0 & 1 & 2 & 1 \\
\hline \multirow{4}{*}{ 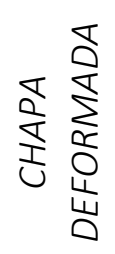 } & Geometria deformada $(\mathrm{Hz})$ & 87,4 & 102,5 & 173,9 & 184,8 & 280,3 \\
\hline & Ganho em frequência (\%) & 211 & 23,2 & 100 & 5,5 & 56,4 \\
\hline & Formato modal & Flexão & Flexão & Torção & Torção & Flexão \\
\hline & Número de nós modais & 1 & 2 & 3 & 1 & 3 \\
\hline
\end{tabular}

\subsubsection{Engastada em 3 pontos, com plano de simetria}

Neste caso a chapa é engastada somente em 3 pontos, sendo dois deles os vértices de uma das arestas de $100 \mathrm{~mm}$ da chapa e o terceiro o ponto médio da aresta de $100 \mathrm{~mm}$ oposta (Figura 38). Todos os engastes foram simulados pela aplicação de restrições nos 6 graus de liberdade dos respectivos nós. Nesta configuração existe um plano de simetria na chapa passando pelo ponto médio das arestas de $100 \mathrm{~mm}$. 
a)

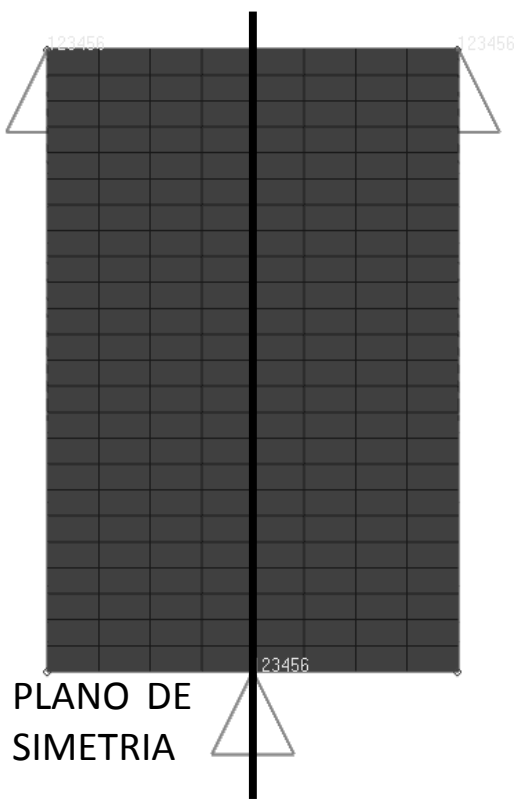

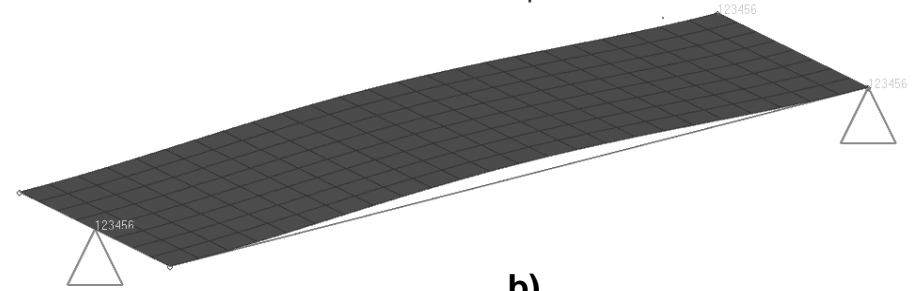

b)

Figura 38 - Formato original (a) e formato deformado (b) seguindo o primeiro formato modal da chapa engastada em três vértices, com plano de simetria indicado

Os resultados da tabela 9 mostram que o engaste da chapa em três vértices, criando um plano de simetria, tendo o formato modal do primeiro modo de flexão como referência para deformação da chapa, produz resultados no aumento da frequência natural. Constatouse também a supressão do formato modal utilizado como referência na deformação da chapa, sem afetar a contraparte de torção, alterando-se a sequência de formatos modais.

Tabela 9 - Valores de frequência em $\mathrm{Hz}$ para as primeiras cinco frequências naturais da chapa original e da chapa deformada conforme o primeiro formato modal de flexão na condição de engaste em três pontos com plano de simetria

\begin{tabular}{|c|c|c|c|c|c|c|}
\hline & Frequência natural & 1 & 2 & 3 & 4 & 5 \\
\hline \multirow{3}{*}{ 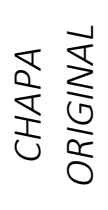 } & Geometria original $(\mathrm{Hz})$ & 28,9 & 60 & 86,5 & 136,5 & 172,3 \\
\hline & Formato modal & Flexão & Torção & Flexão & Torção & Flexão \\
\hline & Número de nós modais & 0 & 0 & 1 & 1 & 2 \\
\hline \multirow{4}{*}{ 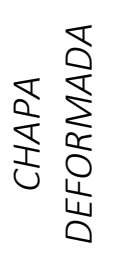 } & Geometria deformada $(\mathrm{Hz})$ & 87,4 & 102,9 & 105,2 & 162,4 & 275,5 \\
\hline & Ganho em frequência (\%) & 202,4 & 71,5 & 21,6 & 18,9 & 59,8 \\
\hline & Formato modal & Flexão & Flexão & Torção & Torção & Torção \\
\hline & Número de nós modais & 1 & 2 & 0 & 1 & 2 \\
\hline
\end{tabular}




\subsubsection{Engastada em 3 pontos, sem plano de simetria}

Neste caso a chapa é engastada nos 6 graus de liberdade somente em 3 pontos, sendo dois deles os vértices de uma das arestas de $100 \mathrm{~mm}$ da chapa e o terceiro deslocado $10 \mathrm{~mm}$ em relação ao ponto médio da aresta de $100 \mathrm{~mm}$ aposta (Figura 39). Essa configuração visa retirar o plano de simetria identificado no item 3.2.6 e verificar o impacto deste nos resultados.

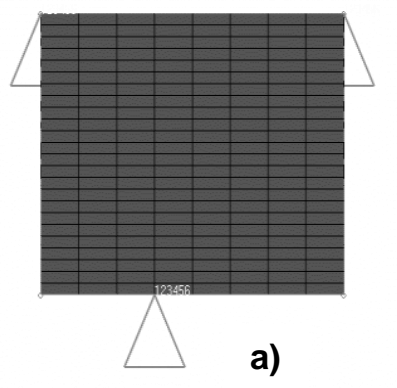

Figura 39 - Formato original modal da chapa engastada em três vértices, sem plano de simetria

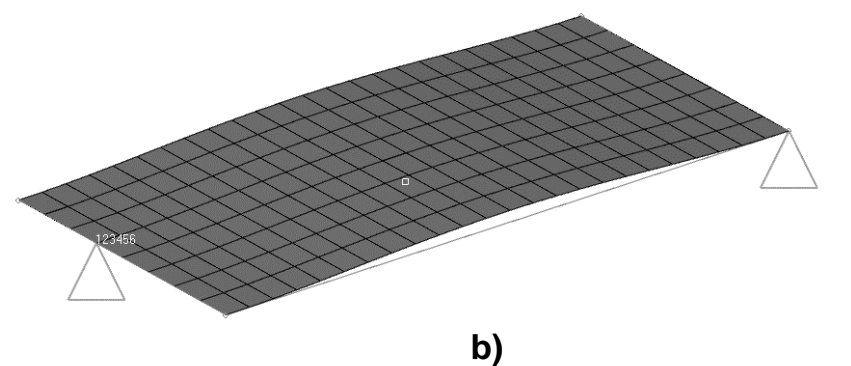

b)

Os resultados da tabela 10 mostram que a condição de 3 apoios sem plano de simetria é suficiente para que a aplicação do primeiro formato modal de flexão como padrão de deformação da chapa aumente a primeira frequência natural da chapa. Entretanto não houve a supressão clara desse formato modal na chapa deformada (modo de flexão sem nós.) Em comparação com o caso de chapa com plano de simetria, o ganho percentual da primeira frequência foi ligeiramente inferior, sendo que em ambos os casos este se tornou o modo de flexão com um nó. 
Tabela 10 - Valores de frequência em $\mathrm{Hz}$ para as primeiras cinco frequências naturais da chapa original e da chapa deformada conforme o primeiro formato modal de flexão na condição de engaste em três pontos sem plano de simetria

\begin{tabular}{|c|c|c|c|c|c|c|}
\hline \multicolumn{2}{|r|}{ Frequência natural } & 1 & 2 & 3 & 4 & 5 \\
\hline \multirow{3}{*}{ 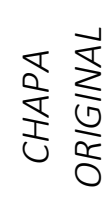 } & Geometria original $(\mathrm{Hz})$ & 28,1 & 58,6 & 87 & 132 & 175,7 \\
\hline & Formato modal & Flexão & Torção & Flexão & Torção & Flexão \\
\hline & Número de nós modais & 0 & 0 & 1 & 1 & 2 \\
\hline \multirow{4}{*}{ 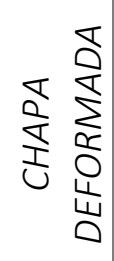 } & Geometria deformada $(\mathrm{Hz})$ & 83,7 & 95,8 & 115,1 & 161,8 & 246,6 \\
\hline & Ganho em frequência (\%) & 197,8 & 63,5 & 32,2 & 22,5 & 40,3 \\
\hline & Formato modal & Flexão & Flexão & Torção & Torção & Torção \\
\hline & Número de nós modais & 1 & 0 & 0 & 1 & 2 \\
\hline
\end{tabular}

\subsubsection{Engastada no ponto central das arestas de $100 \mathrm{~mm}$}

Neste caso a chapa recebeu engastes nos pontos médios das arestas de $100 \mathrm{~mm}$ através da aplicação de restrições nos 6 graus de liberdade nos nós respectivos (Figura 40).

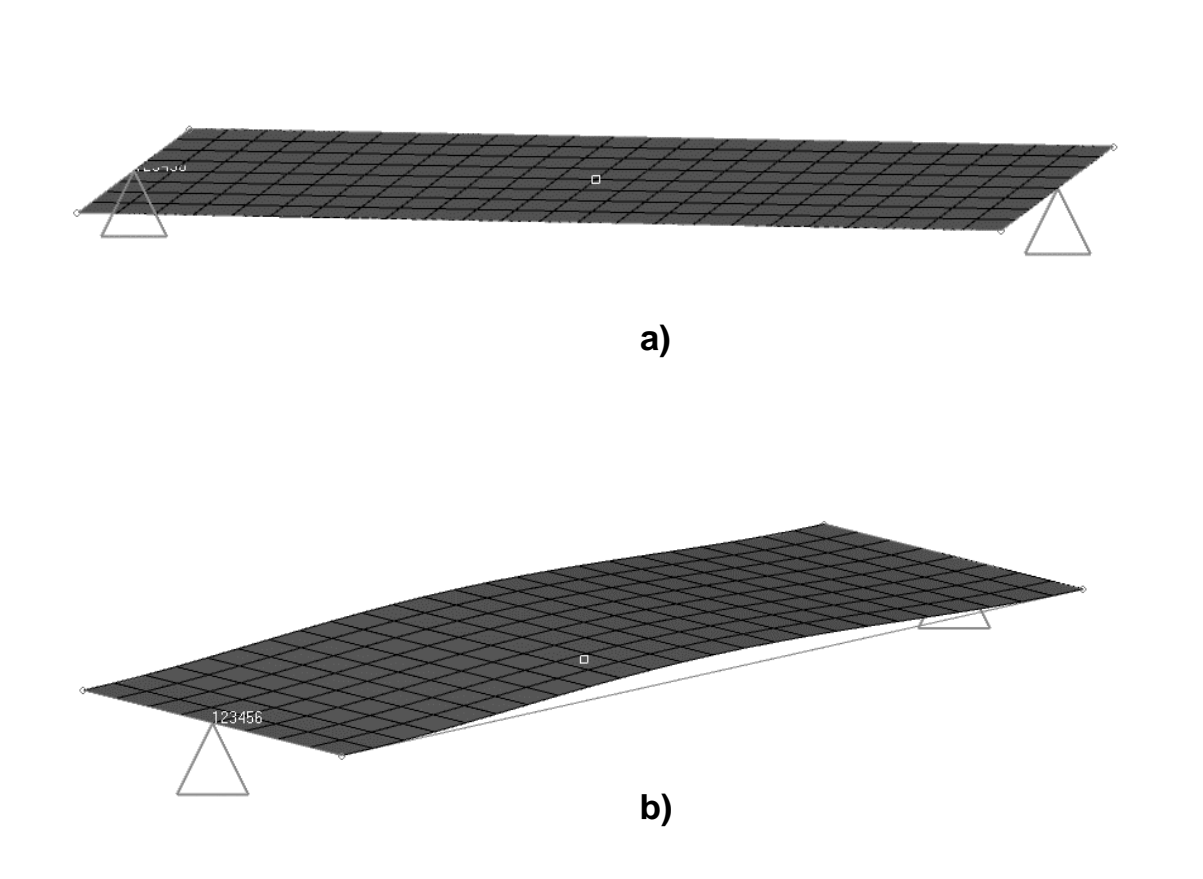

Figura 40 - Formato original (a) e formato deformado (b) seguindo o primeiro formato modal da chapa engastada em dois vértices no ponto central das arestas de $100 \mathrm{~mm}$ 
Os resultados da tabela 11 indicam que dois engastes nos pontos médios de arestas opostas provêm restrição suficiente para a chapa deformada conforme o primeiro formato modal para que ocorra ganho nas frequências naturais, porém sem supressão do modo de vibrar. Observa-se também alteração na sequência dos modos de vibrar da chapa deformada. Cabe ressaltar também que neste caso o ganho na primeira frequência natural foi o menor em termos percentuais que as configurações com mais pontos de restrição

Tabela 11 - Valores de frequência em $\mathrm{Hz}$ para as primeiras cinco frequências naturais da chapa original e da chapa deformada conforme o primeiro formato modal de flexão na condição de engaste em dois pontos no centro das arestas

\begin{tabular}{|c|c|c|c|c|c|c|}
\hline & Frequência natural & 1 & 2 & 3 & 4 & 5 \\
\hline \multirow{3}{*}{ 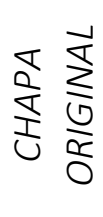 } & Geometria original $(\mathrm{Hz})$ & 28,7 & 45,6 & 86,3 & 105,9 & 169,6 \\
\hline & Formato modal & Flexão & Torção & Flexão & Torção & Flexão \\
\hline & Número de nós modais & 0 & 0 & 1 & 1 & 2 \\
\hline \multirow{4}{*}{ 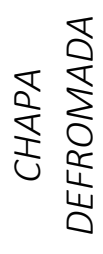 } & Geometria deformada $(\mathrm{Hz})$ & 47,2 & 87,4 & 103,5 & 107.9 & 189 \\
\hline & Ganho em frequência (\%) & 64,4 & 91,6 & 19,9 & 1,8 & 11,4 \\
\hline & Formato modal & Torção & Flexão & Flexão & Torção & Torção \\
\hline & Número de nós modais & 0 & 1 & 0 & 1 & 2 \\
\hline
\end{tabular}

\subsection{Efeito da relação comprimento-largura da chapa}

Aqui verifica-se o impacto da relação comprimento por largura $(C / L)$ da chapa, considerando uma chapa de largura constante de $100 \mathrm{~mm}$ e comprimento variando de $100 \mathrm{a}$ $300 \mathrm{~mm}$. Neste estudo buscou-se diferenças no incremento das frequências naturais ao se comparar a chapa original com o chapa deformada conforme o primeiro modo de flexão, sendo a chapa sempre engastada nas duas arestas de $100 \mathrm{~mm}$. 
Por simplicidade, as deformações aplicadas para obter o novo formato da chapa foram sempre aplicadas somente na direção vertical dos nós do modelo de elementos finitos, sendo baseadas nos formatos modais da chapa não deformada.

A Figura 41 mostra a evolução dos valores da primeira frequência natural da chapa original e da chapa deformada juntamente do ganho percentual da frequência, conforme a relação entre comprimento e largura varia. Em todos os casos, a primeira frequência natural aumentou consideravelmente, com a razão comprimento por largura $(C / L)$, ocorrendo pouca variação no ganho percentual da primeira frequência (variando entre $275 \%$ a $280 \%$ ).

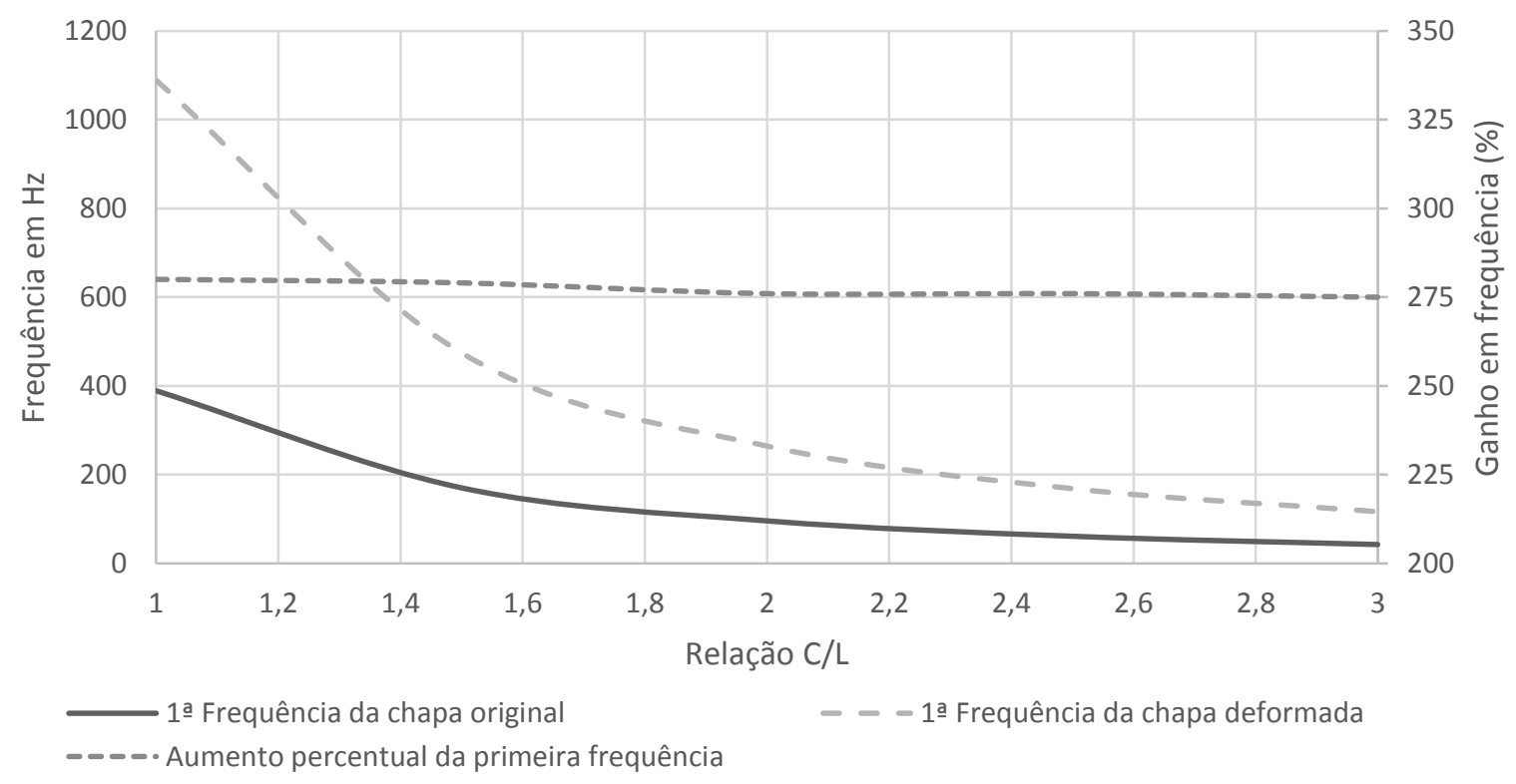

Figura 41 - Valores de frequência para o primeiro modo em $\mathrm{Hz}$ comparado com a razão entre o comprimento e a largura (C/L) da chapa.

\subsection{Efeito do ângulo de conexão dos elementos da chapa}

Neste estudo, variou-se o ângulo máximo aplicado entre os elementos da chapa, partindo do limite indicado pela hipersensibilidade de $5^{\circ}$ chegando até o ângulo de $25^{\circ}$, sendo que a chapa avaliada estava engastada nas duas arestas de $100 \mathrm{~mm}$, e o formato modal do primeiro modo de flexão foi utilizado como padrão de deformação (chapa de dimensões 100 por $300 \mathrm{~mm}$ ). A Figura 42 mostra a evolução da primeira frequência natural em função do ângulo máximo entre os elementos, mostrando ainda mostra que os maiores valores da primeira frequência natural da chapa deformada ocorrem quando o ângulo máximo entre os 
elementos está entre $2,5^{\circ}$ a $5^{\circ}$. Por simplicidade, as deformações foram sempre aplicadas somente na direção vertical dos nós do modelo de elementos finitos, sendo baseadas nos formatos modais da chapa não deformada.

Isso confirma o efeito da hipersensibilidade, no qual os maiores ganhos são obtidos com pequenos ângulos entre os elementos. Considerando-se que quanto maior o ângulo entre os elementos maior será a deformação da chapa, os resultados indicam que a utilização do máximo ângulo de $5^{\circ}$ fornece a melhor relação entre a deformação da chapa e o ganho em frequência. A utilização de ângulos superiores não fornece ganhos significativos, e ângulos inferiores podem gerar resultados menores de ganho em frequência.

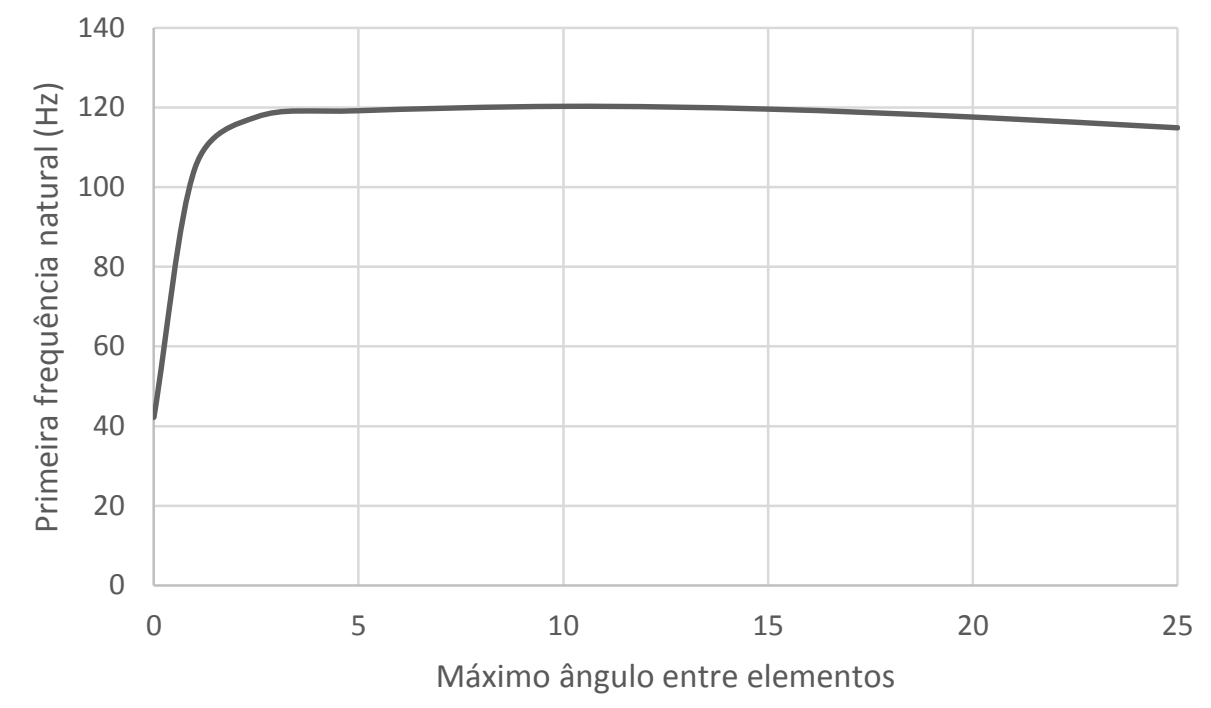

Figura 42 - Primeira frequência natural da chapa deformada em função do máximo ângulo entre os elementos da chapa.

\subsection{Resumo dos resultados obtidos}

Os resultados das investigações neste capítulo permitem algumas observações:

1. A supressão de um dado formato modal somente ocorreu nos casos de estudo quando o formato utilizado como padrão de deformação por bossas da chapa for de flexão e a chapa tiver as condições necessárias de engaste (ambas as arestas perpendiculares ao movimento principal do modo de vibrar engastadas e com um plano de simetria presente); 
2. O tipo de formato modal utilizado na deformação influenciou diretamente qual frequência natural sofreu ganhos na chapa deformada, conforme ilustra a Figura 43;

3. Os formatos de torção, quando utilizados como padrão de deformação, não produzem o efeito de supressão do formato modal, porém aumentam a rigidez da chapa deformada (Figura 43);

4. Independentemente de qual formato modal for escolhido para deformar a chapa, não somente a frequência natural associada a esse modo foi afetada, mas também todas as frequências superiores, ou seja, a rigidez da chapa sempre é aumentada pelo processo de deformação a partir da frequência associada a um modo utilizado na deformação (Figura 43);

5. A utilização do módulo de um dado formato modal como padrão de deformação, seguindo a recomendação de Fredö e Hedlung (2004) provêm ganhos na frequência natural, porém sem supressão de formatos modais na chapa, possivelmente devido à diferença no comprimento de onda da curvatura da chapa deformada e o comprimento de onda do formato modal utilizado (Figura 43);

6. No caso da chapa de estudo, o mínimo de engastes necessários para se obter ganhos em frequências foram dois engastes nos pontos médios das arestas de $100 \mathrm{~mm}$ da chapa;

7. O tipo e quantidade de engastes presentes na chapa afetam consideravelmente o ganho em frequência obtido na aplicação do padrão de bossas por formas modais na chapa, conforme mostrado na Figura 44;

8. As dimensões da chapa têm mínimo efeito sobre o ganho de rigidez obtido com a aplicação do padrão de bossas por formas modais para o caso em estudo, conforme ilustrado na Figura 41. 


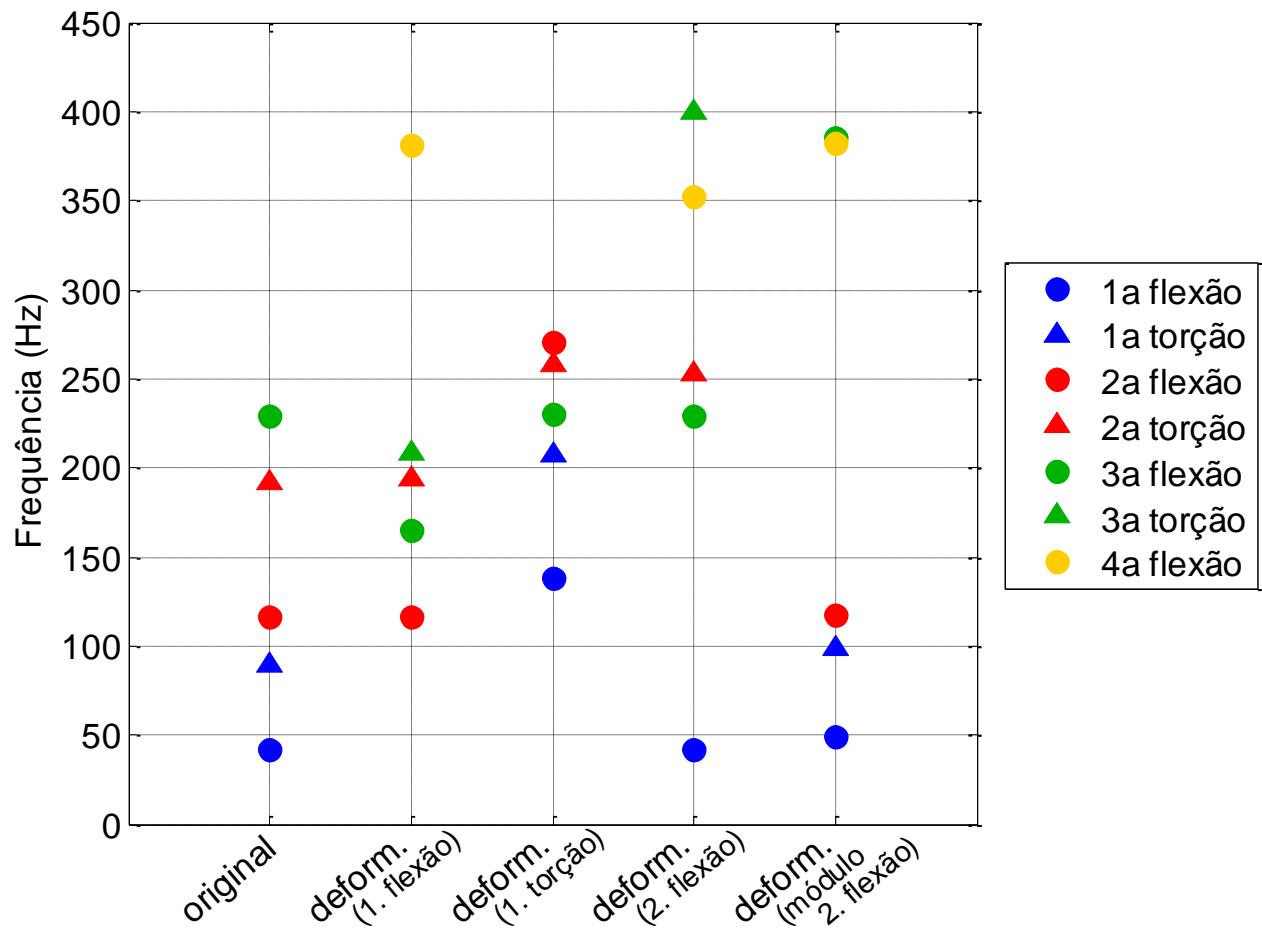

Figura 43 - Frequências naturais da chapa deformada por tipo de formato modal utilizado na deformação (chapa de 100 por $300 \mathrm{~mm}$ engastada nas arestas de $100 \mathrm{~mm}$ ).

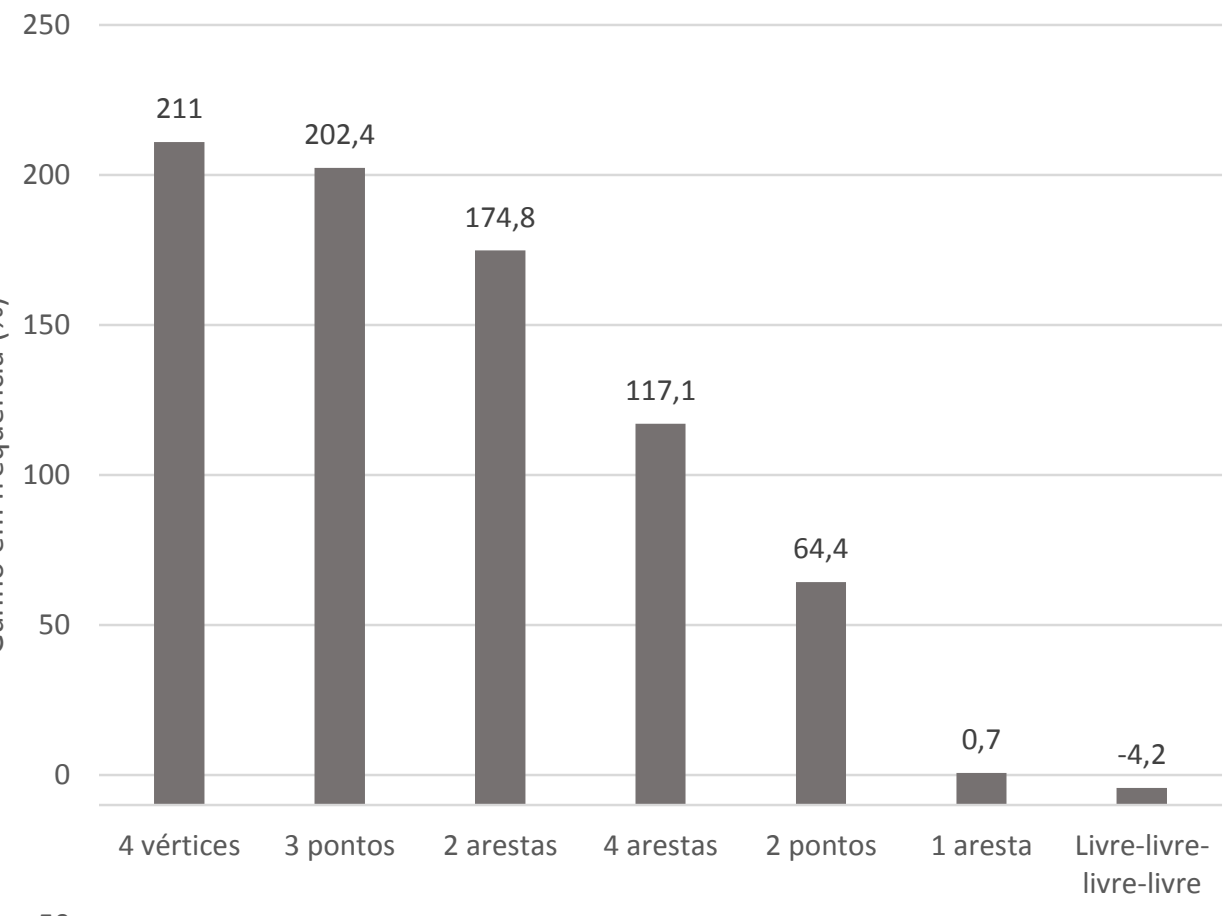

Figura 44 - Valores da primeira frequência natural da chapa deformada por tipo de engaste presente na chapa. 


\section{Estrutura do Programa de Otimização}

\subsection{Definição}

Como observado no Capítulo anterior, a imposição de uma forma modal em uma chapa causa alteração nas suas frequências naturais e modos de vibrar. $O$ trabalho de Fredö e Hedlung (2005) propõe que, não só se utilize uma forma modal da chapa para alterar a suas características dinâmicas, mas também que se utilize uma combinação linear de formas modais. Com isto, segundo os autores, pode-se ter maior flexibilidade no posicionamento das frequências naturais da estrutura. O problema é determinar os coeficientes de ponderação desta combinação linear para se alcançar um determinado objetivo. O presente capítulo visa descrever o algoritmo de otimização proposto para se obter os coeficientes de ponderação dada uma função objetivo.

O primeiro passo para criar um algoritmo computacional (programa) para definir o conjunto ideal de fatores de ponderação $C_{j}$ do método de Fredö e Hedlung (2005) foi definir o método de otimização a ser utilizado. A escolha foi baseada nas características, restrições e número de variáveis do problema, ou seja, no seu modelamento. Em termos de variáveis, o problema a ser resolvido é do tipo multi-variáveis (os coeficientes de ponderação dos formatos modais). Quanto a restrições, tem-se a imposição geométrica do ângulo máximo entre os elementos do modelo, que demanda correções na geometria da chapa a cada iteração, além do engaste da estrutura. No aspecto das características do problema, este pode se tornar não-linear com derivadas e topologia desconhecidas.

Considerando esses três fatores, o método de Nelder-Mead Simplex foi escolhido como base do desenvolvimento do programa. Este método busca mínimos de funções multivariáveis não restritas utilizando um processo que depende somente de avaliações da função objetivo definida pelo usuário, não sendo necessária a derivação da função, associada a um vetor de estimativas iniciais das variáveis de otimização e um conjunto de parâmetros a serem otimizados (PRESS et. al., 2007). 
Por simplicidade, a estrutura em análise será a mesma chapa de aço 300 por $100 \mathrm{~mm}$ utilizada anteriormente, cujos dados estão listados na página 23. Além disso, todas as deformações por padrões de bossas serão aplicadas apenas na direção vertical (perpendicular) da chapa, aplicadas como deslocamentos da coordenada Z dos nós dos elementos (sem alterações nas coordenadas $X$ e $Y$ dos nós).

A função objetivo foi definida de acordo com o objetivo desejado. No presente estudo, o objetivo é conseguir o maior incremento possível numa dada frequência natural com a chapa deformada, tendo ou não objetivos secundários associados, como manter uma outra frequência natural inalterada ou definir o valor objetivo de uma dada frequência, traduzidos numa função objetivo.

A função custo e as restrições foram definidas com base nos resultados do estudo do capítulo 3 e do trabalho de Fredö e Hedlung, conforme descrito no capítulo 4.3 e 4, sendo que as restrições do problema se referem a maneira que a chapa será deformada, e não aos fatores de ponderação que serão otimizados. Com isso o problema de otimização foi resolvido usando a função de minimização "fminsearch" do Matlab $^{\circledR}$, que usa o método Nelder-Mead simplex sem restrições para procurar a melhor combinação de coeficientes $C_{j}$ (fatores de ponderação) para otimizar a forma da chapa (MATH WORKS, 2009). Tal processo foi conduzido combinando

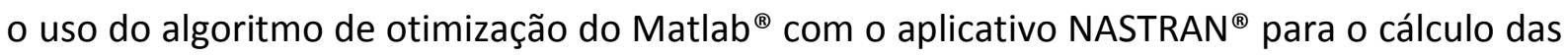
frequências naturais e modos de vibrar da estrutura a cada iteração até que o critério de convergência fosse atingido. O critério de convergência é definido por duas condições, associadas ao valor da função objetivo de otimização e os coeficientes sendo otimizados.

\subsection{Composição do formato deformado}

Uma vez modelado o problema e definido o algoritmo de otimização a ser utilizado, foi necessário definir o processo de criação da forma deformada por formas modais da chapa metálica. Para tal, os formatos modais foram obtidos a partir do arquivo de saída "PUNCH" do Nastran ${ }^{\circledR}$ com os resultados da análise modal pelo método Lanczos através da solução 103 do Nastran ${ }^{\circledR}$ (MSC, 2010). Com os formatos modais conhecidos, foi feita a composição dos deslocamentos verticais a serem aplicados aos nós (deformação da chapa) seguindo a soma 
do deslocamento vertical de cada nó, para cada formato modal, ponderado pelos coeficientes $C_{j}$ da otimização (similar ao processo apresentado na Figura 45). Usualmente o formato deformado gerado não atende os requisitos da hipersensibilidade. Desta forma, uma verificação da geometria da chapa é conduzida para identificar o maior ângulo entre elementos presente, e então um fator de escala (denominado Alfa no Algoritmo do Anexo A) é aplicado nos deslocamentos verticais de todos os nós da chapa para que o maior ângulo entre elementos seja igual a $5^{\circ}$ (limite superior da hipersensibilidade).

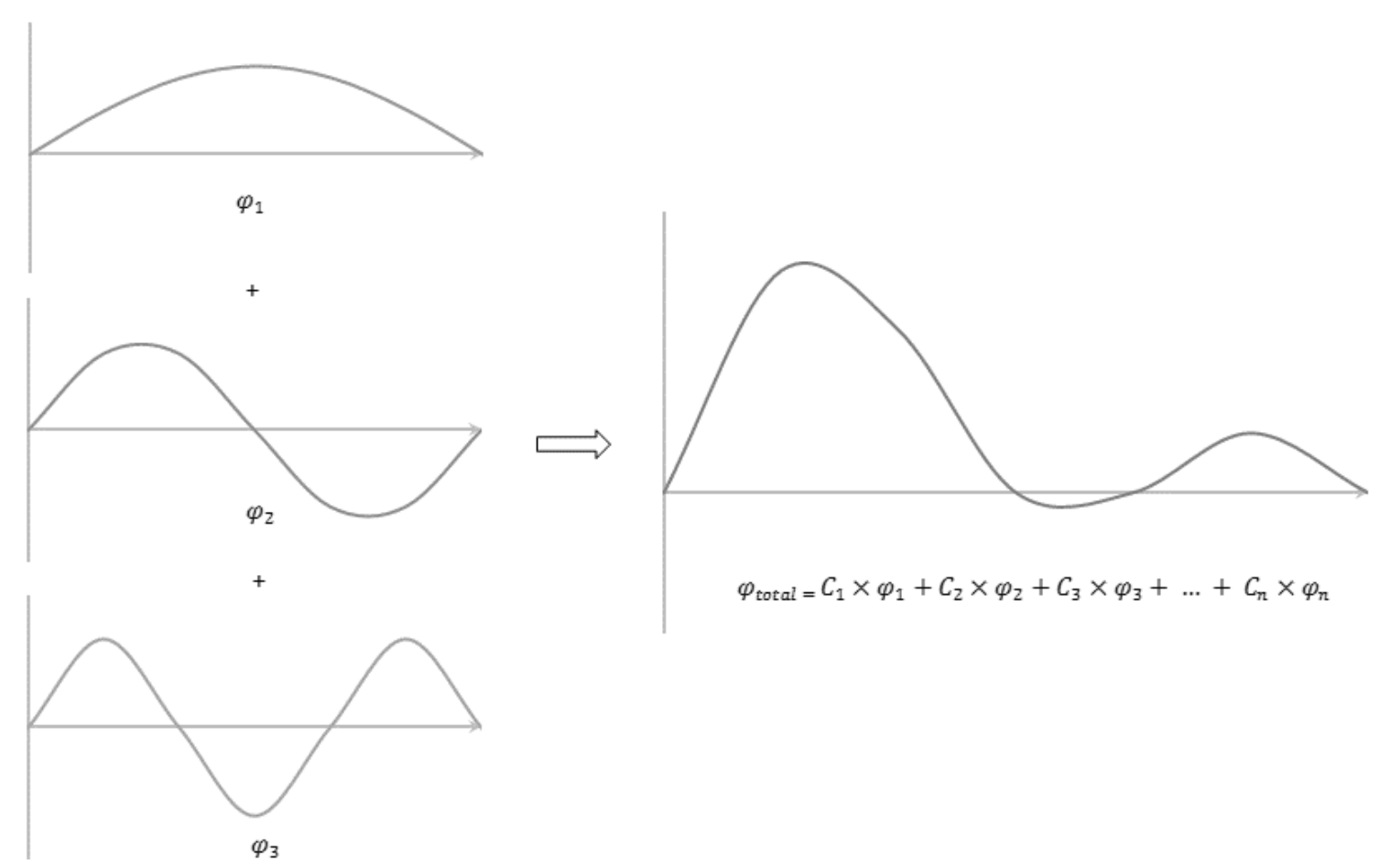

Figura 45 - llustração do processo de composição da formato deformado da chapa utilizando os três primeiros formatos de flexão.

Com esse processo, as duas premissas do método de Fredö e Hedlung (2004) - a composição dos formatos modais como formato deformado e a presença da hipersensibilidade na chapa, estarão asseguradas em cada iteração do processo de otimização. 


\subsection{Restrições}

A restrição a ser adotada no presente estudo é a dos ângulos ( $\alpha$ e $\beta$ ) entre os elementos da malha de elementos finitos nas direções $X$ e $Y$ da chapa, conforme a figura $X X$, de modo a atender da melhor maneira o critério de hipersensibilidade (ângulos entre $2^{\circ}$ e $5^{\circ}$ ). Com o objetivo de simplificar a manipulação geométrica da chapa, adotou-se que os ângulos entre os elementos fiquem sempre inferiores a $5^{\circ}$, de forma que as deformações sigam o formato composto pelos modos da chapa sem o risco de alterações neste formato causadas pela adequação ao do intervalo dos ângulos. Desta forma, tem-se:

$$
\begin{aligned}
& \max \left(\alpha_{i}\right) \leq 5^{\circ} \\
& \max \left(\beta_{i}\right) \leq 5^{\circ}
\end{aligned}
$$

Na qual:

$\alpha i$ : é o ângulo entre os elementos da malha de elementos finitos na direção $\mathrm{X}$ :

$$
\propto_{i}=\arccos \left(\frac{\left(Z i_{n}-Z i_{n-1}\right)}{\left(X i_{n}-X i_{n-1}\right)}\right)
$$

$\beta_{\mathrm{i}}$ : é o ângulo entre os elementos da malha de elementos finitos na direção Y:

$$
\beta_{i}=\arccos \left(\frac{\left(Z i_{n}-Z i_{n-1}\right)}{\left(Y i_{n}-Y i_{n-1}\right)}\right)
$$

Sendo:

$X_{i}$ : é a coordenada na direção " $\mathrm{X}$ " da chapa do nó " $\mathrm{n}$ " da malha de elementos finitos

$Y_{i}$ : é a coordenada na direção " $\mathrm{Y}$ " da chapa do nó " $\mathrm{n}$ " da malha de elementos finitos

$Z_{i:}$ é a coordenada na direção " $\mathrm{Z}$ " da chapa do nó " $\mathrm{n}$ " da malha de elementos finitos $n$ : é o número do nó na malha de elementos finitos

i: é a iteração da otimização 


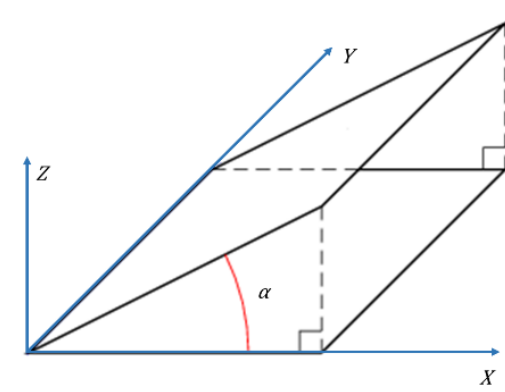

a)

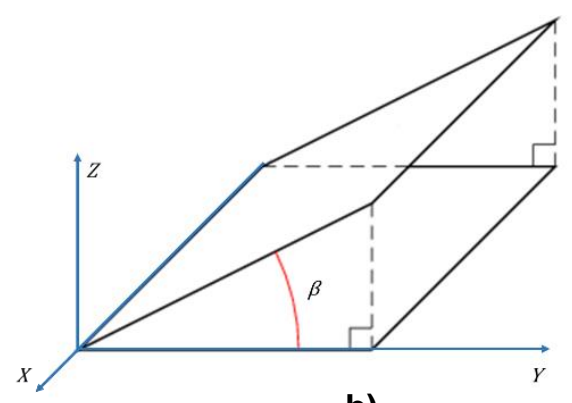

b)

Figura 46 - Ângulos entre os elementos $\alpha$ (a) e $\beta$ (b) utilizados para avaliar a condição de hipersensibilidade na chapa após a deformação ser aplicada.

\subsection{Função de custo da otimização}

Na elaboração do programa, a função custo pode ser ajustada conforme o objetivo desejado. O objetivo mais simples é maximizar uma dada frequência natural da chapa deformada, com ou sem a inclusão de objetivos adicionais dentro de uma equação inserida na função de cálculo do Matlab ${ }^{\circledR}$.

Considerando as características do algoritmo "fminsearch" do Matlab ${ }^{\circledR}$, o objetivo de maximização das frequências foi ajustado para se tornar um problema de minimização expresso por uma equação objetivo, sem afetar o resultado desejado. A equação objetivo pode ser definida de uma das seguintes formas:

$$
J_{1}=\left(f_{k} / f_{k}^{\prime}\right)
$$

Em que:

$\mathrm{J}_{1}$ : é a função objetivo da otimização que maximiza a k-ésima frequência natural da chapa otimizada

$f_{k}$ : é a k-ésima frequência natural da chapa original (a ser maximizada)

$f_{k}^{\prime}$ : é a k-ésima frequência natural da chapa deformada durante a otimização 


$$
J_{2}=\left[\left(f_{k} / f_{k}^{\prime}\right) \times\left(1+\operatorname{abs}\left(f_{j}-f_{j}^{\prime}\right)\right)\right]
$$

Em que:

J2: é a função objetivo da otimização que maximiza a k-ésima frequência natural e posiciona a j-ésima frequência natural na chapa otimizada

$f_{k}$ : é a k-ésima frequência natural da chapa original (a ser maximizada)

$f_{k}^{\prime}$ : é a k-ésima frequência natural da chapa deformada durante a otimização

$f_{j}$ : é a j-ésima frequência natural da chapa original (valor desejado)

$f_{j:}^{\prime}$ é a j-ésima frequência natural da chapa deformada durante a otimização

\subsection{Fluxograma do programa de otimização}

O programa foi criado em linguagem Matlab $^{\circledR}$ em comunicação com o programa NASTRAN para o cálculo das frequências naturais e formas modais a cada iteração. Assim, o fluxograma do programa de otimização é o mostrado na Figura 47. 


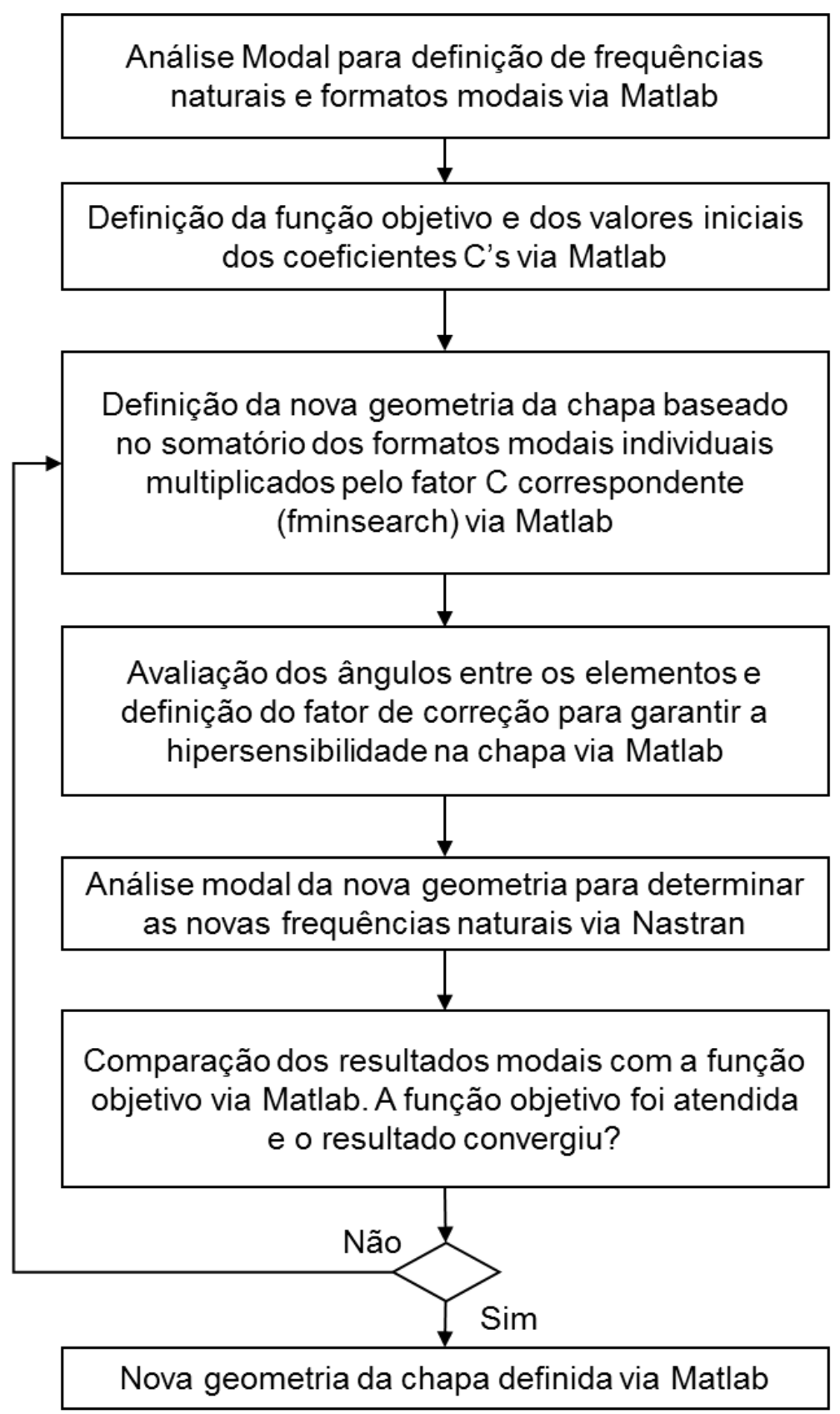

Figura 47 - Fluxograma simplificado do programa de otimização adotado. 


\section{Estudo de Casos}

Neste capítulo, aplica-se o algoritmo de otimização proposto no Capítulo 4 com diversos parâmetros iniciais incluindo a variação de restrições geométricas da chapa. Assim, avalia-se o impacto de diferentes parâmetros iniciais na otimização, o impacto do tipo de forma modal utilizada na otimização, e o estudo do uso de diferentes funções objetivos. Para o estudo do impacto das condições iniciais na otimização, novamente se recorre à chapa de teste utilizada no estudo do método de Fredö e Hedlung (2004) no Capítulo 3, constituída de aço, medindo $300 \mathrm{~mm}$ de comprimento por $100 \mathrm{~mm}$ de largura, com as mesmas propriedades adotadas anteriormente:

- Tipo de elemento: placa fina isoparamétrica baseada na teoria de Mindlin (OJALVO e PILON, 1987)

- Espessura: 0,7 mm

- Tamanho de elemento: $12,5 \mathrm{~mm}$ por $12,5 \mathrm{~mm}$

- Densidade: $7860 \mathrm{~kg} / \mathrm{m}^{3}$

- Módulo de Young: 2,07 x $10^{11} \mathrm{GPa}$

- Módulo de torção: 7,93 x $10^{10} \mathrm{GPa}$

- Coeficiente de Poisson: 0.3

Os parâmetros de entrada do comando "fminsearch" do Matlab ${ }^{\circledR}$ adotados foram (alterações dos parâmetros em estudos específicos informadas caso a caso):

- Função objetivo: $J_{1}=\left(f_{k} / f_{k}^{\prime}\right)$ ou $J_{2}=\left(f_{k} / f_{k}^{\prime}\right) \times\left(1+a b s\left(f_{j}-f_{j}^{\prime}\right)\right)$

- Coeficientes de ponderação iniciais unitários

- Tolerância de convergência dos coeficientes de ponderação $C_{j}: 10^{-1}$

- Tolerância de convergência do valor da função objetivo: $10^{-1}$

- Número máximo de iterações: 200 vezes o número de variáveis

A deformação da chapa será aplicada, em cada iteração, conforme o fluxograma definido na Figura 47 e seguindo o algoritmo apresentado no Apêndice A. Por simplicidade, as 
deformações foram aplicadas somente na direção vertical (perpendicular ao plano da chapa) do modelo em elementos finitos, sendo baseadas nos formatos modais da chapa não deformada, assim como no capítulo 3.

\subsection{Efeito da utilização dos modos de torção na otimização}

Neste estudo, os resultados da otimização da função objetivo $J_{1}$ utilizando os três primeiros modos de flexão são comparados aos resultados obtidos pela otimização quando se incluem os dois primeiros modos de torção aos modos que serão combinados para gerar o formato deformado da chapa. Para tal estudo, com base nos resultados do capítulo 3, foi escolhida a condição de contorno da chapa engastada nos 4 vértices, por ser o caso que apresentou maior ganho percentual da primeira frequência natural.

A Figura 48 mostra a chapa original e a chapa deformada conforme os resultados da otimização. A tabela 12 mostra a comparação dos resultados obtidos com a otimização utilizando somente modos de flexão e tanto os modos de flexão quanto torção, indicando os ganhos em frequência, os coeficientes de ponderação obtidos e a quantidade de iterações realizadas.

Os resultados indicam que a utilização de modos de torção juntamente com os de flexão na definição do formato deformado da chapa apresentou os maiores aumentos de rigidez na chapa. Em ambos os casos o resultado da primeira frequência natural da chapa otimizada atingiu valores superiores aos obtidos no estudo do capítulo 3. Observa-se que o primeiro formato modal de flexão continua predominante em ambos os casos, mas a influência do primeiro modo de torção é significativa em comparação aos demais formatos modais no aumento da rigidez da estrutura. No caso da otimização somente com modos de flexão observa-se alguma presença do terceiro modo de flexão na solução otimizada. 

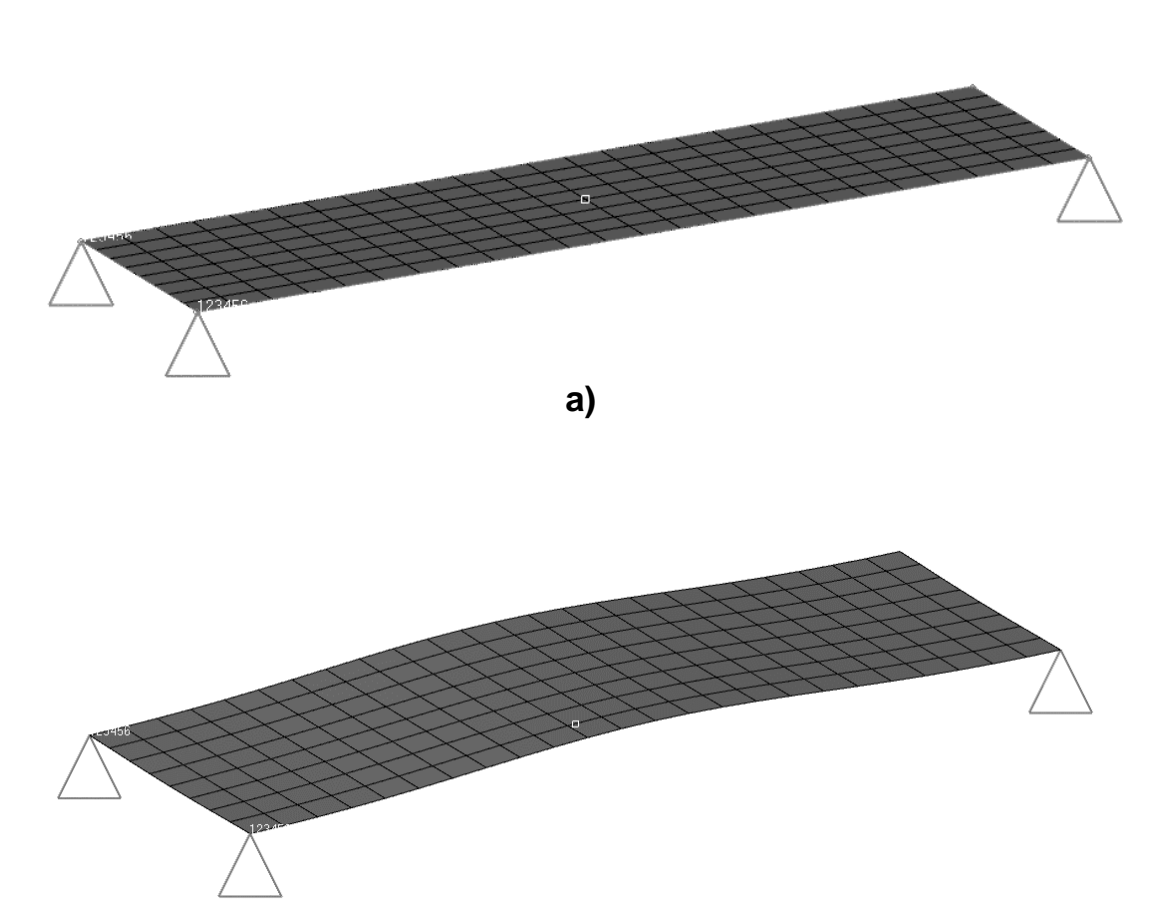

b)

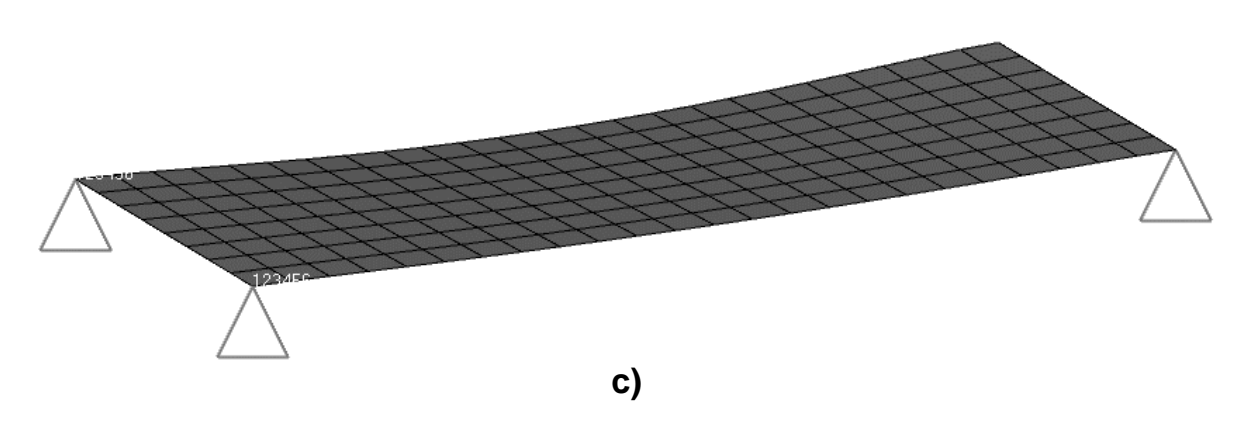

Figura 48 - Chapa apoiada nos quatro vértices original (a) e deformada pelo programa de otimização utilizando somente formatos de flexão (b) e deformada pelo programa utilizando tanto modos de flexão quanto de torção (c).

A Figura 49 mostra a evolução da primeira frequência natural em função dos cálculos da função objetivo durante a otimização, tanto para a otimização somente com modos de flexão quanto para a otimização com modos de flexão e torção. Adicionalmente, a linha pontilhada indica a primeira frequência natural da chapa apoiada nos quatro vértices deformada conforme o primeiro formato de flexão, cujo valor é de $87,4 \mathrm{~Hz}$ ( $2 \%$ inferior ao valor da placa otimizada somente com modos de flexão). Em contrapartida, a linha tracejada indica a primeira frequência natural da chapa deformada pelo primeiro modo de torção, cujo valor é 105,4 Hz (20\% superior ao valor da placa deformada conforme o primeiro modo de flexão). Esse resultado confirma as observações apontadas no capítulo 3, no qual o modo de 
torção individualmente causa impacto superior no ganho de rigidez da chapa do que o de flexão individualmente, sendo que a combinação de ambos fornece o resultado ótimo, conforme os resultados da Tabela 12.

Tabela 12 - Resultados da otimização somente com modos de flexão e com modos de flexão e torção comparados à chapa original.

\begin{tabular}{|c|c|c|c|c|c|c|}
\hline \multicolumn{2}{|r|}{ Frequência natural } & 1 & 2 & 3 & 4 & 5 \\
\hline \multirow{3}{*}{$\begin{array}{l}\frac{1}{\vdots} \\
\frac{1}{0} \\
\frac{1}{0} \\
0 \\
\frac{1}{0} \\
\frac{1}{1} \\
\frac{1}{v}\end{array}$} & Geometria não deformada $(\mathrm{Hz})$ & 28 & 83,4 & 86,3 & 172,8 & 179,2 \\
\hline & Formato modal & Flexão & Torção & Flexão & Flexão & Torção \\
\hline & Número de nós modais & 0 & 0 & 1 & 2 & 1 \\
\hline \multirow{6}{*}{ 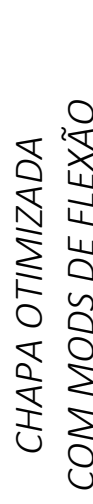 } & Coeficientes ponderação otimizados & 2,37 & - & 0 & - & 0,40 \\
\hline & Valor da simulação (Hz) & 89,1 & 92,7 & 163,5 & 201,2 & 295,9 \\
\hline & Ganho em frequência (\%) & 218 & 11,1 & 89,5 & 16,4 & 65,1 \\
\hline & Formato modal & Flexão & Flexão & Torção & Torção & Flexão \\
\hline & Número de nós modais & 1 & 2 & 0 & 1 & 3 \\
\hline & Número de iterações & & & 81 & & \\
\hline \multirow{6}{*}{ 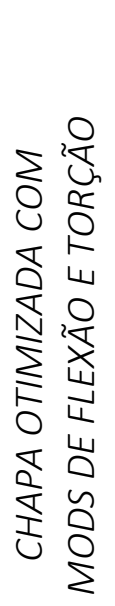 } & Coeficientes ponderação otimizados & 4,07 & 1,23 & 0,002 & $-0,095$ & $-0,002$ \\
\hline & Valor da simulação (Hz) & 137,3 & 137,4 & 171,5 & 219,3 & 266,6 \\
\hline & Ganho em frequência (\%) & 391,7 & 64,7 & 98,7 & 26,9 & 48,7 \\
\hline & Formato modal & Flexão & Flexão & Flexão & Torção & Torção \\
\hline & Número de nós modais & 1 & 0 & 2 & 1 & 3 \\
\hline & Número de iterações & & & 284 & & \\
\hline
\end{tabular}




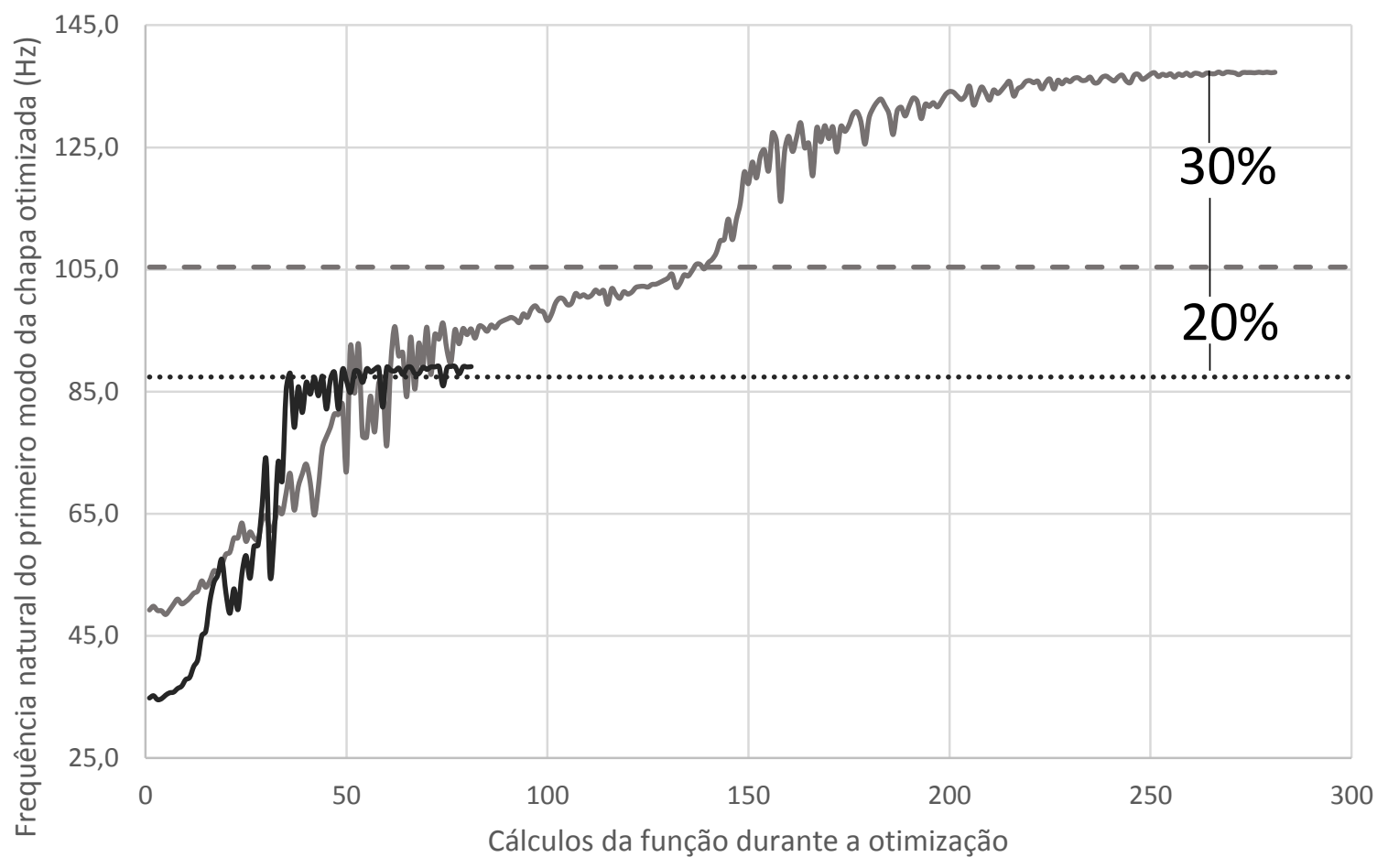

— Otimização com modos de flexão e torção —— Otimização com modos de flexão
......... Chapa deformada pelo $1^{\circ}$ modo de flexão - - Chapa deformada pelo $1^{\circ}$ modo de torção

Figura 49 - Evolução da primeira frequência natural da chapa otimizada em cada avaliação da função objetivo realizada durante a otimização.

\subsection{Efeito dos coeficientes de ponderação iniciais no resultado da otimização}

Neste estudo, variam-se os valores dos coeficientes de ponderação iniciais no processo de otimização (os parâmetros iniciais fornecidos ao algoritmo de otimização). Assim, verifica-se o efeito destes coeficientes nos resultados da otimização. Neste caso, utilizou-se a mesma chapa de aço mostrada na Figura 17, engastada em suas extremidades menores, com o objetivo de maximizar a primeira frequência natural da chapa $\left(J_{1}\right)$. 


\subsubsection{Coeficientes negativos}

Neste caso, os resultados foram comparados utilizando-se um vetor de coeficientes de ponderação iniciais unitário positivo contra um vetor unitário negativo, utilizando-se somente os formatos modais de flexão na otimização. A tabela 13 apresenta os resultados obtidos, na qual se nota que os ganhos percentuais da primeira frequência natural são equivalentes entre a otimização com os coeficientes inicias positivos e negativos, sendo a única diferença que os coeficientes de ponderação otimizados acompanham o sinal dos coeficientes iniciais.

Tabela 13 - Comparação dos resultados da otimização utilizando-se coeficientes iniciais positivos e negativos.

\begin{tabular}{|c|c|c|c|c|c|c|}
\hline & Frequência natural & 1 & 2 & 3 & 4 & 5 \\
\hline \multirow{3}{*}{ 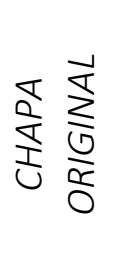 } & Geometria não deformada (Hz) & 42,2 & 89,3 & 116 & 192 & 229 \\
\hline & Formato modal & Flexão & Torção & Flexão & Torção & Flexão \\
\hline & Número de nós modais & 0 & 0 & 1 & 1 & 2 \\
\hline \multirow{5}{*}{ 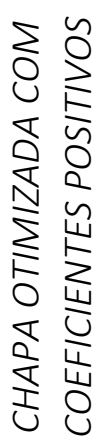 } & Coeficientes ponderação otimizados & 2,55 & - & 0 & - & 0,24 \\
\hline & Valor da simulação $(\mathrm{Hz})$ & 119,5 & 225,2 & 231,2 & 305,9 & 335,3 \\
\hline & Ganho em frequência (\%) & 183,2 & 152,2 & 99,3 & 59,3 & 46,4 \\
\hline & Formato modal & Flexão & Torção & Flexão & Torção & Flexão \\
\hline & Número de nós modais & 1 & 1 & 2 & 2 & 3 \\
\hline \multirow{5}{*}{ 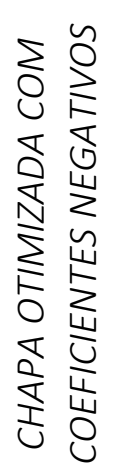 } & Coeficientes ponderação otimizados & $-2,59$ & - & 0 & - & $-0,21$ \\
\hline & Valor da simulação (Hz) & 119,3 & 227,8 & 231,7 & 309 & 331,2 \\
\hline & Ganho em frequência (\%) & 182,7 & 155 & 99,7 & 60,9 & 44,6 \\
\hline & Formato modal & Flexão & Torção & Flexão & Torção & Flexão \\
\hline & Número de nós modais & 1 & 1 & 2 & 2 & 3 \\
\hline
\end{tabular}




\subsubsection{Variação do coeficiente $C 1$}

Neste caso, o coeficiente de ponderação da otimização do primeiro formato modal de flexão (C1) foi variado de 0 a 1, enquanto os demais foram mantidos unitários, buscando encontrar os seus efeitos no resultado da otimização. Novamente, o estudo foi conduzido utilizando-se somente os modos de flexão na otimização, em uma chapa engastadas nas duas arestas de $100 \mathrm{~mm}$.

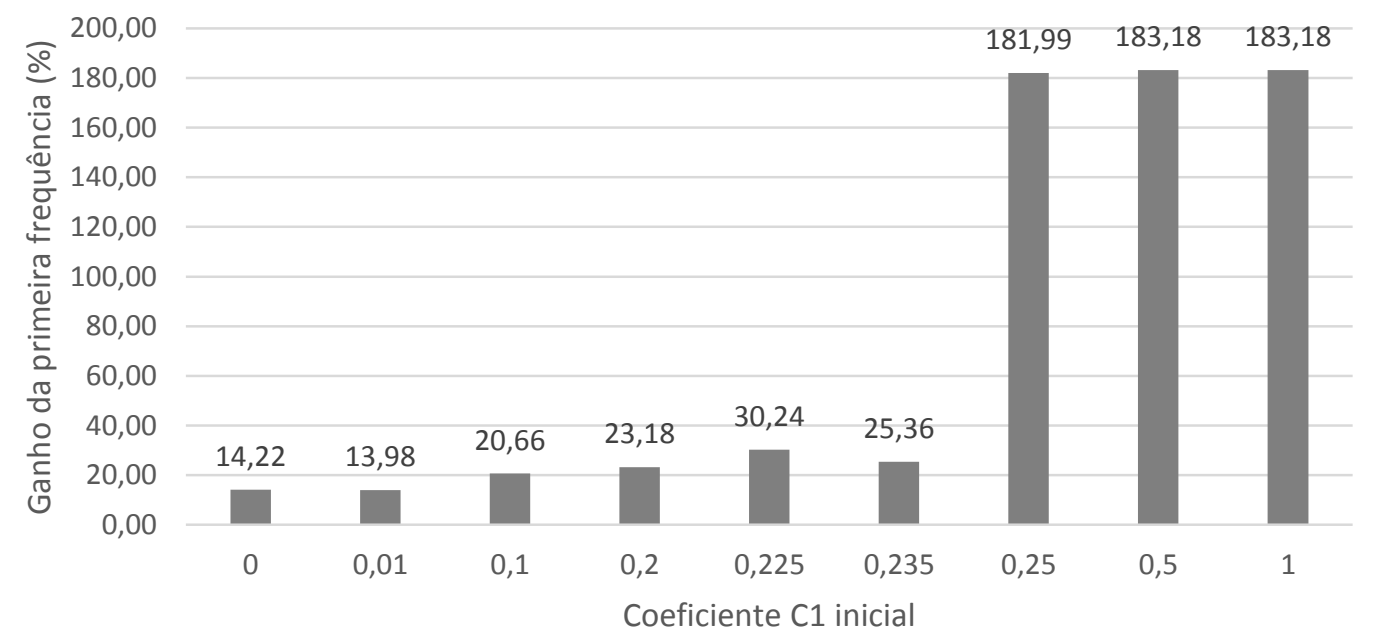

Figura 50 - Ganho percentual da primeira frequência natural da chapa otimizada em função do valor do de ponderação inicial $C 1$.

A Figura 50 mostra os ganhos da primeira frequência natural da chapa deformada para os diversos valores iniciais de $C 1$, enquanto a tabela 14 mostra os coeficientes de ponderação otimizados obtidos para cada $C 1$ inicial adotado. Nota-se pelos resultados que a otimização convergiu para um mínimo local nos casos em que o coeficiente $C 1$ foi inferior a 0,25 (quatro vezes menor quer os demais coeficientes iniciais da otimização). Observa-se também que o valor ótimo somente foi obtido quando o valor de $C 1$ foi igual a 0,5 , sendo que no caso de $C 1$ igual a 0,25 o valor obtido foi $0,7 \%$ inferior ao máximo, indicando tratar-se também de um mínimo local, apesar de próximo do ótimo. Cabe ressaltar que essa otimização tinha por objetivo maximizar a primeira frequência natural, sendo que o comportamento das demais frequências pode variar consideravelmente entre os resultados. 
Tabela 14 - Comparação dos coeficientes de ponderação otimizados para diferentes valores do coeficiente de ponderação inicial $C 1$.

\begin{tabular}{|c|c|c|c|c|}
\hline \multicolumn{2}{|c|}{$\begin{array}{c}\text { Coeficientes de ponderação } \\
\text { otimizados }\end{array}$} & $C 1$ & C3 & $C 5$ \\
\hline \multirow{9}{*}{ 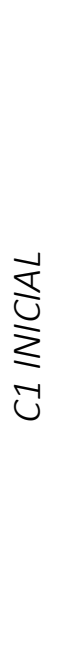 } & 0 & 0 & 0,03 & 1,54 \\
\hline & 0,01 & 0,01 & $-0,01$ & 1,6 \\
\hline & 0,1 & $-1,77$ & 1,15 & 7,54 \\
\hline & 0,2 & $-2,278$ & 1,13 & 7,041 \\
\hline & 0,225 & $-0,67$ & 0,37 & 1,15 \\
\hline & 0,235 & 0 & 0,48 & 1,72 \\
\hline & 0,25 & $-9,47$ & 0 & $-2,34$ \\
\hline & 0,5 & $-2,26$ & 0 & $-0,26$ \\
\hline & 1 & 2,55 & 0 & 0,24 \\
\hline
\end{tabular}

\subsubsection{Coeficientes distintos}

Neste caso, avaliou-se o comportamento da otimização utilizando-se um dos coeficientes iniciais com valor unitário, tendo os demais valores nulos. A otimização foi conduzida com formatos modais de flexão na chapa engastada em duas arestas, maximizando a primeira frequência natural da chapa otimizada, como nos dois casos anteriores, conforme as configurações a seguir:

- Caso 1 - coeficientes de ponderação iniciais: $\mathrm{C} 1=1$ e C3 = C5 = 0

- Caso 2 - coeficientes de ponderação iniciais: $\mathrm{C3}=1$ e C1 = C5 = 0

- Caso 3-coeficientes de ponderação iniciais: $\mathrm{C5}=1$ e C1 = C3 = 0

Os resultados da tabela 15 mostram o efeito dos coeficientes iniciais, mostrando que nos casos 2 e 3 a otimização encontrou um mínimo local da função objetivo. Esse resultado indica que a melhor opção de coeficientes de ponderação é a utilização de valor unitário para todos os coeficientes, pois permite que o programa determine qual deles tem mais impacto sobre a função de objetivo desejada. 
Tabela 15 - Resultados obtidos para os diferentes valores de coeficientes de ponderação iniciais

\begin{tabular}{|c|c|c|c|c|c|c|}
\hline & Frequência natural & 1 & 2 & 3 & 4 & 5 \\
\hline \multirow{6}{*}{ 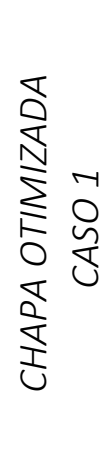 } & Coeficientes iniciais & 1 & - & 0 & - & 0 \\
\hline & Coeficientes ponderação otimizados & 1 & - & 0 & - & 0 \\
\hline & Valor da simulação $(\mathrm{Hz})$ & 118,9 & 175,1 & 192,3 & 222,8 & 382,9 \\
\hline & Ganho em frequência (\%) & 181,7 & 96 & 65,3 & 15,6 & 67,5 \\
\hline & Formato modal & Flexão & Flexão & Torção & Torção & Flexão \\
\hline & Número de nós modais & 1 & 2 & 2 & 2 & 3 \\
\hline \multirow{6}{*}{ 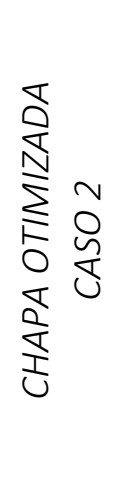 } & Coeficientes iniciais & 0 & - & 1 & - & 0 \\
\hline & Coeficientes ponderação otimizados & 0 & - & 0,12 & - & 0 \\
\hline & Valor da simulação $(\mathrm{Hz})$ & 42,8 & 231,8 & 236,6 & 356,6 & 410,4 \\
\hline & Ganho em frequência (\%) & 1,5 & 159,6 & 103,4 & 85,1 & 79,5 \\
\hline & Formato modal & Flexão & Flexão & Torção & Flexão & Torção \\
\hline & Número de nós modais & 0 & 2 & 0 & 3 & 2 \\
\hline \multirow{6}{*}{ 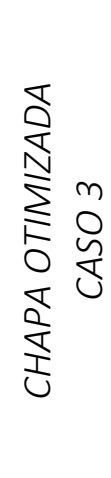 } & Coeficientes iniciais & 0 & - & 0 & - & 1 \\
\hline & Coeficientes ponderação otimizados & 0,4 & - & 0,1 & - & 36,2 \\
\hline & Valor da simulação $(\mathrm{Hz})$ & 48,3 & 90 & 118 & 358,8 & 380,8 \\
\hline & Ganho em frequência (\%) & 14,5 & 0,7 & 1,4 & 86,3 & 66,6 \\
\hline & Formato modal & Flexão & Torção & Flexão & Torção & Flexão \\
\hline & Número de nós modais & 0 & 0 & 1 & 1 & 3 \\
\hline
\end{tabular}

Outro resultado observado na tabela 15 é a capacidade do processo de otimização de criar grandes diferenças entre duas frequências naturais (acima de $200 \mathrm{~Hz}$ de separação entre o terceiro e quarto modos de vibrar do caso 3). Isso permite que regiões críticas de trabalho da chapa otimizada possam ser alinhadas com essas regiões de separação evitando, por exemplo, interações entre a estrutura e os carregamentos aos quais ela esteja sujeita. 


\subsection{Efeito de adições na função objetivo}

Neste estudo, utilizando-se novamente a chapa apoiada nas duas arestas de $100 \mathrm{~mm}$ da Figura 17, analisa-se a capacidade do programa de otimizar as frequências naturais da chapa com condições extras incluídas na função objetivo $\left(J_{2}\right)$. Tais condições são obtidas com a restrição do valor desejado de uma das frequências naturais da chapa otimizada, seguindo as funções objetivo descritas no item 4.4 (equação 6). Todas as otimizações conduzidas utilizaram tanto modos de flexão quanto modos de torção na definição da chapa otimizada.

\subsubsection{Maximização da primeira frequência natural e restrição da terceira}

Nesta otimização, a função objetivo foi definida para maximizar a primeira frequência natural da chapa $\left(f_{1}\right)$, ao mesmo tempo em que mantém o valor da terceira frequência natural inalterada $\left(f^{\prime}{ }_{3}\right.$ igual a $f_{3}$ ), seguindo a equação 6 . A tabela 16 mostra os resultados da chapa otimizada e da chapa original. Os resultados indicam que o programa conseguiu obter um ganho de aproximadamente $20 \%$ na primeira frequência natural da chapa otimizada, enquanto o impacto na terceira frequência natural foi restrito a $2 \%$ do valor original.

Tabela 16 - Resultados da otimização comparados à chapa original na otimização da primeira frequência natural, com o mínimo impacto no valor da terceira frequência.

\begin{tabular}{|c|c|c|c|c|c|c|}
\hline & Frequência natural & 1 & 2 & 3 & 4 & 5 \\
\hline \multirow{3}{*}{ 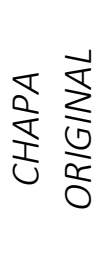 } & Geometria não deformada $(\mathrm{Hz})$ & 42,2 & 89,3 & 116 & 192 & 229 \\
\hline & Formato modal & Flexão & Torção & Flexão & Torção & Flexão \\
\hline & Número de nós modais & 0 & 0 & 1 & 1 & 2 \\
\hline \multirow{5}{*}{ 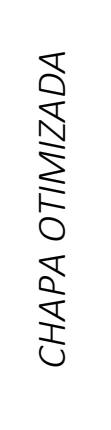 } & Coeficientes ponderação otimizados & $-3,37$ & 2,9 & 0,4 & 0,2 & 15,6 \\
\hline & Valor da simulação $(\mathrm{Hz})$ & 51 & 92,3 & 118,3 & 345,7 & 380,8 \\
\hline & Ganho em frequência (\%) & 20,8 & 3,3 & 2 & 80 & 66,3 \\
\hline & Formato modal & Flexão & Torção & Flexão & Torção & Flexão \\
\hline & Número de nós modais & 0 & 0 & 1 & 1 & 3 \\
\hline
\end{tabular}




\subsubsection{Maximização da quinta frequência natural e posicionamento da terceira}

Nesta otimização, a função objetivo foi definida para maximizar a quinta frequência natural da chapa $\left(f_{5}\right)$, ao mesmo tempo em que terceira frequência da chapa otimizada tinha por objetivo o valor de $200 \mathrm{~Hz}\left(f_{3}^{\prime}\right)$, seguindo a equação 6. A tabela 17 mostra os resultados da chapa otimizada e da chapa original. Os resultados indicam que o programa conseguiu obter um ganho de aproximadamente $62 \%$ na quinta frequência natural da chapa otimizada, enquanto o resultado da terceira frequência alcançou valor de $200 \mathrm{~Hz}$ estabelecidos como objetivo. Cabe ressaltar que, nesta otimização, a sequência dos formatos modais não foi alterada.

Tabela 17 - Resultados da otimização comparados à chapa original na otimização da quinta frequência natural, com o posicionamento da terceira frequência.

\begin{tabular}{|c|c|c|c|c|c|c|}
\hline & Frequência natural & 1 & 2 & 3 & 4 & 5 \\
\hline \multirow{3}{*}{ 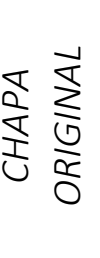 } & Geometria não deformada $(\mathrm{Hz})$ & 42,2 & 89,3 & 116 & 192 & 229 \\
\hline & Formato modal & Flexão & Torção & Flexão & Torção & Flexão \\
\hline & Número de nós modais & 0 & 0 & 1 & 1 & 2 \\
\hline \multirow{5}{*}{ 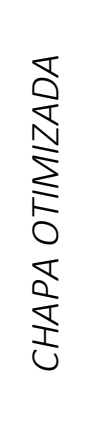 } & Coeficientes ponderação otimizados & 1,12 & 1,00 & 0,50 & 1,34 & 1,11 \\
\hline & Valor da simulação $(\mathrm{Hz})$ & 47,4 & 115,1 & 200 & 289 & 372 \\
\hline & Ganho em frequência (\%) & 12,3 & 28,9 & 72,4 & 50,5 & 62,4 \\
\hline & Formato modal & Flexão & Torção & Flexão & Torção & Flexão \\
\hline & Número de nós modais & 0 & 0 & 1 & 1 & 2 \\
\hline
\end{tabular}




\subsection{Discussão}

Os resultados das investigações realizadas permitem algumas observações:

1. Os resultados da otimização são superiores quando os modos de torção também são utilizados na otimização, o que é coerente com as observações dos resultados do capítulo 3;

2. Os sinais dos coeficientes de ponderação iniciais não apresentaram impacto na otimização da chapa, ou seja, coeficientes iniciais positivos ou negativos obtiveram resultados equivalentes na otimização;

3. A escolha dos coeficientes de ponderação inicial tem impacto significativo no resultado da otimização, podendo levar a otimização a encontrar um mínimo local da solução. Recomenda-se, com base nos resultados, que os coeficientes iniciais sejam todos unitários;

4. O programa de otimização mostrou-se capaz de encontrar soluções otimizadas para a chapa mediante funções objetivo complexas, otimizando uma das frequências naturais enquanto mantêm o correto posicionamento de outras frequências naturais;

5. Utilizando-se a função objetivo adequada, o programa é capaz de criar grandes regiões sem modos de vibrar na chapa, conforme os resultados do item 5.2.3, permitindo alinhar regiões críticas de funcionamento da estrutura com as faixas sem modos de vibrar da chapa, por exemplo. 


\section{Conclusões}

O trabalho apresentado conduziu uma investigação da literatura presente de otimização estrutural dinâmica de estruturas, salientando os benefícios de cada tipo de otimização e alguns trabalhos recentes publicados. A partir da metodologia apresentada por Fredö e Hedlung (2005) foi modelado um problema de otimização de frequências naturais para chapas metálicas baseado na composição de formatos modais para criação do padrão de deformação, cujos fatores de ponderação são as variáveis de otimização, associado às restrições da hipersensibilidade.

Para tal, um estudo da metodologia proposta por Fredö e Hedlung (2005) permitiu identificar as condições e características de funcionamento do método, permitindo o correto modelamento do problema. A partir do modelo elaborado, um programa de otimização foi criado utilizando modelação matemática em Matlab $^{\circledR}$, associado ao programa de análises por elementos finitos Nastran ${ }^{\circledR}$, o qual foi avaliado em diversas condições de otimização no capítulo 5. A partir dos resultados otimizados, foi possível obter as seguintes conclusões:

- O método de Padrões de Bossas por Formas Modais proposto por Fredö e Hedlung (2005) produz ganhos significativos de rigidez na chapa, ou seja, a combinação de formatos modais como padrão de deformação da chapa traz ganhos nas frequências naturais da chapa deformada;

- A definição dos coeficientes de ponderação para a composição do formato deformado tem relação direta com os ganhos observados nas frequências naturais, sendo possível balanceá-los para se atender a função objetivo conforme desejado;

- As condições de contorno têm impacto nos resultados da otimização, inclusive influenciando a supressão ou não dos formatos modais na faixa de frequência analisada;

- A escolha dos coeficientes de ponderação iniciais da otimização impacta o volume computacional da otimização, sendo que a escolha de fatores inicias distintos entre si (não unitários) pode acarretar a convergência da otimização 
em mínimos locais, ou seja, recomenda-se a utilização de coeficientes iniciais unitários durante a utilização do programa desenvolvido;

- A presença de formatos modais de torção na otimização produz resultados superiores ao obtidos quando somente formatos de flexão são utilizados;

- O programa proposto foi capaz não somente de maximizar uma dada frequência natural desejada, mas também realizar o correto posicionamento de frequências naturais, conforme a definição da função objetivo desejada.

\subsection{Trabalhos futuros}

Durante a elaboração do trabalho, algumas possibilidades foram levantadas, porém não aprofundadas, pois ampliariam o escopo da pesquisa em detrimento da objetividade do trabalho. A partir delas, seguem algumas sugestões de abordagem para trabalhos futuros que possam ser desenvolvidos a partir do estudo apresentado.

Primeiramente, se propõe a implementação experimental dos resultados obtidos com a aplicação do padrão de bossas por formas modais na otimização de frequências naturais, explorando tanto o estudo do formato otimizado obtido quanto o impacto da linearização da geometria da chapa deformada. Para tal, recomenda-se a utilização de dispositivos de fabricação que permitam a dobra e conformação da chapa em formatos complexos, bem como a avaliação da utilização de moldes de estampagem para a obtenção dos formatos deformados. Após a fabricação, será possível conduzir um estudo de correlação dos resultados experimentais e numéricos do método.

Em segundo, propõem-se avaliar o impacto da aplicação do formato modal completo na deformação da chapa, deslocando os nós da malha de elementos finitos em todas as direções do formato modal, ao invés da abordagem simplificada do estudo presente que somente utilizou deslocamentos verticais na deformação. Tal abordagem permitirá avaliar quanto de ganho a metodologia poderá prover na chapa em relação ao grau de aplicação da deformação nas 3 direções da chapa. 
A terceira possiblidade é o estudo da aplicação do método em condições geométricas mais complexas, onde a geometria original já possua ângulos em sua construção que não possam ser alterados por necessidade de projeto, por exemplo. Tal estudo investigaria a complexidade de definição dos fatores de ponderação e sua relação com as restrições geométricas existentes, gerando um programa de otimização com aplicação amplificada para problemas de otimização em comparação com o apresentado neste trabalho.

Adicionalmente, o trabalho apresentado pode ser expandido pela aplicação e comparação dos resultados de otimização obtidos através da utilização de outros métodos de otimização, como os métodos heurísticos de algoritmos genéticos ou particle swarming. Desta forma o programa de otimização se tornaria menos suscetível à mínimos locais e a influência dos coeficientes inicias da otimização.

Por fim, sugere-se a investigação das causas do fenômeno de supressão de alguns modos de vibrar na faixa de frequências utilizada no trabalho, visto que tal efeito mostrou-se dependente das condições de contorno existentes, bem como do formato modal predominante utilizado na deformação da chapa. 


\section{Referências Bibliográficas ${ }^{1}$}

AVITABILE, P. Twenty Years of Structural Dynamic Modification - A Review, Sound and Vibration Magazine, Janeiro de 2003.

CHEN, J.; SHAPIRO, V.; SURESH, K.; TSUKANOV, I. Parametric and topological control in shape optimization In: Proceedings of IDETC/CIE International Design Engineering Technical Conferences and Computers and Information in Engineering conference, September 10-13, 2006, Philadelphia, 2006.

FREDÖ, C.R.; HEDLUNG, A. NVH optimization of truck cab floor panel embossing pattern, SAE International, 2004.

FREDÖ, C.R.; HEDLUNG. A; Panel embossing pattern optimization method. In: NAFEMS Seminar: "Components and System Analysis Using Numerical Simulation Techniques - FEA, CFD, MBS", November 23-24, 2005. Gothenburg, Sweden, 2005.

GERMANO, E. B. M. R.; NICOLETTI, R. Shape optimization of plates for desired natural frequencies from coarse grid results In: Topics in Model Validation and Uncertainty Quantification, Volume 4 - Conference Proceedings of the Society for Experimental Mechanics Series, v.29, 2012.

GRANDHI, R. Structural optimization with frequency constrains - A Review AIAA/USAF/NASA/OAI Symposium on Multidisciplinary Analysis and Optimization, Paper 92-4813, Julho 1993.

HSU, Y. A review of structural shape optimization, Computers in Industry, v.26, pp 3-13, 1994

LEE, J.; KIM, G.; PARK, Y. A geometry constrain handling technique for stiffener layout optimization problem Journal of Sound and Vibration, v.285, pp.101120, 2005.

LIU, Y.; SHIMODA, M. Parameter-free shape optimization method for natural vibration Design of stiffeners on thin-walled structures, APCOM \& ISCM, 2013.

\footnotetext{
${ }^{1}$ De acordo com a Associação Brasileira de Normas Técnicas. NBR 6023
} 
MCKINNON, K. I. M. Convergence of the nelder-mead simlpex method to a nonstationary point, Society for Industrial and Applied Mathematics, Vol. 9, No. 1 , pp. $148-158,1998$.

MATH WORKS: MATLAB R2009a Documentation, The Math Works, Natick, MA (2009)

MA, Z.; KIKUCHI, N.; HAGIWARA, I. Structural topology and shape optimization for a frequency response problem, Computational Mechanics, v.13, pp.157174, 1993.

MESKE, R.; LAUBER, B.; SCHNACK, E. A new optimality criteria method for shape optimization of natural frequency problems, Structural Multidisciplinary Optimization, v.31, pp.295-310, 2005.

MSC NASTRAN: Dynamic Analysis User's Guide, MSC Software, 2010.

NAD, M. Structural dynamic modification of vibration systems, Applied and Computational Mechanics, v.1, pp.203-214, 2007.

NOCEDAL, J.; WRIGHT, S. J. Numerical optimization 2 ed., New York: Springer, 2006 .

OJALVO, I. U.; PILON, D. Assumptions and accuracies associated with the MSC/Nastran rod, bar and cquad4 elements MSC World User's Conference, Los Angeles, CA, 1987.

PARK, M.; PARK, Y.; PARK, Y. Raising natural frequencies of a structure via surface-grooving technique, Structural Multidisciplinary Optimization, v.34, pp.491-505, 2007.

PARK, Y.; PARK, Y. Structure optimization to enhance its natural frequencies based on measured frequency response functions, Journal of Sound and Vibration, v.229, pp.1235-1255, 2000.

PRESS, W. H.; TEUKOLSKY, S.A.; VETTERLING, W. T.; FLANNERY, B. P. Numerical recipes - the art of scientific computing, 3 ed., Cambridge: Cambridge/University Press, 2007. 
RAO, S. S., Engineering Optimization: theory and practice, New Jersey: John Wiley \& Sons, 2009.

REBILLARD, E.; GUYADER, J. L. Vibrational behavior of lattices of plates: basic behavior and hypersensitivity phenomena, Journal of Sound and Vibration, v.205, n.3, pp.337-354, 1997.

ROZVANY, G. I. N. A critical review of established methods of structural topology optimization, Structural Multidisciplinary Optimization, v. 37, pp. 217237, 2008.

SAITOU, K.; IZUI, K.; NISHIWAKI, S.; PAPALAMBROS, P. A survey of structural optimization in mechanical product development, Journal of Computing and Information Science in Engineering, v.5, pp.214-226, 2005.

SOTELO Jr, J.; FRANÇA, L. N. F. Introdução às vibrações mecânicas, São Paulo: Edgar Blücher, 2006.

VU, V. T. Weight minimization of trusses with natural frequency constrains, In: 11th World Congress on Structural and Multidisciplinary Optimization, June 7-12, Sydney, 2015.

XIE, Y. M.; STEVEN, G. P. Evolutionary structural optimization for dynamic problems, Computers \& Structures, v.58, n.6, pp.1067-1073, 1996.

YANG, R. J. Multidiscipline topology optimization, Computers \& Structures, v.63, n.6, pp.1205-1212, 1997.

ZHAO, C.; XIE, G.; STEVEN, G. P. Evolutionary natural frequency optimization of thin plate bending vibration problems, Structural Optimization, v.11, pp. 244251,1996 


\section{Apêndice A - Programa Matlab®}

\section{A.1 Linha de comando Matlab® para a otimização \\ [xpoint,fval,output,a]=fminsearch('myfun',[1,1,1])}

\section{Instruções e notas:}

Este programa executa a otimização utilizando o primeiro, terceiro e quinto modos da chapa original simulada. Para que sejam utilizados mais formatos modais é necessário alterar a compilação do novo formato da chapa e a entrada do comando de otimização, acrescentando os formatos desejados após a definição da função de otimização, além de alterar a atribuição das variáveis de otimização.

Também por simplificação, todas as operações de alteração de formato da chapa são efetuadas na direção "Z". A inclusão das outras direções acarretaria em alterações no processo de cálculo do formato da chapa deformada (precisando ser replicado o processo em "Z" para as demais direções) bem como a definição de um novo processo de verificação da violação das condições de hipersensibilidade no formato da chapa e posterior ajuste da geometria.

Por simplicidade do programa, o arquivo Nastran ${ }^{\circledR}$ do modelo é subdividido em partes, carregadas pelo comando "include". Tal estrutura permite comandos de leitura das informações do modelo pelo Matlab ${ }^{\circledR}$ através de rotinas simples, porém necessita que os arquivos com as partes do modelo de elementos finitos, tais como os nós (Grid Data) e os elementos (Element Data) sigam o formato estabelecido.

Para as análises modais da chapa deformada, durante a otimização, é utilizado um outro arquivo Nastran ${ }^{\circledR}$ de formatação similar à do modelo original. Tal formatação também foi feita visando simplificar as rotinas de Matlab $^{\circledR}$ do programa.

As variáveis do vetor recebem nome dentro da função, para evitar erros.

- xpoint retorna o vetor mínimo da otimização

- fval retorna o valor da função no mínimo 
- output retorna se a convergência ocorreu

- "a" retorna o número de iterações, funcCount (número funções avaliadas) e o tipo de programa)

- (Opcional) Optimset pode ser utilizado, permitindo ajustes na iteração

- 'Maxlter' diz o número de iterações

- 'TolFun' é a tolerância da função

o 'TolX' é a tolerância de X

\section{A.2 Programa Matlab}

function Output $=$ myfun $(C)$

$\%$

\% Atribuição das variáveis de otimização para cálculos de novo formato modal (fatores de ponderação)

$\%$ Neste caso somente o primeiro, o terceiro e o quinto formato modais estão sendo considerados

$\%$

$\mathrm{C} 1=\mathrm{C}(1) ;$

$\mathrm{C} 3=\mathrm{C}(2) ;$

$\mathrm{C} 5=\mathrm{C}(3) ;$

$\%$

\% Análise modal da chapa original via Nastran ${ }^{\circledR}$ - pode ser suprimida se a análise for executada $\%$ antes do fminsearch dentro do Matlab

\% Arquivo nastran.dat inclui todo o modelo da chapa e os parâmetros da análise modal, com

$\%$ arquivos de suporte para SPC, Grid Data e Element Data

\% O comando abaixo considera a análise utilizando o Nastran 2010SE - precisa se alterado para

$\%$ cada versão de Nastran em uso

$\%$

!C:\MSC.Software\MD_Nastran_Student_Edition\20102\Nastran\bin\mdnastran.exe nastran.dat $\%$

\% Comando Matlab para ler o Grid data da chapa original dentro da variável "GD" a partir do

$\%$ arquivo de suporte "Grid_Data.dat"

$\%$

fid=fopen('Grid_Data.dat','r'); block_size = 5000;

while $\sim$ feof(fid) tlineGD = textscan(fid, '\%s', block_size, 'delimiter', '\n');

$\mathrm{e}=1$;

while e $<=$ length(tlineGD $\{1,1\}$ )

$\mathrm{I}=$ length(tlineGD $\{1,1\}\{\mathrm{e}, 1\}) ;$ for $\mathrm{k}=1:(\operatorname{ceil}(\mathrm{I} / 8))$

$\mathrm{b}=\mathrm{k}^{*} 8$

if $(I)>=b$

$\mathrm{GD}\{\mathrm{e}, \mathrm{k}\}=$ tlineGD $\{1,1\}\{\mathrm{e}, 1\}((\mathrm{b}-7): \mathrm{b}) ;$

else $G D\{e, k\}=$ tlineGD $\{1,1\}\{e, 1\}((b-7):(I))$;

end

end

$\mathrm{e}=\mathrm{e}+1$;

end

end

$\%$

\% Limpeza das variáveis de suporte da leitura utilizadas

$\%$ 
clear e;

clear I;

clear b;

clear k;

clear block_size;

fclose(fid);

$\%$

\% Comando Matlab para leitura do Element Data e armazenamento dos dados na variável ED a $\%$ partir dos dados do arquivo de suporte "element.dat"

$\%$

fid=fopen('element.dat','r'); block_size = 5000;

while $\sim$ feof(fid) tlineEL = textscan(fid, '\%s',block_size,'delimiter', '\n');

$\mathrm{e}=1$;

while e $<=$ length(tlineEL $\{1,1\}$ )

I = length(tlineEL $\{1,1\}\{e, 1\})$; for $k=1$ :(ceil(I/8))

$\mathrm{b}=\mathrm{k}^{*} 8$;

if $(I)>=b$

$\operatorname{ED}\{e, k\}=$ tlineEL $\{1,1\}\{e, 1\}((b-7): b)$;

else $\operatorname{ED}\{e, k\}=$ tlineEL\{1,1\}\{e,1\}((b-7):(I));

end

end

$\mathrm{e}=\mathrm{e}+1$;

end

end

$\%$

\% Limpeza das variáveis de suporte da leitura utilizadas

$\%$

clear e;

clear I;

clear b;

clear k;

clear block_size;

fclose(fid);

$\%$

\% Leitura do Punch (simples) - este comando faz a leitura do punch data da análise modal da

$\%$ chapa original, através do uso da função "textscan". Esses dados são armazenados na variável \% PCH $\%$

fid=fopen('nastran.pch','r'); block_size = 100000;

while $\sim$ feof(fid) PCH = textscan(fid, '\%s', block_size,'delimiter','\n');

end

fclose(fid);

$\%$

\% Limpeza da variável de suporte da leitura utilizada

$\%$

clear block_size;

$\%$

\% O comando abaixo executa a leitura do deslocamento em " $Z$ " dos formatos modais da chapa $\%$ original que estão armazenados na variável PCH. Por simplificação, os valores do formato são $\%$ armazenados em um vetor "Modo", que utiliza o número da coluna para identificar qual $\%$ formato está armazenado Em paralelo, os valores das frequências naturais são armazenados $\%$ no vetor "Mode" em Hz 
\% A variável K é o tamanho da matriz PCH. Os comandos estão adaptados para leitura do $\%$ formato "punch" do Nastran ${ }^{\circledR}$

$\%$

for $\mathrm{k}=1$ :length(PCH $\{1,1\})$

if PCH $\{1,1\}\{k, 1\}(1: 11)==$ '\$EIGENVALUE'

ModeNr = str2num(PCH $\{1,1\}\{k, 1\}(41: 42))$;

Mode $\{1$, ModeNr $\}=(\operatorname{sqrt}(\operatorname{str} 2$ num $(\mathrm{PCH}\{1,1\}\{k, 1\}(16: 28)))) /(2 *$ pi $)$;

elseif PCH $\{1,1\}\{k, 1\}(1: 3) \sim=$ '-CO' \& PCH $\{1,1\}\{k, 1\}(1: 1) \sim=$ '\$'

Modo\{str2num(PCH $\{1,1\}\{k, 1\}(1: 3))$,ModeNr\}=str2num(PCH $\{1,1\}\{k, 1\}(53: 65))$;

end

end

$\%$

$\%$ Limpeza das variáveis de suporte da leitura utilizadas

$\%$

clear k;

clear ModeNr;

$\%$

\% O comando a seguir compila o novo formato da chapa utilizando os fatores de ponderação da \% otimização e o formato modal armazenado no vetor "Modo" e armazena na variável "shape" $\%$ Importante ressaltar que o comando abaixo somente considera o primeiro, o terceiro e o $\%$ quinto formatos modais.

$\%$

for $\mathrm{k}=1$ :length(GD)

if $\mathrm{GD}\{k, 1\}(1: 4)==$ 'GRID'

shape $\{\operatorname{str} 2 \operatorname{num}(G D\{k, 2\}), 1\}=(C 1 *(\operatorname{Modo}\{\operatorname{str} 2 n u m(G D\{k, 2\}), 1\}))+(C 3 *($ Modo $\{\operatorname{str} 2 n u m($ $\mathrm{GD}\{k, 2\}), 3\}))+(\mathrm{C} 5 *(\operatorname{Modo}\{\operatorname{str} 2 \operatorname{num}(\mathrm{GD}\{k, 2\}), 5\}))$;

end

end

$\%$

\% Limpeza das variáveis de suporte da leitura utilizadas

$\%$

clear k;

$\%$

\% O comando a seguir realiza a verificação do ângulo entre os elementos da chapa, para verificar \% se ocorre, e quão grande é, a violação da condição de hipersensibilidade entre os elementos $\%$ (ângulo entre os elementos menor que $5^{\circ}$ e maior que $5^{\circ}$ )

\% O coeficiente "Alfa" é o valor que o formato modal da nova chapa precisa ser multiplicado 5 para que nenhum ângulo entre as chapas seja superior a $5^{\circ}$

\% A variável "Temp" armazena o maior ângulo entre os elementos

$\%$

Alfa=1;

for $\mathrm{y}=1$ :length(ED)

$A\{1,1\}=a b s((\operatorname{shape}\{\operatorname{str} 2 \operatorname{num}(\operatorname{ED}\{y, 4\}), 1\})-(\operatorname{shape}\{\operatorname{str} 2 \operatorname{num}(\operatorname{ED}\{y, 5\}), 1\}))$;

$A\{1,2\}=\operatorname{abs}((\operatorname{shape}\{\operatorname{str} 2$ num $(\operatorname{ED}\{y, 4\}), 1\})-(\operatorname{shape}\{\operatorname{str} 2 \operatorname{num}(\operatorname{ED}\{y, 6\}), 1\}))$;

$A\{1,3\}=\operatorname{abs}((\operatorname{shape}\{\operatorname{str} 2 \operatorname{num}(\operatorname{ED}\{y, 4\}), 1\})-(\operatorname{shape}\{\operatorname{str} 2 \operatorname{num}(\operatorname{ED}\{y, 7\}), 1\}))$;

$A\{1,4\}=a b s((\operatorname{shape}\{\operatorname{str} 2 \operatorname{num}(\operatorname{ED}\{y, 5\}), 1\})-(\operatorname{shape}\{\operatorname{str} 2 \operatorname{num}(\operatorname{ED}\{y, 6\}), 1\}))$;

$A\{1,5\}=\operatorname{abs}((\operatorname{shape}\{\operatorname{str} 2 \operatorname{num}(\operatorname{ED}\{y, 5\}), 1\})-(\operatorname{shape}\{\operatorname{str} 2 \operatorname{num}(\operatorname{ED}\{y, 7\}), 1\}))$;

$A\{1,6\}=\operatorname{abs}((\operatorname{shape}\{\operatorname{str} 2 \operatorname{num}(\operatorname{ED}\{y, 6\}), 1\})-(\operatorname{shape}\{\operatorname{str} 2 \operatorname{num}(\operatorname{ED}\{y, 7\}), 1\}))$;

Temp $=\max ([A\{:\}])$;

if (Alfa*Temp) $>0.001$

Alfa $=0.001 /$ Temp;

end 
end

$\%$

$\%$ Limpeza das variáveis de suporte da leitura utilizadas

$\%$

clear Temp;

clear $\mathrm{y}$;

clear A;

$\%$

\% O comando a seguir multiplica o formato modal da chapa deformada pelo coeficiente "Alfa" $\%$ Esse procedimento garante que no formato deformado nenhum ângulo entre elementos $\%$ seja superior ao limite de $5^{\circ}$ da hipersensibilidade $\%$

for $\mathrm{i}=1$ :length(shape) shape $\{\mathrm{i}, 1\}=$ shape $\{\mathrm{i}, 1\}\}^{*}$ Alfa;

end

$\%$

$\%$ Limpeza das variáveis de suporte da leitura utilizadas

$\%$

clear i;

$\%$

\% O comando abaixo transfere o formato calculado da chapa deformada, presente na variável \% "shape" em formato numérico para a variável GD em formato texto para que seja

$\%$ posteriormente feita a análise modal da chapa com formato deformado $\%$

for $x=1$ :length(GD)

$$
\text { if } G D\{x, 1\}(1: 4)==\text { 'GRID' }
$$$$
\mathrm{GD}\{x, 6\}=\text { num } 2 \operatorname{str}\left(\operatorname{shape}\{\operatorname{str} 2 \mathrm{num}(\mathrm{GD}\{\mathrm{x}, 2\}), 1\},{ }^{\prime} \% 1.5 f^{\prime}\right) \text {; }
$$

end

end

$\%$

$\%$ Limpeza das variáveis de suporte da leitura utilizadas

$\%$

clear $\mathrm{x}$;

$\%$

\% O comando abaixo transfere o formato calculado da chapa deformada, presente na variável \% "shape" para um novo arquivo "Grid_New.dat" que é utilizado no arquivo "nastran_new.dat" $\%$ para que seja feita a análise modal da chapa com formato deformado $\%$

fid=fopen('Grid_New.dat','wt');

[rows,cols]=size(GD);

$a=1$;

$\mathrm{b}=1$;

while $a<=$ rows

while $b<=$ cols

fprintf(fid, GD $\{a, b\})$;

$b=b+1$;

end

$b=1$;

fprintf(fid, '\n');

$a=a+1$;

end 
$\%$

\% Limpeza das variáveis de suporte da leitura utilizadas

$\%$

clear a;

clear b;

clear rows;

clear cols;

fclose(fid);

clear fid;

\% Análise modal da chapa deformada via Nastran

\% Arquivo nastran_new.dat inclui todo o modelo da chapa e os parâmetros da análise modal

$\%$ com arquivos de suporte para SPC, Grid New e Element Data

\% O comando abaixo considera a análise utilizando o Nastran 2010SE - precisa se alterado para

$\%$ cada versão de Nastran $^{\circledR}$ em uso

!C:\MSC.Software\MD_Nastran_Student_Edition\20102\Nastran\bin\mdnastran.exe prog=edu auth=edu arch=32 nastran_new.dat

$\%$

\% Leitura do arquivo "punch" da análise modal em Nastran ${ }^{\circledR}$ da chapa deformada utilizando

\% mesmo comando da leitura do "punch" da análise da chapa original

$\%$

fid=fopen('nastran_new.pch','r'); block_size = 100000;

while feof(fid) PCH_New = textscan(fid,'\%s',block_size,'delimiter', '\n');

end

fclose(fid);

$\%$

\% Limpeza das variáveis de suporte da leitura utilizadas

$\%$

clear block_size;

$\%$

\% Comando para leitura das frequências naturais da chapa deformada, que são armazenadas \% em Hz na variável Mode_New para posterior comparação com as frequências originais

\% Este comando é o mesmo utilizado na leitura das frequências da chapa original, porém sem a

$\%$ leitura dos formatos modais

$\%$

for $\mathrm{k}=1$ :length(PCH_New $\{1,1\})$

if PCH_New $\{1,1\}\{k, 1\}(1: 11)==$ '\$EIGENVALUE'

ModeNr = str2num $\left(\mathrm{PCH} \_\right.$New $\left.\{1,1\}\{\mathrm{k}, 1\}(41: 42)\right)$;

Mode_New $\{1, M o d e N r\}=\left(\operatorname{sqrt}\left(\operatorname{str} 2 \operatorname{num}\left(P C H \_N e w\{1,1\}\{k, 1\}(16: 28)\right)\right)\right) /(2 *$ pi $)$;

end

end

$\%$

\% Limpeza das variáveis de suporte da leitura utilizadas

$\%$

clear k;

clear ModeNr;

$\%$

\% Comando para verificação do output (função objetivo) da otimização

\% Neste caso a função divide a menor frequência da chapa deformada pela menor frequência

\% da chapa original. Essa função pode ser alterada conforme o objetivo da otimização

$\%$

Output $=(\min ([$ Mode_New $\{:\}])) /(\min ([\operatorname{Mode}\{:\}]))$ 


\section{A.3 Arquivos Nastran®}

Os arquivos apresentados consideram uma chapa retangular apoiada nos quatro vértices, e mostra a formatação dos arquivos Nastran ${ }^{\circledR}$ a ser utilizada em conjunto do programa Matlab ${ }^{\circledR}$.

O material considerado foi aço comum de engenharia e a análise modal considera a solução 103 do Nastran ${ }^{\circledR}$ buscando as 20 primeiras frequências naturais, até o limite de 1000 $\mathrm{Hz}$.

\section{A.3.1 Nastran.dat}

SOL 103

CEND

SUBCASE 2

LABEL= fixed_Modal

$\mathrm{SPC}=3$

METHOD $=3$

DISPLACEMENT $($ PUNCH $)=$ ALL

BEGIN BULK

Include 'Grid_Data.dat'

Include 'element.dat'

$\begin{array}{lllll}\text { PSHELL } & 1 & 17.00 \mathrm{E}-04 & 1 & 1\end{array}$

MAT1 $12.07 \mathrm{E}+117.90 \mathrm{E}+100.3 \quad 7860.0$

$\begin{array}{lllll}\text { EIGRL } & 30.0 & 1000.0 & 20 & \text { MASS }\end{array}$

Include 'spc.dat'

ENDDATA

\section{A.3.2 Grid_data.dat}

$\begin{array}{lllll}\text { GRID } & 258 & 0.0 & 0.0 & 0.0 \\ \text { GRID } & 259 & 0.0 & 0.0125 & 0.0 \\ \text { GRID } & 260 & 0.0 & 0.025 & 0.0 \\ \text { GRID } & 261 & 0.0 & 0.0375 & 0.0 \\ \text { GRID } & 262 & 0.0 & 0.05 & 0.0 \\ \text { GRID } & 263 & 0.0 & 0.0625 & 0.0 \\ \text { GRID } & 264 & 0.0 & 0.075 & 0.0 \\ \text { GRID } & 265 & 0.0 & 0.0875 & 0.0 \\ \text { GRID } & 266 & 0.0 & 0.1 & 0.0 \\ \text { GRID } & 267 & 0.0 & 0.1125 & 0.0 \\ \text { GRID } & 268 & 0.0 & 0.125 & 0.0 \\ \text { GRID } & 269 & 0.0 & 0.1375 & 0.0 \\ \text { GRID } & 270 & 0.0 & 0.15 & 0.0 \\ \text { GRID } & 271 & 0.0 & 0.1625 & 0.0 \\ \text { GRID } & 272 & 0.0 & 0.175 & 0.0\end{array}$




\begin{tabular}{|c|c|c|c|}
\hline GRID & 273 & 0.0 & 0.1875 \\
\hline GRID & 274 & 0.0 & 0.2 \\
\hline RID & 75 & 0.0 & 0.21250 \\
\hline RID & 76 & .0 & $0.225 \quad 0.0$ \\
\hline RID & 277 & 0.0 & 0.23750 .0 \\
\hline RID & 278 & 0.0 & $0.25 \quad 0.0$ \\
\hline RID & 279 & 0.0 & 0.26250 .0 \\
\hline RID & 280 & 0.0 & $0.275 \quad 0.0$ \\
\hline RID & 281 & 0.0 & 0.28750 .0 \\
\hline RID & 282 & 0.0 & $0.3 \quad 0.0$ \\
\hline RID & 283 & 0.012 & $\begin{array}{lll}25 & 0.3 & 0.6\end{array}$ \\
\hline RID & 284 & 0.025 & $\begin{array}{lll}5 & 0.3 & 0.0\end{array}$ \\
\hline SID & 285 & 0.037 & $\begin{array}{lll}75 & 0.3 & 0.0\end{array}$ \\
\hline RID & 286 & 0.05 & $0.3 \quad 0.0$ \\
\hline RID & 287 & 0.062 & 250.3 \\
\hline RID & 288 & 0.075 & $\begin{array}{lll}5 & 0.3 & 0.0\end{array}$ \\
\hline RID & 289 & 0.087 & $\begin{array}{lll}75 & 0.3 & 0.0\end{array}$ \\
\hline RID & 290 & 0.1 & $0.3 \quad 0.0$ \\
\hline GRID & 291 & 0.1 & 0.28750 .0 \\
\hline RID & 92 & 0.1 & $0.275 \quad 0.0$ \\
\hline RID & 93 & 0.1 & 0.26250 .0 \\
\hline RID & 294 & 0.1 & $0.25 \quad 0.0$ \\
\hline RID & 95 & 0.1 & 0.23750 .0 \\
\hline RID & 96 & 0.1 & $0.225 \quad 0.0$ \\
\hline RID & 97 & 0.1 & 0.21250 .0 \\
\hline RID & 98 & 0.1 & $0.2 \quad 0.0$ \\
\hline RID & 99 & 0.1 & 0.18750 .0 \\
\hline RID & 300 & 0.1 & $0.175 \quad 0.0$ \\
\hline RID & 301 & 0.1 & 0.16250 .0 \\
\hline GRID & 02 & 0.1 & $0.15 \quad 0.0$ \\
\hline GRID & 303 & 0.1 & 0.13750 .0 \\
\hline RID & 304 & 0.1 & $0.125 \quad 0.0$ \\
\hline RID & 305 & 0.1 & 0.11250 .0 \\
\hline RID & 306 & 0.1 & $0.1 \quad 0.0$ \\
\hline GRID & 307 & 0.1 & 0.08750 .0 \\
\hline GRID & 08 & 0.1 & $0.075 \quad 0.0$ \\
\hline RID & 309 & 0.1 & 0.06250 .0 \\
\hline GRID & 310 & 0.1 & $0.05 \quad 0.0$ \\
\hline GRID & 311 & 0.1 & 0.03750 .0 \\
\hline GRID & 312 & 0.1 & 0.0250 .0 \\
\hline GRID & 313 & 0.1 & 0.01250 .0 \\
\hline GRID & 314 & 0.1 & $0.0 \quad 0.0$ \\
\hline GRID & 315 & 0.087 & $\begin{array}{lll}75 & 0.0 & 0.0\end{array}$ \\
\hline GRID & 316 & 0.075 & $\begin{array}{lll}5 & 0.0 & 0.0\end{array}$ \\
\hline GRID & 317 & 0.062 & $\begin{array}{lll}25 & 0.0 & 0.0\end{array}$ \\
\hline GRID & 318 & 0.05 & $0.0 \quad 0.0$ \\
\hline GRID & 319 & 0.037 & $\begin{array}{lll}75 & 0.0 & 0.0\end{array}$ \\
\hline GRID & 320 & 0.025 & $\begin{array}{lll}5 & 0.0 & 0.0\end{array}$ \\
\hline GRID & 321 & 0.012 & $25 \quad 0.0 \quad 0$. \\
\hline GRID & 322 & 0.087 & $\begin{array}{lll}75 & 0.15 & 0.0\end{array}$ \\
\hline GRID & 323 & 0.075 & $\begin{array}{lll}5 & 0.15 & 0.0\end{array}$ \\
\hline GRID & 324 & 0.062 & 250.15 \\
\hline
\end{tabular}




\begin{tabular}{|c|c|c|}
\hline GRID & 325 & $\begin{array}{lll}0.05 & 0.15 & 0.0\end{array}$ \\
\hline GRID & 326 & $\begin{array}{lll}0.0375 & 0.15 & 0.0\end{array}$ \\
\hline GRID & 327 & $\begin{array}{lll}0.025 & 0.15 & 0.0\end{array}$ \\
\hline RID & 328 & $\begin{array}{lll}0.0125 & 0.15 & 0.0\end{array}$ \\
\hline RID & 329 & $\begin{array}{lll}0.0875 & 0.225 & 0.0\end{array}$ \\
\hline GRID & 330 & $\begin{array}{lll}0.075 & 0.225 & 0.0\end{array}$ \\
\hline GRID & 331 & $\begin{array}{lll}0.0625 & 0.225 & 0.0\end{array}$ \\
\hline GRID & 332 & $\begin{array}{lll}0.05 & 0.225 & 0.0\end{array}$ \\
\hline RID & 333 & $\begin{array}{lll}0.0375 & 0.225 & 0.0\end{array}$ \\
\hline RID & 334 & $\begin{array}{lll}0.025 & 0.225 & 0.0\end{array}$ \\
\hline RID & 335 & $\begin{array}{lll}0.0125 & 0.225 & 0.0\end{array}$ \\
\hline RID & 336 & $\begin{array}{lll}0.05 & 0.2375 & 0.0\end{array}$ \\
\hline RID & 337 & $\begin{array}{lll}0.05 & 0.25 & 0.0\end{array}$ \\
\hline RID & 38 & $\begin{array}{lll}0.05 & 0.2625 & 0.0\end{array}$ \\
\hline RID & 339 & $\begin{array}{lll}0.05 & 0.275 & 0.0\end{array}$ \\
\hline RID & 340 & $\begin{array}{lll}0.05 & 0.2875 & 0.0\end{array}$ \\
\hline RID & 341 & $\begin{array}{lll}0.0625 & 0.2625 & 0.0\end{array}$ \\
\hline RID & 342 & $\begin{array}{llll}0.075 & 0.2625 & 0.0\end{array}$ \\
\hline GRID & 343 & $\begin{array}{lll}0.0875 & 0.2625 & 0.0\end{array}$ \\
\hline GRID & 344 & $\begin{array}{lll}0.075 & 0.25 & 0.0\end{array}$ \\
\hline RID & 345 & $\begin{array}{lll}0.075 & 0.2375 & 0.0\end{array}$ \\
\hline RID & 346 & $\begin{array}{lll}0.0625 & 0.25 & 0.0\end{array}$ \\
\hline RID & 347 & $\begin{array}{lll}0.0625 & 0.2375 & 0.0\end{array}$ \\
\hline GRID & 348 & $\begin{array}{lll}0.0875 & 0.25 & 0.0\end{array}$ \\
\hline GRID & 349 & $\begin{array}{lll}0.0875 & 0.2375 & 0.0\end{array}$ \\
\hline RID & 350 & $\begin{array}{llll}0.075 & 0.2875 & 0.0\end{array}$ \\
\hline RID & 351 & $\begin{array}{lll}0.075 & 0.275 & 0.0\end{array}$ \\
\hline RID & 352 & $\begin{array}{lll}0.0625 & 0.2875 & 0.0\end{array}$ \\
\hline RID & 353 & $\begin{array}{lll}0.0625 & 0.275 & 0.0\end{array}$ \\
\hline GRID & 354 & $\begin{array}{lll}0.0875 & 0.2875 & 0.0\end{array}$ \\
\hline GRID & 355 & $\begin{array}{lll}0.0875 & 0.275 & 0.0\end{array}$ \\
\hline GRID & 356 & $\begin{array}{lll}0.0125 & 0.2625 & 0.0\end{array}$ \\
\hline RID & 357 & $\begin{array}{llll}0.025 & 0.2625 & 0.0\end{array}$ \\
\hline GRID & 358 & $\begin{array}{lll}0.0375 & 0.2625 & 0.0\end{array}$ \\
\hline GRID & 359 & $\begin{array}{lll}0.025 & 0.25 & 0.0\end{array}$ \\
\hline GRID & 360 & $\begin{array}{llll}0.025 & 0.2375 & 0.0\end{array}$ \\
\hline GRID & 361 & $\begin{array}{lll}0.0125 & 0.25 & 0.0\end{array}$ \\
\hline GRID & 362 & $\begin{array}{lll}0.0125 & 0.2375 & 0.0\end{array}$ \\
\hline GRID & 363 & $\begin{array}{lll}0.0375 & 0.25 & 0.0\end{array}$ \\
\hline GRID & 364 & $\begin{array}{lll}0.0375 & 0.2375 & 0.0\end{array}$ \\
\hline GRID & 365 & $\begin{array}{llll}0.025 & 0.2875 & 0.0\end{array}$ \\
\hline GRID & 366 & $\begin{array}{lll}0.025 & 0.275 & 0.0\end{array}$ \\
\hline GRID & 367 & $\begin{array}{lll}0.0125 & 0.2875 & 0.0\end{array}$ \\
\hline GRID & 368 & $\begin{array}{lll}0.0125 & 0.275 & 0.0\end{array}$ \\
\hline GRID & 369 & $\begin{array}{lll}0.0375 & 0.2875 & 0.0\end{array}$ \\
\hline GRID & 370 & $\begin{array}{lll}0.0375 & 0.275 & 0.0\end{array}$ \\
\hline GRID & 371 & $\begin{array}{lll}0.05 & 0.1625 & 0.0\end{array}$ \\
\hline GRID & 372 & $\begin{array}{lll}0.05 & 0.175 & 0.0\end{array}$ \\
\hline GRID & 373 & $\begin{array}{lll}0.05 & 0.1875 & 0.0\end{array}$ \\
\hline GRID & 374 & $\begin{array}{lll}0.05 & 0.2 & 0.0\end{array}$ \\
\hline GRID & 375 & $\begin{array}{lll}0.05 & 0.2125 & 0.0\end{array}$ \\
\hline
\end{tabular}




\begin{tabular}{|c|c|c|}
\hline GRID & 376 & $\begin{array}{lll}0.0625 & 0.1875 & 0.0\end{array}$ \\
\hline GRID & 377 & $\begin{array}{llll}0.075 & 0.1875 & 0.0\end{array}$ \\
\hline GRID & 378 & 0.08750 .18750 .0 \\
\hline GRID & 379 & $\begin{array}{lll}0.075 & 0.175 & 0.0\end{array}$ \\
\hline GRID & 380 & $\begin{array}{lll}0.075 & 0.1625 & 0.0\end{array}$ \\
\hline GRID & 381 & $\begin{array}{lll}0.0625 & 0.175 & 0.0\end{array}$ \\
\hline GRID & 382 & $\begin{array}{llll}0.0625 & 0.1625 & 0.0\end{array}$ \\
\hline GRID & 383 & $\begin{array}{lll}0.0875 & 0.175 & 0.0\end{array}$ \\
\hline GRID & 384 & $\begin{array}{lll}0.0875 & 0.1625 & 0.0\end{array}$ \\
\hline GRID & 385 & $\begin{array}{llll}0.075 & 0.2125 & 0.0\end{array}$ \\
\hline GRID & 386 & $\begin{array}{lll}0.075 & 0.2 & 0.0\end{array}$ \\
\hline GRID & 387 & $\begin{array}{lll}0.0625 & 0.2125 & 0.0\end{array}$ \\
\hline GRID & 388 & $\begin{array}{lll}0.0625 & 0.2 & 0.0\end{array}$ \\
\hline GRID & 389 & $\begin{array}{lll}0.0875 & 0.2125 & 0.0\end{array}$ \\
\hline GRID & 390 & $\begin{array}{lll}0.0875 & 0.2 & 0.0\end{array}$ \\
\hline GRID & 391 & $\begin{array}{lll}0.0125 & 0.1875 & 0.0\end{array}$ \\
\hline GRID & 392 & $\begin{array}{lll}0.025 & 0.1875 & 0.0\end{array}$ \\
\hline GRID & 393 & $\begin{array}{lll}0.0375 & 0.1875 & 0.0\end{array}$ \\
\hline GRID & 394 & $\begin{array}{lll}0.025 & 0.175 & 0.0\end{array}$ \\
\hline GRID & 395 & $\begin{array}{lll}0.025 & 0.1625 & 0.0\end{array}$ \\
\hline GRID & 396 & $\begin{array}{lll}0.0125 & 0.175 & 0.0\end{array}$ \\
\hline GRID & 397 & $\begin{array}{lll}0.0125 & 0.1625 & 0.0\end{array}$ \\
\hline GRID & 398 & $\begin{array}{lll}0.0375 & 0.175 & 0.0\end{array}$ \\
\hline GRID & 399 & $\begin{array}{llll}0.0375 & 0.1625 & 0.0\end{array}$ \\
\hline GRID & 400 & $\begin{array}{lll}0.025 & 0.2125 & 0.0\end{array}$ \\
\hline GRID & 401 & $\begin{array}{lll}0.025 & 0.2 & 0.0\end{array}$ \\
\hline GRID & 402 & $\begin{array}{lll}0.0125 & 0.2125 & 0.0\end{array}$ \\
\hline GRID & 403 & $\begin{array}{lll}0.0125 & 0.2 & 0.0\end{array}$ \\
\hline GRID & 404 & $\begin{array}{lll}0.0375 & 0.2125 & 0.0\end{array}$ \\
\hline GRID & 405 & $\begin{array}{lll}0.0375 & 0.2 & 0.0\end{array}$ \\
\hline GRID & 406 & $\begin{array}{lll}0.0875 & 0.075 & 0.0\end{array}$ \\
\hline GRID & 407 & $\begin{array}{lll}0.075 & 0.075 & 0.0\end{array}$ \\
\hline GRID & 408 & $\begin{array}{lll}0.0625 & 0.075 & 0.0\end{array}$ \\
\hline GRID & 409 & $\begin{array}{lll}0.05 & 0.075 & 0.0\end{array}$ \\
\hline GRID & 410 & $\begin{array}{lll}0.0375 & 0.075 & 0.0\end{array}$ \\
\hline GRID & 411 & $\begin{array}{lll}0.025 & 0.075 & 0.0\end{array}$ \\
\hline GRID & 412 & $\begin{array}{lll}0.0125 & 0.075 & 0.0\end{array}$ \\
\hline GRID & 413 & $\begin{array}{lll}0.05 & 0.0875 & 0.0\end{array}$ \\
\hline GRID & 414 & $\begin{array}{lll}0.05 & 0.1 & 0.0\end{array}$ \\
\hline GRID & 415 & $\begin{array}{lll}0.05 & 0.1125 & 0.0\end{array}$ \\
\hline GRID & 416 & $\begin{array}{lll}0.05 & 0.125 & 0.0\end{array}$ \\
\hline GRID & 417 & $\begin{array}{lll}0.05 & 0.1375 & 0.0\end{array}$ \\
\hline GRID & 418 & $\begin{array}{lll}0.0625 & 0.1125 & 0.0\end{array}$ \\
\hline GRID & 419 & $\begin{array}{lll}0.075 & 0.1125 & 0.0\end{array}$ \\
\hline GRID & 420 & $\begin{array}{lll}0.0875 & 0.1125 & 0.0\end{array}$ \\
\hline GRID & 421 & $\begin{array}{lll}0.075 & 0.1 & 0.0\end{array}$ \\
\hline GRID & 422 & $\begin{array}{llll}0.075 & 0.0875 & 0.0\end{array}$ \\
\hline GRID & 423 & $\begin{array}{lll}0.0625 & 0.1 & 0.0\end{array}$ \\
\hline GRID & 424 & $\begin{array}{lll}0.0625 & 0.0875 & 0.0\end{array}$ \\
\hline GRID & 425 & $\begin{array}{lll}0.0875 & 0.1 & 0.0\end{array}$ \\
\hline GRID & 426 & $\begin{array}{lll}0.0875 & 0.0875 & 0.0\end{array}$ \\
\hline GRID & 427 & $\begin{array}{llll}0.075 & 0.1375 & 0.0\end{array}$ \\
\hline
\end{tabular}




\begin{tabular}{|c|c|c|}
\hline GRID & 428 & $\begin{array}{lll}0.075 & 0.125 & 0.0\end{array}$ \\
\hline GRID & 429 & $\begin{array}{lll}0.0625 & 0.1375 & 0.0\end{array}$ \\
\hline GRID & 130 & $\begin{array}{lll}0.0625 & 0.125 & 0.0\end{array}$ \\
\hline RID & 431 & $\begin{array}{lll}0.0875 & 0.1375 & 0.0\end{array}$ \\
\hline RID & 432 & $\begin{array}{lll}0.0875 & 0.125 & 0.0\end{array}$ \\
\hline GRID & 433 & $\begin{array}{lll}0.0125 & 0.1125 & 0.0\end{array}$ \\
\hline GRID & 434 & $\begin{array}{lll}0.025 & 0.1125 & 0.0\end{array}$ \\
\hline GRID & 435 & $\begin{array}{lll}0.0375 & 0.1125 & 0.0\end{array}$ \\
\hline RID & 436 & $\begin{array}{lll}0.025 & 0.1 & 0.0\end{array}$ \\
\hline RID & 437 & $\begin{array}{llll}0.025 & 0.0875 & 0.0\end{array}$ \\
\hline RID & 438 & $\begin{array}{lll}0.0125 & 0.1 & 0.0\end{array}$ \\
\hline GRID & 439 & $\begin{array}{lll}0.0125 & 0.0875 & 0.0\end{array}$ \\
\hline GRID & 440 & $\begin{array}{lll}0.0375 & 0.1 & 0.0\end{array}$ \\
\hline RID & 441 & $\begin{array}{lll}0.0375 & 0.0875 & 0.0\end{array}$ \\
\hline RID & 442 & $\begin{array}{llll}0.025 & 0.1375 & 0.0\end{array}$ \\
\hline RID & 443 & $\begin{array}{lll}0.025 & 0.125 & 0.0\end{array}$ \\
\hline GRID & 444 & $\begin{array}{lll}0.0125 & 0.1375 & 0.0\end{array}$ \\
\hline GRID & 445 & $\begin{array}{lll}0.0125 & 0.125 & 0.0\end{array}$ \\
\hline GRID & 446 & 0.03750 .13750 .0 \\
\hline GRID & 447 & $\begin{array}{lll}0.0375 & 0.125 & 0.0\end{array}$ \\
\hline GRID & 448 & $\begin{array}{lll}0.05 & 0.0125 & 0.0\end{array}$ \\
\hline GRID & 449 & $\begin{array}{lll}0.05 & 0.025 & 0.0\end{array}$ \\
\hline GRID & 450 & $\begin{array}{lll}0.05 & 0.0375 & 0.0\end{array}$ \\
\hline GRID & 451 & $\begin{array}{lll}0.05 & 0.05 & 0.0\end{array}$ \\
\hline GRID & 452 & $\begin{array}{lll}0.05 & 0.0625 & 0.0\end{array}$ \\
\hline GRID & 453 & $\begin{array}{lll}0.0625 & 0.0375 & 0.0\end{array}$ \\
\hline GRID & 454 & $\begin{array}{llll}0.075 & 0.0375 & 0.0\end{array}$ \\
\hline GRID & 455 & $\begin{array}{lll}0.0875 & 0.0375 & 0.0\end{array}$ \\
\hline GRID & 456 & $\begin{array}{lll}0.075 & 0.025 & 0.0\end{array}$ \\
\hline GRID & 457 & $\begin{array}{llll}0.075 & 0.0125 & 0.0\end{array}$ \\
\hline GRID & 458 & $\begin{array}{lll}0.0625 & 0.025 & 0.0\end{array}$ \\
\hline GRID & 459 & $\begin{array}{lll}0.0625 & 0.0125 & 0.0\end{array}$ \\
\hline GRID & 460 & $\begin{array}{lll}0.0875 & 0.025 & 0.0\end{array}$ \\
\hline GRID & 461 & $\begin{array}{lll}0.0875 & 0.0125 & 0.0\end{array}$ \\
\hline GRID & 462 & $\begin{array}{llll}0.075 & 0.0625 & 0.0\end{array}$ \\
\hline GRID & 463 & $\begin{array}{lll}0.075 & 0.05 & 0.0\end{array}$ \\
\hline GRID & 464 & $\begin{array}{lll}0.0625 & 0.0625 & 0.0\end{array}$ \\
\hline GRID & 465 & $\begin{array}{lll}0.0625 & 0.05 & 0.0\end{array}$ \\
\hline GRID & 466 & $\begin{array}{lll}0.0875 & 0.0625 & 0.0\end{array}$ \\
\hline GRID & 467 & $\begin{array}{lll}0.0875 & 0.05 & 0.0\end{array}$ \\
\hline GRID & 468 & $\begin{array}{lll}0.0125 & 0.0375 & 0.0\end{array}$ \\
\hline GRID & 469 & $\begin{array}{llll}0.025 & 0.0375 & 0.0\end{array}$ \\
\hline GRID & 470 & $\begin{array}{lll}0.0375 & 0.0375 & 0.0\end{array}$ \\
\hline GRID & 471 & $\begin{array}{lll}0.025 & 0.025 & 0.0\end{array}$ \\
\hline GRID & 472 & $\begin{array}{llll}0.025 & 0.0125 & 0.0\end{array}$ \\
\hline GRID & 473 & $\begin{array}{lll}0.0125 & 0.025 & 0.0\end{array}$ \\
\hline GRID & 474 & $\begin{array}{lll}0.0125 & 0.0125 & 0.0\end{array}$ \\
\hline GRID & 475 & $\begin{array}{lll}0.0375 & 0.025 & 0.0\end{array}$ \\
\hline GRID & 476 & $\begin{array}{lll}0.0375 & 0.0125 & 0.0\end{array}$ \\
\hline GRID & 477 & $\begin{array}{llll}0.025 & 0.0625 & 0.0\end{array}$ \\
\hline GRID & 478 & $\begin{array}{lll}0.025 & 0.05 & 0.0\end{array}$ \\
\hline
\end{tabular}




$\begin{array}{lllll}\text { GRID } & 479 & 0.0125 & 0.0625 & 0.0 \\ \text { GRID } & 480 & 0.0125 & 0.05 & 0.0 \\ \text { GRID } & 481 & 0.0375 & 0.0625 & 0.0 \\ \text { GRID } & 482 & 0.0375 & 0.05 & 0.0\end{array}$

\section{A.3.3 Element.dat}

$\begin{array}{lllllll}\text { CQUAD4 } & 260 & 1 & 342 & 344 & 346 & 341 \\ \text { CQUAD4 } & 261 & 1 & 341 & 346 & 337 & 338 \\ \text { CQUAD4 } & 262 & 1 & 331 & 347 & 345 & 330 \\ \text { CQUAD4 } & 263 & 1 & 347 & 346 & 344 & 345 \\ \text { CQUAD4 } & 264 & 1 & 332 & 336 & 347 & 331 \\ \text { CQUAD4 } & 265 & 1 & 336 & 337 & 346 & 347 \\ \text { CQUAD4 } & 266 & 1 & 293 & 294 & 348 & 343 \\ \text { CQUAD4 } & 267 & 1 & 343 & 348 & 344 & 342 \\ \text { CQUAD4 } & 268 & 1 & 329 & 349 & 295 & 296 \\ \text { CQUAD4 } & 269 & 1 & 349 & 348 & 294 & 295 \\ \text { CQUAD4 } & 270 & 1 & 330 & 345 & 349 & 329 \\ \text { CQUAD4 } & 271 & 1 & 345 & 344 & 348 & 349 \\ \text { CQUAD4 } & 272 & 1 & 288 & 350 & 352 & 287 \\ \text { CQUAD4 } & 273 & 1 & 287 & 352 & 340 & 286 \\ \text { CQUAD4 } & 274 & 1 & 341 & 353 & 351 & 342 \\ \text { CQUAD4 } & 275 & 1 & 353 & 352 & 350 & 351 \\ \text { CQUAD4 } & 276 & 1 & 338 & 339 & 353 & 341 \\ \text { CQUAD4 } & 277 & 1 & 339 & 340 & 352 & 353 \\ \text { CQUAD4 } & 278 & 1 & 290 & 291 & 354 & 289 \\ \text { CQUAD4 } & 279 & 1 & 289 & 354 & 350 & 288 \\ \text { CQUAD4 } & 280 & 1 & 343 & 355 & 292 & 293 \\ \text { CQUAD4 } & 281 & 1 & 355 & 354 & 291 & 292 \\ \text { CQUAD4 } & 282 & 1 & 342 & 351 & 355 & 343 \\ \text { CQUAD4 } & 283 & 1 & 351 & 350 & 354 & 355 \\ \text { CQUAD4 } & 284 & 1 & 357 & 359 & 361 & 356 \\ \text { CQUAD4 } & 285 & 1 & 356 & 361 & 278 & 279 \\ \text { CQUAD4 } & 286 & 1 & 335 & 362 & 360 & 334 \\ \text { CQUAD4 } & 287 & 1 & 362 & 361 & 359 & 360 \\ \text { CQUAD4 } & 288 & 1 & 276 & 277 & 362 & 335 \\ \text { CQUAD4 } & 289 & 1 & 277 & 278 & 361 & 362 \\ \text { CQUAD4 } & 290 & 1 & 338 & 337 & 363 & 358 \\ \text { CQUAD4 } & 291 & 1 & 358 & 363 & 359 & 357 \\ \text { CQUAD4 } & 292 & 1 & 333 & 364 & 336 & 332 \\ \text { CQUAD4 } & 293 & 1 & 364 & 363 & 337 & 336 \\ \text { CQUAD4 } & 294 & 1 & 334 & 360 & 364 & 333 \\ \text { CQUAD4 } & 295 & 1 & 360 & 359 & 363 & 364 \\ \text { CQUAD4 } & 296 & 1 & 284 & 365 & 367 & 283 \\ \text { CQUAD4 } & 297 & 1 & 283 & 367 & 281 & 282 \\ \text { CQUAD4 } & 298 & 1 & 356 & 368 & 366 & 357 \\ \text { CQUAD4 } & 299 & 1 & 368 & 367 & 365 & 366 \\ \text { CQUAD4 } & 300 & 1 & 279 & 280 & 368 & 356 \\ \text { CQUAD4 } & 301 & 1 & 280 & 281 & 367 & 368 \\ \text { CQUAD4 } & 302 & 1 & 286 & 340 & 369 & 285 \\ \text { CQ3 } & 1 & 285 & 369 & 365 & 284\end{array}$




\begin{tabular}{|c|c|c|c|c|c|c|}
\hline CQUAD4 & 304 & 1 & 358 & 370 & 339 & 338 \\
\hline CQUAD4 & 305 & 1 & 370 & 369 & 340 & 339 \\
\hline QUAD4 & 306 & & 357 & 366 & 370 & 358 \\
\hline QUAD4 & 307 & 1 & 366 & 365 & 369 & 370 \\
\hline CQUAD4 & 308 & 1 & 377 & 379 & 381 & 376 \\
\hline CQUAD4 & 309 & 1 & 376 & 381 & 372 & 373 \\
\hline CQUAD4 & 310 & & 324 & 382 & 380 & 323 \\
\hline CQUAD4 & 311 & & 382 & 381 & 379 & 380 \\
\hline QUAD4 & 312 & & 325 & 371 & 382 & 324 \\
\hline CQUAD4 & 313 & 1 & 371 & 372 & 381 & 382 \\
\hline CQUAD4 & 314 & & 299 & 300 & 383 & 378 \\
\hline CQUAD4 & 315 & & 378 & 383 & 379 & 377 \\
\hline CQUAD4 & 316 & & 322 & 384 & 301 & 302 \\
\hline CQUAD4 & 317 & & 384 & 383 & 300 & 301 \\
\hline QUAD4 & 318 & 1 & 323 & 380 & 384 & 322 \\
\hline CQUAD4 & 319 & 1 & 380 & 379 & 383 & 384 \\
\hline CQUAD4 & 320 & & 330 & 385 & 387 & 331 \\
\hline CQUAD4 & 321 & & 331 & 387 & 375 & 332 \\
\hline CQUAD4 & 322 & & 376 & 388 & 386 & 377 \\
\hline CQUAD4 & 323 & 1 & 388 & 387 & 385 & 386 \\
\hline CQUAD4 & 324 & 1 & 373 & 374 & 388 & 376 \\
\hline CQUAD4 & 325 & & 374 & 375 & 387 & 388 \\
\hline CQUAD4 & 326 & & 296 & 297 & 389 & 329 \\
\hline CQUAD4 & 327 & & 329 & 389 & 385 & 330 \\
\hline CQUAD4 & 328 & & 297 & 298 & 390 & 389 \\
\hline CQUAD4 & 329 & 1 & 389 & 390 & 386 & 385 \\
\hline CQUAD4 & 330 & . & 298 & 299 & 378 & 390 \\
\hline CQUAD4 & 331 & & 390 & 378 & 377 & 386 \\
\hline CQUAD4 & 332 & & 392 & 394 & 396 & 391 \\
\hline CQUAD4 & 333 & 1 & 391 & 396 & 272 & 273 \\
\hline CQUAD4 & 334 & 1 & 328 & 397 & 395 & 327 \\
\hline CQUAD4 & 335 & 1 & 397 & 396 & 394 & 395 \\
\hline CQUAD4 & 336 & 1 & 270 & 271 & 397 & 328 \\
\hline CQUAD4 & 337 & 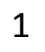 & 271 & 272 & 396 & 397 \\
\hline CQUAD4 & 338 & 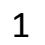 & 373 & 372 & 398 & 393 \\
\hline CQUAD4 & 339 & 1 & 393 & 398 & 394 & 392 \\
\hline CQUAD4 & 340 & 1 & 326 & 399 & 371 & 325 \\
\hline CQUAD4 & 341 & 1 & 399 & 398 & 372 & 371 \\
\hline CQUAD4 & 342 & + & 327 & 395 & 399 & 326 \\
\hline CQUAD4 & 343 & 1 & 395 & 394 & 398 & 399 \\
\hline CQUAD4 & 344 & 1 & 334 & 400 & 402 & 335 \\
\hline CQUAD4 & 345 & 1 & 335 & 402 & 275 & 276 \\
\hline CQUAD4 & 346 & 1 & 391 & 403 & 401 & 392 \\
\hline CQUAD4 & 347 & 1 & 403 & 402 & 400 & 401 \\
\hline CQUAD4 & 348 & 1 & 273 & 274 & 403 & 391 \\
\hline CQUAD4 & 349 & 1 & 274 & 275 & 402 & 403 \\
\hline CQUAD4 & 350 & - & 332 & 375 & 404 & 333 \\
\hline CQUAD4 & 351 & $\perp$ & 333 & 404 & 400 & 334 \\
\hline CQUAD4 & 352 & 1 & 393 & 405 & 374 & 373 \\
\hline CQUAD4 & 353 & 1 & 405 & 404 & 375 & 374 \\
\hline CQUAD4 & 354 & 1 & 392 & 401 & 405 & 393 \\
\hline
\end{tabular}




\begin{tabular}{|c|c|c|c|c|c|c|}
\hline CQUAD4 & 355 & 1 & 401 & 400 & 404 & 405 \\
\hline CQUAD4 & 356 & 1 & 419 & 421 & 423 & 418 \\
\hline CQUAD4 & 357 & 1 & 418 & 423 & 414 & 415 \\
\hline CQUAD4 & 358 & 1 & 408 & 424 & 422 & 407 \\
\hline CQUAD4 & 359 & 1 & 424 & 423 & 421 & 422 \\
\hline CQUAD4 & 360 & 1 & 409 & 413 & 424 & 408 \\
\hline CQUAD4 & 361 & 1 & 413 & 414 & 423 & 424 \\
\hline CQUAD4 & 362 & 1 & 305 & 306 & 425 & 420 \\
\hline CQUAD4 & 363 & 1 & 420 & 425 & 421 & 110 \\
\hline CQUAD4 & 364 & 1 & 406 & 426 & 307 & 308 \\
\hline CQUAD4 & 365 & 1 & 426 & 425 & 306 & 307 \\
\hline CQUAD4 & 366 & 1 & 407 & 422 & 426 & 40 \\
\hline CQUAD4 & 367 & 1 & 422 & 421 & 425 & $42 \epsilon$ \\
\hline CQUAD4 & 368 & 1 & 323 & 427 & 429 & 324 \\
\hline CQUAD4 & 369 & 1 & 324 & 429 & 417 & 325 \\
\hline CQUAD4 & 370 & 1 & 418 & 430 & 428 & 419 \\
\hline CQUAD4 & 371 & 1 & 430 & 429 & 427 & 428 \\
\hline CQUAD4 & 372 & 1 & 415 & 416 & 430 & $41 \varepsilon$ \\
\hline CQUAD4 & 373 & 1 & 416 & 417 & 429 & 430 \\
\hline CQUAD4 & 374 & 1 & 302 & 303 & 431 & 322 \\
\hline CQUAD4 & 375 & 1 & 322 & 431 & 427 & 323 \\
\hline CQUAD4 & 376 & 1 & 303 & 304 & 432 & 431 \\
\hline CQUAD4 & 377 & 1 & 431 & 432 & 428 & 427 \\
\hline CQUAD4 & 378 & 1 & 304 & 305 & 420 & 432 \\
\hline CQUAD4 & 379 & 1 & 432 & 420 & 419 & 428 \\
\hline CQUAD4 & 380 & 1 & 434 & 436 & 438 & 433 \\
\hline CQUAD4 & 381 & 1 & 433 & 438 & 266 & 267 \\
\hline CQUAD4 & 382 & 1 & 436 & 437 & 439 & 438 \\
\hline CQUAD4 & 383 & 1 & 438 & 439 & 265 & 266 \\
\hline CQUAD4 & 384 & 1 & 437 & 411 & 412 & 439 \\
\hline CQUAD4 & 385 & 1 & 439 & 412 & 264 & 265 \\
\hline CQUAD4 & 386 & 1 & 415 & 414 & 440 & 43 \\
\hline CQUAD4 & 387 & 1 & 435 & 440 & 436 & 434 \\
\hline CQUAD4 & 388 & 1 & 410 & 441 & 413 & 40 \\
\hline CQUAD4 & 389 & 1 & 441 & 440 & 414 & 413 \\
\hline CQUAD4 & 390 & 1 & 411 & 437 & 441 & 410 \\
\hline CQUAD4 & 391 & 1 & 437 & 436 & 440 & 441 \\
\hline CQUAD4 & 392 & 1 & 327 & 442 & 444 & 328 \\
\hline CQUAD4 & 393 & 1 & 328 & 444 & 269 & 270 \\
\hline CQUAD4 & 394 & 1 & 442 & 443 & 445 & 444 \\
\hline CQUAD4 & 395 & 1 & 444 & 445 & 268 & 269 \\
\hline CQUAD4 & 396 & 1 & 443 & 434 & 433 & 445 \\
\hline CQUAD4 & 397 & 1 & 445 & 433 & 267 & 268 \\
\hline CQUAD4 & 398 & 1 & 325 & 417 & 446 & 32 \\
\hline CQUAD4 & 399 & 1 & 326 & 446 & 442 & 32 \\
\hline CQUAD4 & 400 & 1 & 417 & 416 & 447 & 446 \\
\hline CQUAD4 & 401 & 1 & 446 & 447 & 443 & 442 \\
\hline CQUAD4 & 402 & 1 & 416 & 415 & 435 & 447 \\
\hline CQUAD4 & 403 & 1 & 447 & 435 & 434 & 44 \\
\hline CQUAD4 & 404 & 1 & 454 & 456 & 458 & 45 \\
\hline CQUAD4 & 405 & 1 & 453 & 458 & 449 & 45 \\
\hline CQUAD4 & 406 & 1 & 317 & 459 & 457 & \\
\hline
\end{tabular}




$\begin{array}{lllllll}\text { CQUAD4 } & 407 & 1 & 459 & 458 & 456 & 457 \\ \text { CQUAD4 } & 408 & 1 & 318 & 448 & 459 & 317 \\ \text { CQUAD4 } & 409 & 1 & 448 & 449 & 458 & 459 \\ \text { CQUAD4 } & 410 & 1 & 311 & 312 & 460 & 455 \\ \text { CQUAD4 } & 411 & 1 & 455 & 460 & 456 & 454 \\ \text { CQUAD4 } & 412 & 1 & 312 & 313 & 461 & 460 \\ \text { CQUAD4 } & 413 & 1 & 460 & 461 & 457 & 456 \\ \text { CQUAD4 } & 414 & 1 & 313 & 314 & 315 & 461 \\ \text { CQUAD4 } & 415 & 1 & 461 & 315 & 316 & 457 \\ \text { CQUAD4 } & 416 & 1 & 407 & 462 & 464 & 408 \\ \text { CQUAD4 } & 417 & 1 & 408 & 464 & 452 & 409 \\ \text { CQUAD4 } & 418 & 1 & 453 & 465 & 463 & 454 \\ \text { CQUAD4 } & 419 & 1 & 465 & 464 & 462 & 463 \\ \text { CQUAD4 } & 420 & 1 & 450 & 451 & 465 & 453 \\ \text { CQUAD4 } & 421 & 1 & 451 & 452 & 464 & 465 \\ \text { CQUAD4 } & 422 & 1 & 308 & 309 & 466 & 406 \\ \text { CQUAD4 } & 423 & 1 & 406 & 466 & 462 & 407 \\ \text { CQUAD4 } & 424 & 1 & 455 & 467 & 310 & 311 \\ \text { CQUAD4 } & 425 & 1 & 467 & 466 & 309 & 310 \\ \text { CQUAD4 } & 426 & 1 & 454 & 463 & 467 & 455 \\ \text { CQUAD4 } & 427 & 1 & 463 & 462 & 466 & 467 \\ \text { CQUAD4 } & 428 & 1 & 469 & 471 & 473 & 468 \\ \text { CQUAD4 } & 429 & 1 & 468 & 473 & 260 & 261 \\ \text { CQUAD4 } & 430 & 1 & 321 & 474 & 472 & 320 \\ \text { CQUAD4 } & 431 & 1 & 474 & 473 & 471 & 472 \\ \text { CQUAD4 } & 432 & 1 & 258 & 259 & 474 & 321 \\ \text { CQUAD4 } & 433 & 1 & 259 & 260 & 473 & 474 \\ \text { CQUAD4 } & 434 & 1 & 450 & 449 & 475 & 470 \\ \text { CQUAD4 } & 435 & 1 & 470 & 475 & 471 & 469 \\ \text { CQUAD4 } & 436 & 1 & 319 & 476 & 448 & 318 \\ \text { CQUAD4 } & 437 & 1 & 476 & 475 & 449 & 448 \\ \text { CQUAD4 } & 438 & 1 & 320 & 472 & 476 & 319 \\ \text { CQUAD4 } & 439 & 1 & 472 & 471 & 475 & 476 \\ \text { CQUAD4 } & 440 & 1 & 411 & 477 & 479 & 412 \\ \text { CQUAD4 } & 441 & 1 & 412 & 479 & 263 & 264 \\ \text { CQUAD4 } & 442 & 1 & 468 & 480 & 478 & 469 \\ \text { CQUAD4 } & 443 & 1 & 480 & 479 & 477 & 478 \\ \text { CQUAD4 } & 444 & 1 & 261 & 262 & 480 & 468 \\ \text { CQUAD4 } & 445 & 1 & 262 & 263 & 479 & 480 \\ \text { CQUAD4 } & 446 & 1 & 409 & 452 & 481 & 410 \\ \text { CQUAD4 } & 447 & 1 & 410 & 481 & 477 & 411 \\ \text { CQUAD4 } & 448 & 1 & 470 & 482 & 451 & 450 \\ \text { CQUAD4 } & 449 & 1 & 482 & 481 & 452 & 451 \\ \text { CQUAD4 } & 450 & 1 & 469 & 478 & 482 & 470 \\ \text { CQUAD4 } & 451 & 1 & 478 & 477 & 481 & 482\end{array}$




\section{A.3.4 Nastran_new.dat}

SOL 103

CEND

SUBCASE 2

LABEL= fixed_Modal

$\mathrm{SPC}=3$

METHOD $=3$

DISPLACEMENT $($ PUNCH $)=$ ALL

BEGIN BULK

Include 'Grid_New.dat'

Include 'element.dat'

$\begin{array}{lllll}\text { PSHELL } & 1 & 17.00 \mathrm{E}-04 & 1 & 1\end{array}$

MAT1 12.07E+117.90E+100.3 7860.0

$\begin{array}{lllll}\text { EIGRL } & 30.0 & 1000.0 & 20 & \text { MASS }\end{array}$

Include 'spc.dat'

ENDDATA

\section{A.3.5 Grid_New.dat}

$\begin{array}{lllll}\text { GRID } & 258 & 0.0 & 0.0 & 0.00000 \\ \text { GRID } & 259 & 0.0 & 0.0125 & 0.00013 \\ \text { GRID } & 260 & 0.0 & 0.025 & 0.00038 \\ \text { GRID } & 261 & 0.0 & 0.0375 & 0.00064 \\ \text { GRID } & 262 & 0.0 & 0.05 & 0.00091 \\ \text { GRID } & 263 & 0.0 & 0.0625 & 0.00116 \\ \text { GRID } & 264 & 0.0 & 0.075 & 0.00139 \\ \text { GRID } & 265 & 0.0 & 0.0875 & 0.00158 \\ \text { GRID } & 266 & 0.0 & 0.1 & 0.00174 \\ \text { GRID } & 267 & 0.0 & 0.1125 & 0.00187 \\ \text { GRID } & 268 & 0.0 & 0.125 & 0.00196 \\ \text { GRID } & 269 & 0.0 & 0.1375 & 0.00201 \\ \text { GRID } & 270 & 0.0 & 0.15 & 0.00203 \\ \text { GRID } & 271 & 0.0 & 0.1625 & 0.00201 \\ \text { GRID } & 272 & 0.0 & 0.175 & 0.00196 \\ \text { GRID } & 273 & 0.0 & 0.1875 & 0.00187 \\ \text { GRID } & 274 & 0.0 & 0.2 & 0.00175 \\ \text { GRID } & 275 & 0.0 & 0.2125 & 0.00158 \\ \text { GRID } & 276 & 0.0 & 0.225 & 0.00139 \\ \text { GRID } & 277 & 0.0 & 0.2375 & 0.00116 \\ \text { GRID } & 278 & 0.0 & 0.25 & 0.00091 \\ \text { GRID } & 279 & 0.0 & 0.2625 & 0.00064 \\ \text { GRID } & 280 & 0.0 & 0.275 & 0.00038 \\ \text { GRID } & 281 & 0.0 & 0.2875 & 0.00013 \\ \text { GRID } & 282 & 0.0 & 0.3 & 0.00000 \\ \text { GRID } & 283 & 0.0125 & 0.3 & 0.00001 \\ \text { GRID } & 284 & 0.025 & 0.3 & 0.00004 \\ \text { GRID } & 285 & 0.0375 & 0.3 & 0.00007 \\ \text { GRID } & 286 & 0.05 & 0.3 & 0.00008 \\ \text { GRID } & 287 & 0.0625 & 0.3 & 0.00006\end{array}$




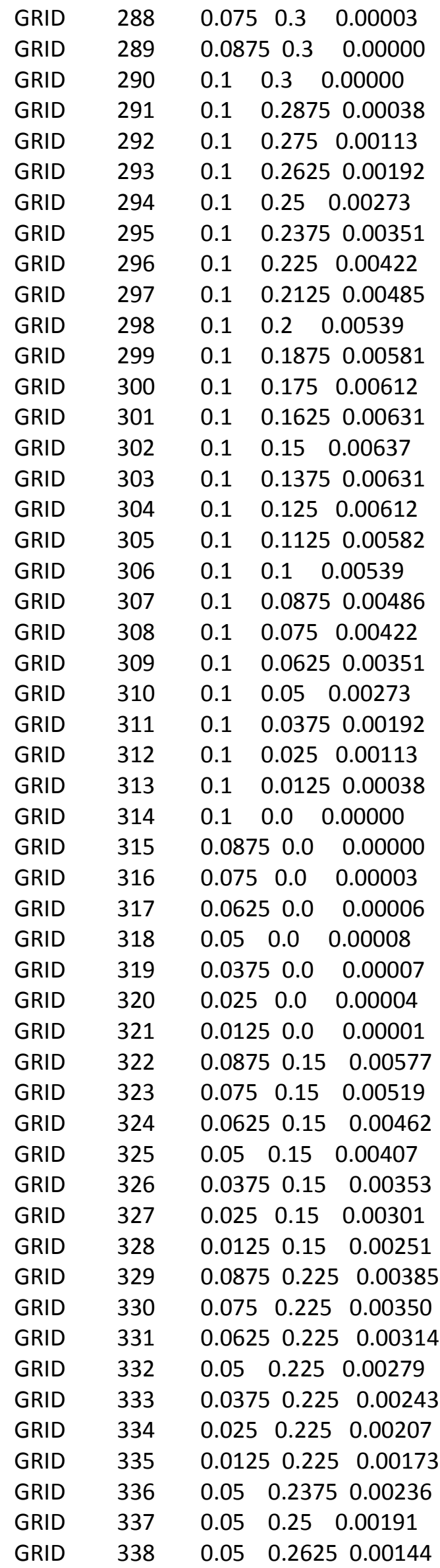




\begin{tabular}{|c|c|c|}
\hline RID & 339 & $\begin{array}{lll}0.05 & 0.275 & 0.00098\end{array}$ \\
\hline SID & 40 & $\begin{array}{lll}0.05 & 0.2875 & 0.00052\end{array}$ \\
\hline ID & 41 & 0.06250 .26250 .0016 \\
\hline ID & 2 & $.075 \quad 0.26250 .00172$ \\
\hline RID & 343 & $\begin{array}{lll}0.0875 & 0.2625 & 0.00183\end{array}$ \\
\hline RID & 44 & $\begin{array}{lll}0.075 & 0.25 & 0.00234\end{array}$ \\
\hline RID & 45 & $\begin{array}{llll}0.075 & 0.2375 & 0.00294\end{array}$ \\
\hline RID & 46 & $\begin{array}{lll}0.0625 & 0.25 & 0.00213\end{array}$ \\
\hline RID & 347 & $\begin{array}{lll}0.0625 & 0.2375 & 0.00266\end{array}$ \\
\hline RID & 348 & $\begin{array}{lll}0.0875 & 0.25 & 0.00254\end{array}$ \\
\hline RID & 349 & $\begin{array}{lll}0.0875 & 0.2375 & 0.00322\end{array}$ \\
\hline RID & 50 & $\begin{array}{llll}0.075 & 0.2875 & 0.00056\end{array}$ \\
\hline RID & 51 & $\begin{array}{lll}0.075 & 0.275 & 0.00112\end{array}$ \\
\hline RID & 52 & $\begin{array}{lll}0.0625 & 0.2875 & 0.00056\end{array}$ \\
\hline RID & 53 & $\begin{array}{lll}0.0625 & 0.275 & 0.00107\end{array}$ \\
\hline RID & 354 & $\begin{array}{lll}0.0875 & 0.2875 & 0.00053\end{array}$ \\
\hline RID & 355 & $\begin{array}{lll}0.0875 & 0.275 & 0.00113\end{array}$ \\
\hline RID & 56 & $\begin{array}{llll}0.0125 & 0.2625 & 0.00086\end{array}$ \\
\hline 2ID & 57 & $\begin{array}{llll}0.025 & 0.2625 & 0.00107\end{array}$ \\
\hline RID & 58 & $\begin{array}{lll}0.0375 & 0.2625 & 0.00126\end{array}$ \\
\hline RID & 59 & $\begin{array}{lll}0.025 & 0.25 & 0.00142\end{array}$ \\
\hline RID & 360 & $\begin{array}{llll}0.025 & 0.2375 & 0.00176\end{array}$ \\
\hline 2ID & 361 & $\begin{array}{lll}0.0125 & 0.25 & 0.00117\end{array}$ \\
\hline RID & 62 & $\begin{array}{llll}0.0125 & 0.2375 & 0.00146\end{array}$ \\
\hline RID & 363 & $\begin{array}{lll}0.0375 & 0.25 & 0.00167\end{array}$ \\
\hline RID & 364 & $\begin{array}{lll}0.0375 & 0.2375 & 0.00207\end{array}$ \\
\hline RID & 365 & $\begin{array}{llll}0.025 & 0.2875 & 0.00037\end{array}$ \\
\hline RID & 366 & $\begin{array}{lll}0.025 & 0.275 & 0.00071\end{array}$ \\
\hline RID & 67 & $\begin{array}{lll}0.0125 & 0.2875 & 0.00027\end{array}$ \\
\hline RID & 368 & $\begin{array}{lll}0.0125 & 0.275 & 0.00055\end{array}$ \\
\hline RID & 369 & $\begin{array}{lll}0.0375 & 0.2875 & 0.00046\end{array}$ \\
\hline RID & 370 & $\begin{array}{lll}0.0375 & 0.275 & 0.00086\end{array}$ \\
\hline RID & 371 & $\begin{array}{llll}0.05 & 0.1625 & 0.00403\end{array}$ \\
\hline RID & 72 & $\begin{array}{lll}0.05 & 0.175 & 0.00392\end{array}$ \\
\hline GRID & D & $\begin{array}{llll}0.05 & 0.1875 & 0.00374\end{array}$ \\
\hline RID & 374 & $\begin{array}{lll}0.05 & 0.2 & 0.00348\end{array}$ \\
\hline RID & 375 & $\begin{array}{llll}0.05 & 0.2125 & 0.00316\end{array}$ \\
\hline RID & 376 & $\begin{array}{lll}0.0625 & 0.1875 & 0.00424\end{array}$ \\
\hline RID & 377 & $\begin{array}{llll}0.075 & 0.1875 & 0.00475\end{array}$ \\
\hline RID & 378 & $\begin{array}{llll}0.0875 & 0.1875 & 0.00527\end{array}$ \\
\hline GRID & 79 & $\begin{array}{lll}0.075 & 0.175 & 0.00499\end{array}$ \\
\hline RID & 380 & $\begin{array}{llll}0.075 & 0.1625 & 0.00514\end{array}$ \\
\hline GRID & 381 & $\begin{array}{lll}0.0625 & 0.175 & 0.00445\end{array}$ \\
\hline RID & 382 & $\begin{array}{lll}0.0625 & 0.1625 & 0.00458\end{array}$ \\
\hline GRID & 3 & $\begin{array}{lll}0.0875 & 0.175 & 0.00555\end{array}$ \\
\hline GRID & 384 & $\begin{array}{llll}0.0875 & 0.1625 & 0.00571\end{array}$ \\
\hline GRID & 385 & $\begin{array}{llll}0.075 & 0.2125 & 0.00399\end{array}$ \\
\hline GRID & 386 & $\begin{array}{lll}0.075 & 0.2 & 0.00441\end{array}$ \\
\hline GRID & 387 & $\begin{array}{lll}0.0625 & 0.2125 & 0.00358\end{array}$ \\
\hline GRID & 388 & $\begin{array}{lll}0.0625 & 0.2 & 0.00394\end{array}$ \\
\hline RID & 389 & $\begin{array}{llll}0.0875 & 0.2125 & 0.00442\end{array}$ \\
\hline אוסי & 390 & $\begin{array}{lll}0.0875 & 0.2 & 0.00489\end{array}$ \\
\hline
\end{tabular}




\begin{tabular}{|c|c|c|}
\hline RID & 91 & $\begin{array}{lll}0.0125 & 0.1875 & 0.00231\end{array}$ \\
\hline RID & & $\begin{array}{lll}0.025 & 0.1875 & 0.00277\end{array}$ \\
\hline ID & & $\begin{array}{lll}0.0375 & 0.1875 & 0.00325\end{array}$ \\
\hline ID & & $\begin{array}{lll}0.025 & 0.175 & 0.00290\end{array}$ \\
\hline RID & 95 & $\begin{array}{llll}0.025 & 0.1625 & 0.00298\end{array}$ \\
\hline RID & 96 & $\begin{array}{lll}0.0125 & 0.175 & 0.00242\end{array}$ \\
\hline RID & 97 & $\begin{array}{llll}0.0125 & 0.1625 & 0.00249\end{array}$ \\
\hline RID & 8 & $\begin{array}{lll}0.0375 & 0.175 & 0.00340\end{array}$ \\
\hline RID & & $\begin{array}{llll}0.0375 & 0.1625 & 0.00350\end{array}$ \\
\hline RID & 0 & $\begin{array}{llll}0.025 & 0.2125 & 0.00235\end{array}$ \\
\hline RID & 01 & $\begin{array}{lll}0.025 & 0.2 & 0.00259\end{array}$ \\
\hline RID & 02 & $\begin{array}{llll}0.0125 & 0.2125 & 0.00196\end{array}$ \\
\hline RID & 3 & $\begin{array}{lll}0.0125 & 0.2 & 0.00216\end{array}$ \\
\hline RID & & $\begin{array}{llll}0.0375 & 0.2125 & 0.00275\end{array}$ \\
\hline RID & & $\begin{array}{lll}0.0375 & 0.2 & 0.00303\end{array}$ \\
\hline RID & 36 & $\begin{array}{lll}0.0875 & 0.075 & 0.00386\end{array}$ \\
\hline RID & 07 & $\begin{array}{lll}0.075 & 0.075 & 0.00350\end{array}$ \\
\hline RID & 08 & $\begin{array}{lll}0.0625 & 0.075 & 0.00314\end{array}$ \\
\hline RID & 09 & $0.05 \quad 0.075 \quad 0.00$ \\
\hline RID & 0 & $\begin{array}{lll}0.0375 & 0.075 & 0.0\end{array}$ \\
\hline RID & 1 & $\begin{array}{lll}0.025 & 0.075 & 0.00207\end{array}$ \\
\hline RID & 2 & $\begin{array}{lll}0.0125 & 0.075 & 0.00172\end{array}$ \\
\hline RID & & $\begin{array}{llll}0.05 & 0.0875 & 0.00316\end{array}$ \\
\hline RID & 14 & $\begin{array}{lll}0.05 & 0.1 & 0.00348\end{array}$ \\
\hline RID & & $\begin{array}{llll}0.05 & 0.1125 & 0.00374\end{array}$ \\
\hline RID & & $\begin{array}{lll}0.05 & 0.125 & 0.00\end{array}$ \\
\hline RID & 7 & $\begin{array}{lll}0.05 & 0.1375 & 0.00403\end{array}$ \\
\hline RID & 18 & $\begin{array}{lll}0.0625 & 0.1125 & 0.00424\end{array}$ \\
\hline RID & & $\begin{array}{lll}0.075 & 0.1125 & 0.00475\end{array}$ \\
\hline RID & 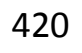 & $\begin{array}{lll}0.0875 & 0.1125 & 0.00527\end{array}$ \\
\hline IID & 1 & $\begin{array}{lll}0.075 & 0.1 & 0.00441\end{array}$ \\
\hline RID & 22 & $\begin{array}{llll}0.075 & 0.0875 & 0.00399\end{array}$ \\
\hline RID & 3 & $\begin{array}{lll}0.0625 & 0.1 & 0.00394\end{array}$ \\
\hline RID & 424 & $\begin{array}{llll}0.0625 & 0.0875 & 0.00358\end{array}$ \\
\hline RID & 425 & $\begin{array}{lll}0.0875 & 0.1 & 0.00489\end{array}$ \\
\hline RID & 6 & 0.08750 .08750$. \\
\hline ID & & $\begin{array}{llll}0.075 & 0.1375 & 0.00514\end{array}$ \\
\hline RID & & $\begin{array}{lll}0.075 & 0.125 & 0.00499\end{array}$ \\
\hline RID & & $\begin{array}{lll}0.0625 & 0.1375 & 0.00458\end{array}$ \\
\hline RID & & $\begin{array}{lll}0.0625 & 0.125 & 0.00445\end{array}$ \\
\hline RID & & $\begin{array}{lll}0.0875 & 0.1375 & 0.00571\end{array}$ \\
\hline ID & 2 & $\begin{array}{lll}0.0875 & 0.125 & 0.00555\end{array}$ \\
\hline RID & & $\begin{array}{lll}0.0125 & 0.1125 & 0.00231\end{array}$ \\
\hline RID & & $\begin{array}{llll}0.025 & 0.1125 & 0.00277\end{array}$ \\
\hline RID & & $\begin{array}{llll}0.0375 & 0.1125 & 0.00324\end{array}$ \\
\hline ID & 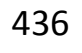 & $\begin{array}{lll}0.025 & 0.1 & 0.00258\end{array}$ \\
\hline ID & 437 & $\begin{array}{lll}0.025 & 0.0875 & 0.00235\end{array}$ \\
\hline ID & 438 & $\begin{array}{lll}0.0125 & 0.1 & 0.00216\end{array}$ \\
\hline ID & 439 & $\begin{array}{lll}0.0125 & 0.0875 & 0.00196\end{array}$ \\
\hline & 40 & $\begin{array}{lll}0.0375 & 0.1 & 0.00303\end{array}$ \\
\hline & 441 & 0.03750 .08750 .00275 \\
\hline
\end{tabular}




$\begin{array}{lllll}\text { GRID } & 442 & 0.025 & 0.1375 & 0.00298 \\ \text { GRID } & 443 & 0.025 & 0.125 & 0.00290 \\ \text { GRID } & 444 & 0.0125 & 0.1375 & 0.00249 \\ \text { GRID } & 445 & 0.0125 & 0.125 & 0.00242 \\ \text { GRID } & 446 & 0.0375 & 0.1375 & 0.00350 \\ \text { GRID } & 447 & 0.0375 & 0.125 & 0.00340 \\ \text { GRID } & 448 & 0.05 & 0.0125 & 0.00052 \\ \text { GRID } & 449 & 0.05 & 0.025 & 0.00098 \\ \text { GRID } & 450 & 0.05 & 0.0375 & 0.00144 \\ \text { GRID } & 451 & 0.05 & 0.05 & 0.00191 \\ \text { GRID } & 452 & 0.05 & 0.0625 & 0.00236 \\ \text { GRID } & 453 & 0.0625 & 0.0375 & 0.00160 \\ \text { GRID } & 454 & 0.075 & 0.0375 & 0.00172 \\ \text { GRID } & 455 & 0.0875 & 0.0375 & 0.00183 \\ \text { GRID } & 456 & 0.075 & 0.025 & 0.00112 \\ \text { GRID } & 457 & 0.075 & 0.0125 & 0.00056 \\ \text { GRID } & 458 & 0.0625 & 0.025 & 0.00107 \\ \text { GRID } & 459 & 0.0625 & 0.0125 & 0.00056 \\ \text { GRID } & 460 & 0.0875 & 0.025 & 0.00113 \\ \text { GRID } & 461 & 0.0875 & 0.0125 & 0.00053 \\ \text { GRID } & 462 & 0.075 & 0.0625 & 0.00294 \\ \text { GRID } & 463 & 0.075 & 0.05 & 0.00234 \\ \text { GRID } & 464 & 0.0625 & 0.0625 & 0.00266 \\ \text { GRID } & 465 & 0.0625 & 0.05 & 0.00214 \\ \text { GRID } & 466 & 0.0875 & 0.0625 & 0.00322 \\ \text { GRID } & 467 & 0.0875 & 0.05 & 0.00254 \\ \text { GRID } & 468 & 0.0125 & 0.0375 & 0.00086 \\ \text { GRID } & 469 & 0.025 & 0.0375 & 0.00107 \\ \text { GRID } & 470 & 0.0375 & 0.0375 & 0.00126 \\ \text { GRID } & 471 & 0.025 & 0.025 & 0.00071 \\ \text { GRID } & 472 & 0.025 & 0.0125 & 0.00037 \\ \text { GRID } & 473 & 0.0125 & 0.025 & 0.00055 \\ \text { GRID } & 474 & 0.0125 & 0.0125 & 0.00027 \\ \text { GRID } & 475 & 0.0375 & 0.025 & 0.00086 \\ \text { GRID } & 476 & 0.0375 & 0.0125 & 0.00046 \\ \text { GRID } & 477 & 0.025 & 0.0625 & 0.00176 \\ \text { GRID } & 478 & 0.025 & 0.05 & 0.00142 \\ \text { GRID } & 479 & 0.0125 & 0.0625 & 0.00146 \\ \text { GRID } & 480 & 0.0125 & 0.05 & 0.00116 \\ \text { GRID } & 481 & 0.0375 & 0.0625 & 0.00206 \\ \text { GRID } & 482 & 0.0375 & 0.05 & 0.00167\end{array}$

A.3.6 SPC.dat

$\begin{array}{llll}\text { SPC } & 3 & 282 & 1234560.0 \\ \text { SPC } & 3 & 290 & 1234560.0 \\ \text { SPC } & 3 & 314 & 1234560.0 \\ \text { SPC } & 3 & 258 & 1234560.0\end{array}$ 